\title{
The Application of a New Tool for Evaluation of Lung Function in COPD
}





\title{
The Application of a New Tool for Evaluation of Lung Function in COPD
}

\author{
PhD Thesis by
}

\section{Lars Pilegaard Thomsen}

Respiratory and Critical Care Group (rcare), Center for Model-Based Medical Decision Support,

Department of Health Science and Technology, Aalborg University, Aalborg, Denmark

River Publishers

Aalborg 
ISBN 978-87-93102-41-5 (e-book)

Published, sold and distributed by:

River Publishers

Niels Jernes Vej 10

9220 Aalborg Ø

Denmark

Tel.: +45369953197

www.riverpublishers.com

Copyright for this work belongs to the author, River Publishers have the sole right to distribute this work commercially.

All rights reserved (c) 2013 Lars Pilegaard Thomsen.

No part of this work may be reproduced, stored in a retrieval system, or transmitted in any form or by any means, electronic, mechanical, photocopying, microfilming, recording or otherwise, without prior written permission from the Publisher. 


\begin{abstract}
The diagnosis and classification of COPD can be seen as the difficult task of describing a heterogeneous disease affecting a complex organ, using relatively simple measurements. Combining these measurements and thus describing the impact of disease on the lung and its functional capacity can provide additional information enabling the clinician to succeed in this task. In this context, this thesis has investigated the clinical description of pulmonary gas exchange abnormalities, the current standard (DLCO), the reference experimental technique (MIGET), and a new alternative (ALPE). The aim of the thesis has been to investigate the challenges ALPE faces in patients suffering from COPD (paper I) and if possible to present and evaluate new methods to overcome these challenges (paper II). Furthermore, integration of ALPE with routinely available clinical measurement and its relation to HRCT-scans was evaluated (paper III).
\end{abstract}

The basics of the ALPE method is a mathematical model of pulmonary gas exchange. The thesis presents a novel method that allows this steady state model of gas exchange to be parameterized using breath by breath data. The principle of the method lies in estimation of delay in $\mathrm{SpO}_{2}$ measurements due to systemic circulation, and with this a corrected dataset for usage with the model can be constructed. The new method was evaluated in patients suffering from COPD and was shown to deliver equivalent results as the traditional steady state method. Another contribution of the thesis, has been the construction of a causal probabilistic network, where routinely available clinical measurement and ALPE is integrated. The network was shown to be able to categorize four well defined cases of COPD, similarly to the radiologic description obtained from HTCT-scans.

This thesis has demonstrated, that ALPE may possibly be used as a tool for functional description in patients suffering from COPD. The developed causal network integrating ALPE with other routinely available measurements, may be used to target radiologic phenotypes of COPD, possibly in long-term clinical cohort studies or in daily clinical practice. 


\section{List of papers}

This thesis is bases on the following papers, which will be referred to in the text by their Arabic numeral 1-3:

1. Thomsen, L. P., Karbing, D. S., Smith, B. W., Murley, D., Weinreich, U., Kjærgaard, S., Toft, E., Thorgaard, P., Andreassen, S., \& Rees, S. E. (2013). Clinical refinement of the automatic lung parameter estimator (ALPE). Journal of Clinical Monitoring and Computing, 27(3):341, doi: 10.1007/s10877-013-9442-9

2. Thomsen, L. P., Weinreich, U. M., Karbing, D. S., Wagner, P. D. \& Rees, S. E. Measuring gas exchange with step changes in inspired oxygen: an analysis of the assumption of oxygen steady state. Invited paper for a Journal of Clinical Monitoring and Computing special issue: IFAC BMS 2012: Modeling in Anaesthesia and Intensive Care. In revision.

a. Bases on the following peer-reviewed conference paper:

Thomsen, L. P., Weinreich, U. M., Karbing, D. S., \& Rees, S. E. (2012). Measuring gas exchange with step changes in inspired oxygen: an analysis of the assumption of oxygen steady state. I Benyo, B., Andreasen, S., Feng, D. D., Carson, E., Chase, J. G., \& Kovács, L. (red.), 8th IFAC Symposium on Biological and Medical Systems (2012). (s. 507-511). Elsevier Science. (Elsevier IFAC Publications / IFAC Proceedings series, Vol. 8). doi: 10.3182/20120829-3-HU-2029.00048

3. Thomsen, L. P., Weinreich, U. M., Karbing, D. S., Jensen, V. G. H., Vuust, M., Frøkjær, J. B., \& Rees, S. E. (2013). Can computed tomography classifications of chronic obstructive pulmonary disease be identified using Bayesian networks and clinical data?. Computer Methods and Programs in Biomedicine, 110(3):361, doi: 10.1016/j.cmpb.2013.02.001 


\section{Contents}

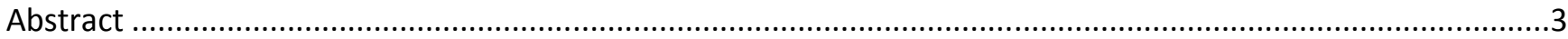

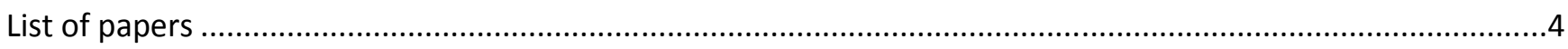

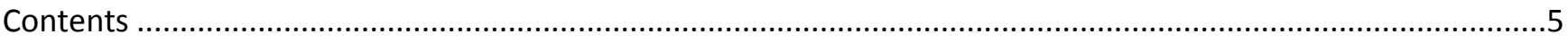

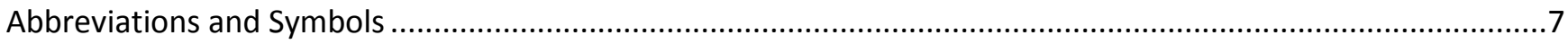

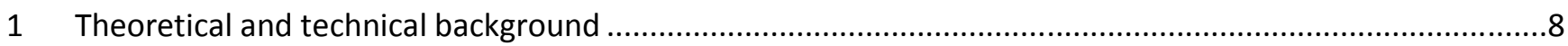

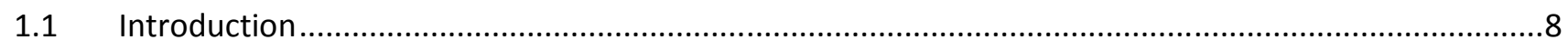

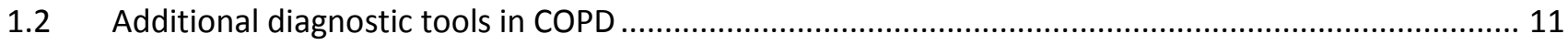

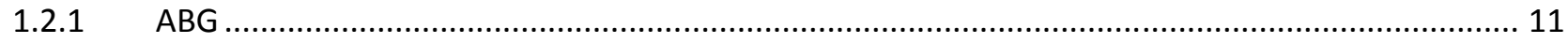

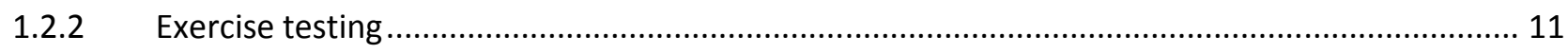

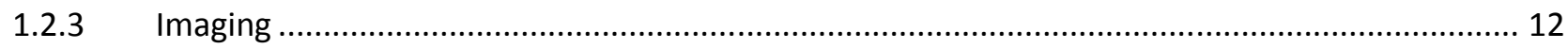

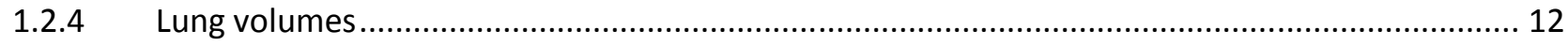

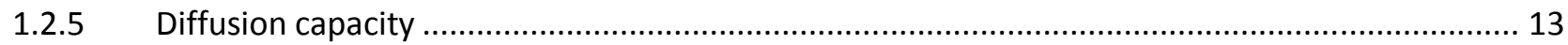

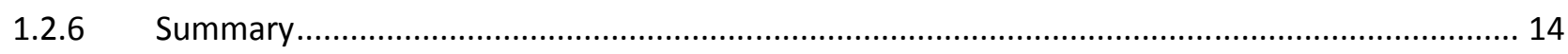

$1.3 \quad$ Description of pulmonary gas exchange in COPD ................................................................ 15

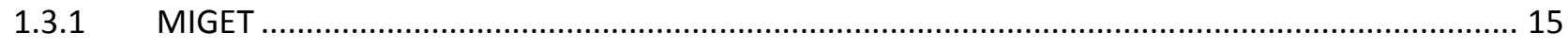

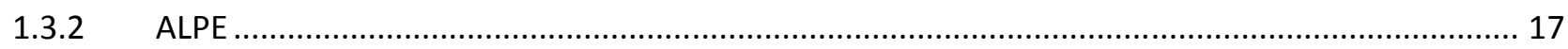

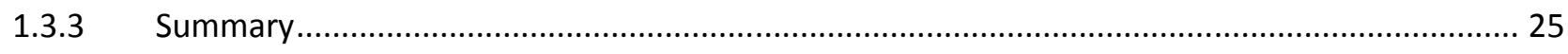

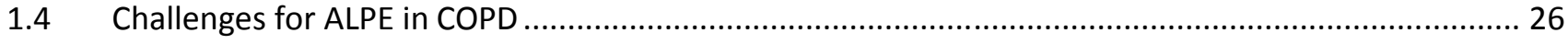

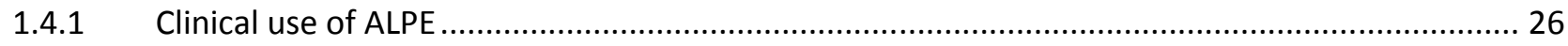

1.4.2 Identification of challenges in relation to application of ALPE in COPD.................................. 28

1.4.3 Integration of ALPE with clinical available measurements ................................................... 30

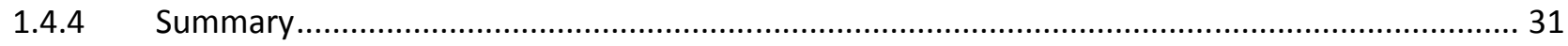

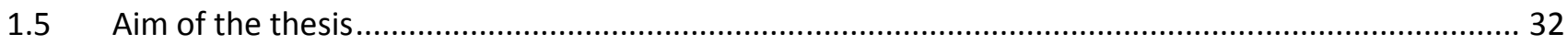

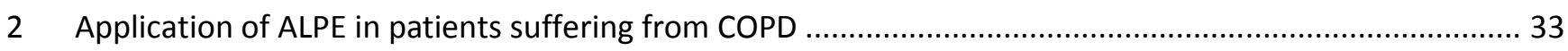

2.1 How can the current ALPE model be modified to enable description of high VA/Q units of the lung? 33

2.1.1 Three parameter model with description of high V̇A/Q …................................................... 33

2.1.2 Measurement of data required for the three parameter model ............................................ 37 
2.2 Can the current ALPE equipment be used in in the often unstable breathing patterns seen in these patients?

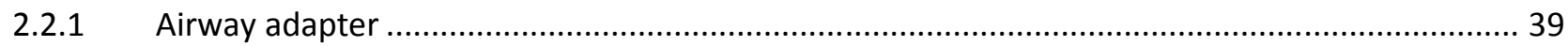

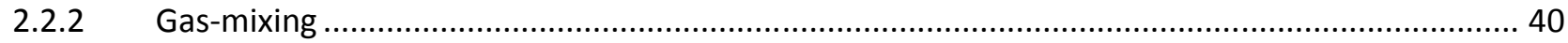

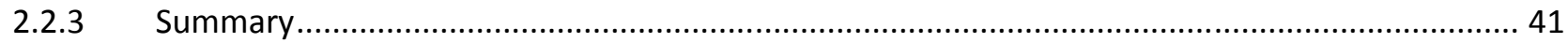

2.3 Is it possible to design a strategy for measurement and model fitting which does not require steady

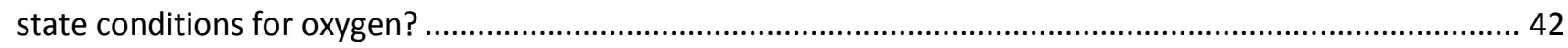

2.3.1 Method for correction of breath by breath data to approximate ALPE data ........................... 42

2.3.2 Comparison of results from normal steady state and breath by breath data .......................... 44

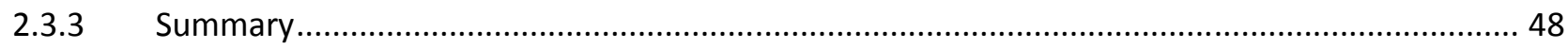

2.4 Do the effects of hypoxic drive prevent the use of oxygen as a tracer in patients with COPD?.......... 49

2.4.1 Method for validation of model input variation ...................................................................... 49

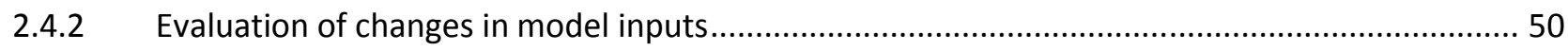

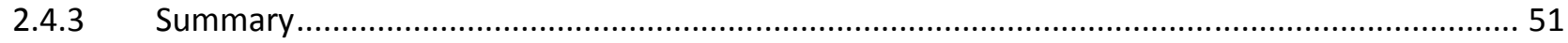

2.5 How can ALPE measurements be integrated with other measurements to provide an integrated clinical picture of the lungs, and if so can such a description provide similar classifications as radiologic

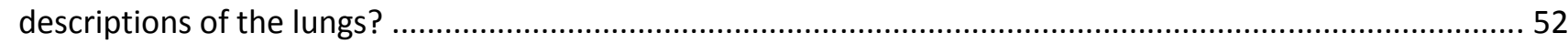

2.5.1 Causal probabilistic network for classification of COPD......................................................... 52

2.5.2 Clinical data for the network and assessment of HRCT ..................................................... 58

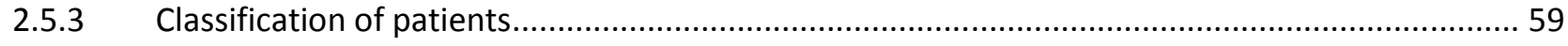

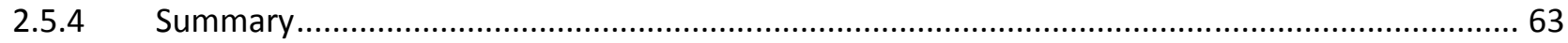

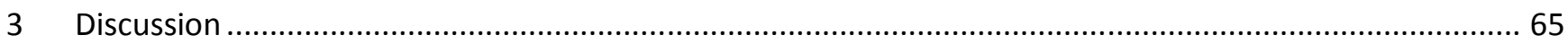

3.1 What complexity is necessary to describe pulmonary gas exchange in COPD? ...............................66

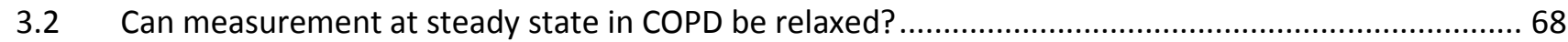

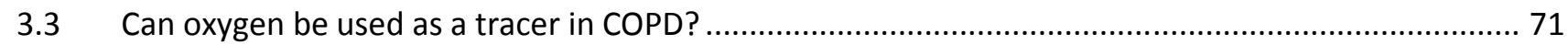

3.4 Can radiologic profiles be classified using both ALPE and other routine measurements in a causal

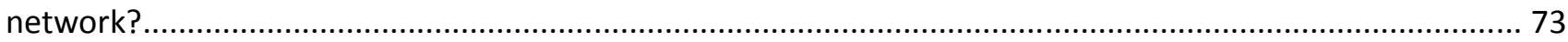

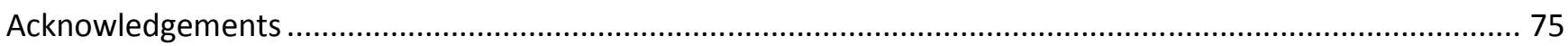

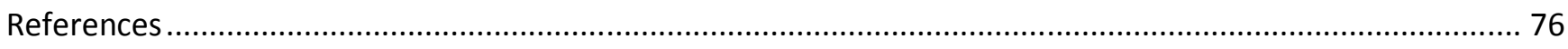

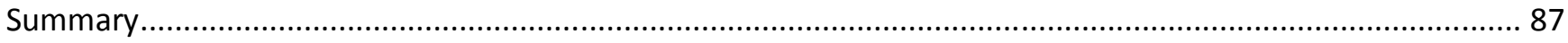

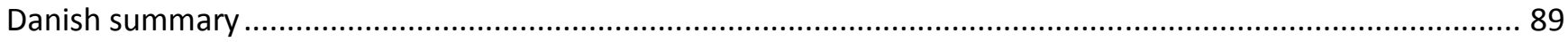




\section{Abbreviations and Symbols}

Through-out the thesis clinical abbreviations for diseases, diagnostic tools etc. are used. These are "popular" abbreviations and will be explained upon first usage.

The symbols and the abbreviations for measurements and variables for the mathematical models are defined as follows: a main symbol followed by a modifier and a substance.

\section{Main symbols}

$\begin{array}{llll}\text { F } & \text { Gas fraction } & \text { V } & \text { Volume } \\ \text { P } & \text { Gas pressure } & \text { Q } & \text { Cardiac output } \\ \text { S } & \text { Saturation } & \dot{V} & \text { Ventilation }\end{array}$

\section{Modifiers}

$\begin{array}{llll}\text { A } & \text { Alveolar } & \text { a } & \text { Arterial } \\ \text { I } & \text { Inspired } & \mathrm{p} & \text { Pulse oximetry } \\ \text { et } & \text { End-tidal } & \mathrm{t} & \text { Tidal } \\ \text { C } & \text { Capillary } & & \end{array}$

\section{Substance}

$\mathrm{O}_{2} \quad$ Oxygen

$\mathrm{CO}_{2} \quad$ Carbon dioxide

$\mathrm{Hb} \quad$ Hemoglobin

CO Carbon monoxide

$\mathrm{COHb} \quad$ Carboxy-hemoglobin

MetHb Met-hemoglobin

\section{Other abbreviations and symbols used in the thesis}

ALPE Automatic Lung Parameter Estimator

MIGET Multiple Inert Gas Elimination Technique

$\triangle \mathrm{PO}_{2} \quad$ Oxygen pressure drop from alveolar air to lung-capillary blood

$\triangle \mathrm{PO}_{2} \quad$ Carbon dioxide pressure drop from lung-capillary blood to alveolar air

$\dot{V} \mathrm{~A} / \mathrm{Q} \quad$ Alveolar ventilation to perfusion ratio 


\section{Theoretical and technical background}

\subsection{Introduction}

Chronic Obstructive Pulmonary Disease (COPD) is a major respiratory disease characterised by a progressive and irreversible decline in lung function resulting in increased morbidity and mortality of the patients. Worldwide, an estimated 210 million people suffer from COPD [1], and even then the disease is considered substantially underdiagnosed [2]. The mortality rate of COPD is high and is expected to increase, with predictions seeing COPD being the fourth most likely cause of death in 2030 with nearly $8 \%$ of all deaths, only exceeded by ischaemic heart disease, cerebrovascular disease, and HIV/AIDS [3]. The primary cause of COPD is tobacco smoke, although in middle and low income countries, in particular, indoor pollution contributes significantly [4].

Diagnosis of COPD is based primarily on post-bronchodilator spirometry. Initially, the rate of obstruction is determined from the ratio between forced expiratory volume in the first second (FEV1) and forced expiratory volume (FVC). The grade of severity of airflow limitation is quantified by the reduction in FEV1 in percent of expected value (FEV1\%). From the worldwide accepted diagnostic recommendations proposed by the Global initiative for chronic Obstructive Lung Disease (GOLD), a FEV1/FVC ratio below 0.7 describes persistent airflow limitation and therefore COPD [5]. The severity of airflow limitation is stratified into four groups, one to four, or mild, moderate, severe and very severe. This is usually termed the GOLD-stratification or -grade and has been the cornerstone in COPD diagnosis up until 2011 [6].

In the most recent revisions of the GOLD classification of COPD starting in 2011, diagnosis using spirometry has been supplemented by a risk assessment for each patient $[5,6]$, as FEV1\% has been shown to correlate poorly with cardinal symptoms of COPD as dyspnoea and impact on daily life [7]. This risk assessment, see Figure 1, combines the stratification based on FEV1\% with the patient's symptoms described by the modified Medical Research Council dyspnoea score (mMRC) [8] or the COPD Assessment Test (CAT) score [9], and the number of 
exacerbations in the preceding year. Patients are grouped in the left or right column according to their symptoms and in the bottom or top row according to the highest ranking decline in FEV1\% or number of exacerbations.

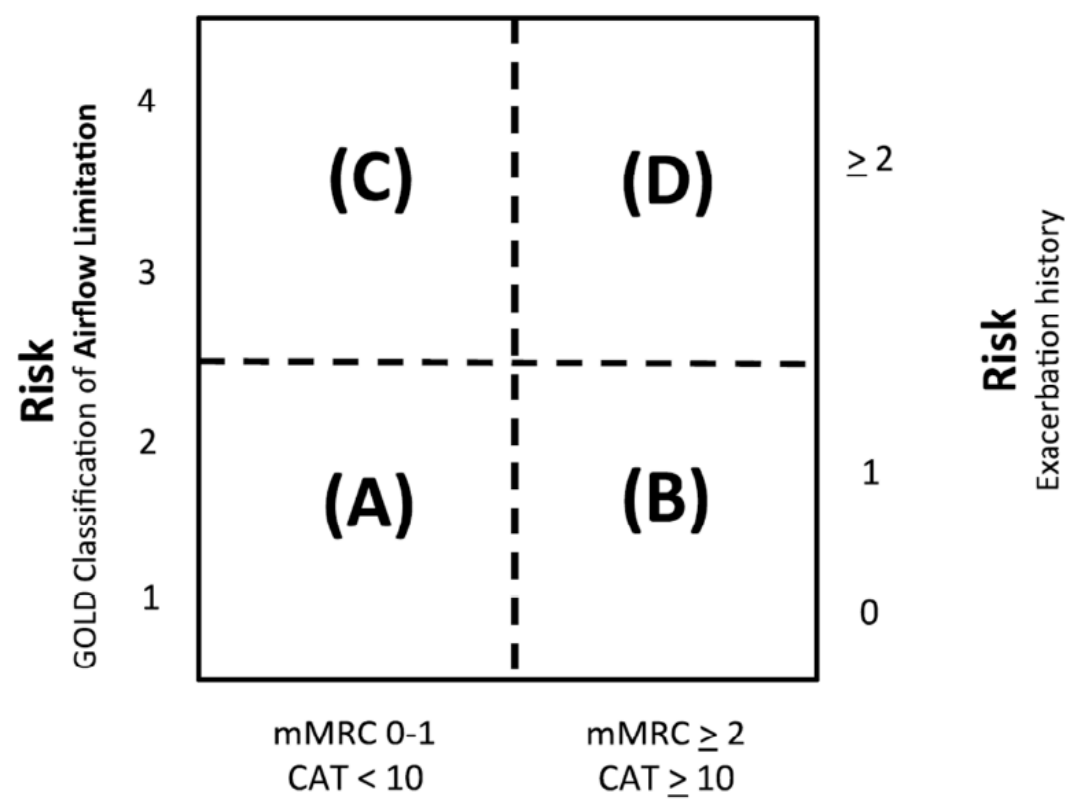

Symptoms

(mMRC or CAT score)

Figure 1: Combined COPD assessment proposed by GOLD, with permission from the Global Strategy for Diagnosis, Management and Prevention of COPD 2013, Global Initiative for Chronic Obstructive Lung Disease (GOLD), www.goldcopd.org. Patients' combined risk is the highest risk according to GOLD grade or exacerbation history, and the symptoms score (mMRC or CAT).

This new assessment attempts to better reflect the complexity of COPD compared to the one-dimensional GOLD grade, and specific treatments are recommended for each group (A to $D$ ) $[5,6]$. Studies evaluating this assessment have however shown, that the prognostic validity of mortality is equal to the former GOLD-stage $[10,11]$. The studies has also shown that patients are distributed unevenly in the four groups. In each of the groups $A$ and $D$ one third of the patients are placed. These are the patients suffering mainly from COPD where their increasing airflow limitation causes a corresponding increase in symptoms. In the groups B and C the remaining patients are found. Group B are those patients with a minor airflow limitation but with a number of 
co-morbidities increasing their symptoms. In group C, patients are found with significant airflow limitation but, interestingly, without many symptoms.

The GOLD stage and the new combined risk assessment are both simplified models aiming to characterise a group of patients known to be very heterogeneous [12]. COPD is a collection of pathoanatomical changes that can affect various structures within the lung, were the two main contributors are emphysema and airway disease [13]. In emphysema the lung parenchyma degenerates and reduced the elastic recoil of the lung. The degeneration leads to a loss in alveoli and changes to the capillary network, thus minimizing the effective area of the lung for exchange of respiratory gases. In airway disease, inflammation is present in the small bronchi or bronchioles which lead to an increase in airway resistance and thus air trapping. Both emphysema and airway disease can impair the main functions of the lung, which are providing oxygen for metabolism in the tissues and removing carbon dioxide to uphold homeostasis.

In order to obtain a deeper understanding of the severity of disease and underlying pathoanatomy of the lung in a specific patient, it is thus often necessary to use further diagnostic tools than the GOLD stage and combined risk assessment. 


\subsection{Additional diagnostic tools in COPD}

In the recommendations from GOLD, additional investigations are to be considered if the clinical picture of the patient and the reported symptoms are inconsistent. The purpose of the additional investigations are primarily to determine the severity of disease but some measures, or combination of several may lead to a deeper understanding of the underlying causes of the disease. The additional investigations include: arterial blood gases ( $A B G)$, exercise testing, imaging, lung volumes, and diffusion capacity.

\subsubsection{ABG}

Samples of arterial blood gases are routinely taken in some pulmonary labs whereas in others it depends on the oxygen saturation by pulse oximetry $\left(\mathrm{SpO}_{2}\right)$, where a level below $92 \%$ often is the criterion for sampling [6]. Additionally, GOLD recommends sampling of ABG in patients with a FEV1\% below 35\% [6]. Acid/base balance, oxygen saturation and pressure, carbon dioxide pressure, and hemoglobin concentration and sub-fractions are all useful to achieve a deeper understanding of the patient's state, although they seldom supply significant information useful in determining cause of disease. Sampling of ABG is associated with a minor risk of infection for the patient [14] and often causes discomfort due to arterial puncture.

\subsubsection{Exercise testing}

Exercise performance tests are often used in pulmonary laboratories, where maximum cardiopulmonary exercise testing using a cycle ergometer, the six-minute walk test and the shuttle walk test are well known [15]. Exercise testing is useful to assess the degree of disability, presence of exercise-induced hypoxemia, and response to treatment. The results from walking tests are easy to interpret, particularly in relation to the patient's performance in daily activities. However, caution should be taken when interpreting these tests, as they are subjective and studies have questioned the reproducibility [16]. Exercise tests provides compound measures, were all aspects of COPD and co-morbidities results in marked underperformance, and therefore cannot be used to establish information that can be related to the underlying cause of disease. 


\subsubsection{Imaging}

Different modalities are available that can visualize the structural changes occurring in the lung as a consequence of COPD. The simple chest $x$-ray has, according to diagnostic guidelines, little value in establishing the diagnosis of COPD as the resolution is to coarse to visualize the lesions associated with COPD, but it can be used to help establish differential diagnosis and determine co-morbidities [17].

CT-scans are capable of depicting both lung tissue and airways, allowing separation between and describing extend of emphysema and airway disease $[18,19]$. CT-scans are not used in routine clinical practice as they have some major disadvantages; the patient is administered a high dose of radiation and often these patients will require follow-up examinations for several years as disease progresses; the equipment and hence the cost of scanning is expensive; and the examination in itself is strenuous for the patient suffering from COPD, as they are often claustrophobic $[20,21]$ and are required to hold their breath at often at maximal inspiration during the procedure. CT-scans are however often used in clinical co-horde trials to achieve full description of the included patients $[22,23]$.

The use of MR-scans has gained increasing interest as it may provide the same description as the CT-scan but without exposing the patient to radiation. New and interesting techniques utilizing MR and tracer gases can be used to create ventilation or perfusion weighted images, although the conventional MR sees a few problems like motion artefact and low proton density in the lungs [19]. A problem with MR may also be the limited availability compared to $\mathrm{CT}$.

\subsubsection{Lung volumes}

Measurement of lung volumes, in particular intrathoracic gas volume (ITGV), residual volume (RV) and total lung capacity (TLC), can be used to further characterize the impact of COPD on lung mechanics [24]. In the early stages of disease, some patient's exhibit gas trapping, and, as a result of increased airflow limitation, hyperinflation can occur. Changes in lung volumes can be measured with a body plethysmograph or "body 
box", that is usually available at larger pulmonary departments. This measurement procedure requires substantial cooperation from the patient to perform breath holdings and expirations against a closed shutter, which may cause that these patients can be unable to co-operate because of anxiety [21]. The patient is also required to be enclosed in the box during the measurement, where again claustrophobia can contribute to a discomforting experience. The body box can also be used to measure dynamic airway resistance which is used to identify obstructive and restrictive components of disease [24].

\subsubsection{Diffusion capacity}

The capacity of the lung to exchange respiratory gases across the alveolar-capillary interface has a significant effect on the functional level of a patient, as lack of oxygen to the tissues or accumulation of carbon dioxide have numerous consequences. This capacity is determined by both structural and functional properties of the lung. The structural properties include gas volume in lungs, and the thickness and area of alveolar-capillary interface. The functional properties include the levels of both ventilation and perfusion, the binding properties and concentration of hemoglobin, and the tension of gas in the blood and alveoli. The single breath diffusion capacity for carbon monoxide (DLCO), aims to describe this property of the lung. With DLCO, the ability of the lung to transport oxygen from the alveoli into blood is measured by the transport of carbon monoxide (CO). DLCO is calculated using population reference values and expressed as a percentage. Impairment of DLCO is seen when the effective alveolar area is reduced, i.e. the alveolar area contribution to gas exchange. Reduction in this area can however occur as a result of other factors than diffusion limitation, e.g. ventilation-perfusion ( $\left.\dot{V}_{A} / \dot{Q}\right)$ mismatch, left to right pulmonary shunt, or oxygen diffusion limitation [25]. In fact, it is widely recognized, that DLCO is a compound measure describing all the above mentioned factors lumped into one measure [26]. The measurement in itself is cumbersome for the patient, as it involves rapid inspiration to vital capacity and breath-holding for 8-12 seconds, and has shown to be somewhat problematic because of multiple 
sources of variability [27]. Due to the variability in the measurement it has been proposed that at least $10 \%$ and maybe up to $25 \%$ constitutes a clinical significant change in DLCO $[27,28]$.

\section{2 .6 Summary}

The diagnosis of COPD can be seen as difficult, and the heterogeneity of the disease often requires additional investigation of the patient's lung in order to fully understand the underlying cause of disease. The additional diagnostic tools contribute with different descriptions of the patient's grade and possible underlying causes of the disease. Imaging has a great potential determining patoanatomical changes and can be used to differentiate between emphysema and airway disease, but is not used in routine clinical practice because of the relatively high cost and risk of radiation. Exercise tests, $A B G^{\prime}$ 's and lung volume measurements are used to further determine the severity of disease and each contributes with diagnostic valuable information. DLCO describes the gas exchange properties of the lung as a simple compound measure. In patients suffering from COPD the lesions in the conducting airway and the degeneration of parenchyma have large effects on the ventilation in the lungs. At the same time, the perfusion is also affected as the alveoli are degenerated. Both effects leads to $\dot{V} A / \dot{Q}$ mismatch and therefore DLCO may not be the optimal measurement to describe pulmonary gas exchange in the lungs.

In the following section the description of pulmonary gas exchange in COPD is investigated further. 


\subsection{Description of pulmonary gas exchange in COPD}

This section describes pulmonary gas exchange in patients suffering from COPD. It begins with a description of the reference experimental technique for describing pulmonary gas exchange, the Multiple Inert Gas Elimination Technique (MIGET), which is presented along with its contribution to the understanding of COPD Because of its complexity, MIGET is usually restricted to an experimental environment and therefore a simpler technique, the Automatic Lung Parameter Estimator (ALPE) is introduced. ALPE has previously been used to describe gas exchange properties in pre- and post-operative patients as well as in patients with ALI/ARDS, using routine available data. Therefore, it may be possible that ALPE can also be used to describe patients suffering from COPD.

\subsubsection{MIGET}

The MIGET procedure, originally proposed in 1974 by Wagner, Saltzman, and West [29] is an experimental procedure and is widely considered the reference technique for describing pulmonary gas exchange of the lung. MIGET includes a complex model of the lung with 50 compartment each with a predefined VA/Q் ratio. Six inert gases (that is, they are only transported as dissolved in blood) are infused into a peripheral vein, and based on their retention and excretion measured from arterial blood and expired gas, the ratio of $\dot{V} A / \dot{Q}$ in the 50 compartments can be calculated [30].

Since its introduction, MIGET has been used in numerous studies and has been revolutionary in describing pulmonary gas exchange in many types of patients, including normal healthy individuals [31], in patients with acute respiratory failure [32], during general anesthesia [33], in cardiac disease [34], and in patients with bronchial asthma [35]. On several occasions patients suffering from COPD have also been investigated. In the pioneering study by Wagner and colleagues, 23 patients suffering from COPD was examined and the investigators characterized three $\dot{V}_{A} / \dot{Q}$ typical patterns; the low pattern, the high pattern, and the high-low pattern [36]. Furthermore, these patterns where correlated with either the emphysematous type or the 
bronchial type of COPD, as suggested by Burrows et al [37]. The investigators reported that the high $\dot{V}_{A} / \dot{Q}$ pattern was associated with the emphysematous type but that no other firm correlations could be made. Similar $\dot{V}_{A} / Q \dot{Q}$ patterns has been documented in other studies, although their association with clinical sub-types of COPD were less profound [38-40]. In Figure 2 the high and the low patterns are see. The horizontal axis shows the $\dot{V}_{A} / \dot{Q}$ ratio on a logarithmic scale, with $\dot{V}_{A} / Q$ ranging from zero (i.e. shunt, black triangle) to infinity (i.e. dead space, white triangle). The vertical axis shows the ventilation (white dots) and perfusion (black dots) calculated from the retention and excretion of inert gases for each of the 50 compartments.
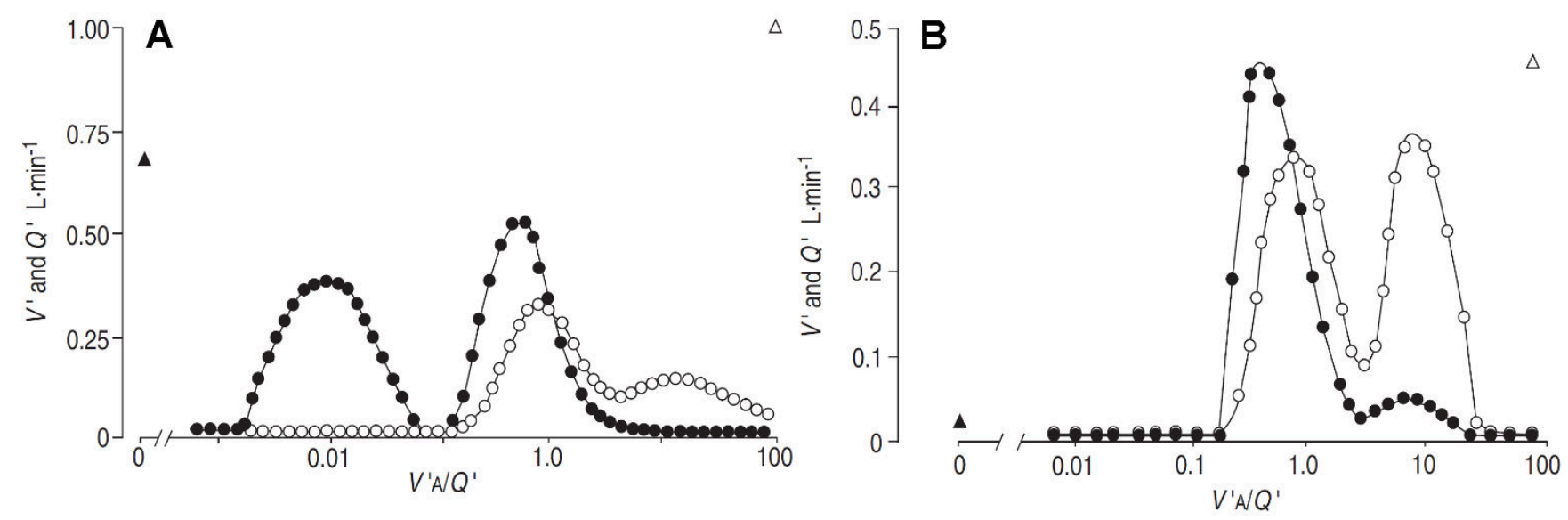

Figure 2: Distribution of ventilation (circles) and perfusion (black dots) patterns in COPD, modified from [36] with permissions. White triangle shows dead space, black triangle shows intrapulmonary shunt. Panel A, low $\dot{V} A / Q$ pattern associated with airway disease. Panel $B$, high $\dot{V} A / Q$ pattern, associated with emphysema.

The low pattern of $\dot{V}_{A} / \dot{Q}$ is seen in Figure $2 A$. Most of the ventilation is distributed around $\dot{V}_{A} / \dot{Q}=1$, whereas the perfusion has a bimodal pattern with a peak in low $\dot{V}_{A} / \dot{Q}$ and normal $\dot{V}_{A} / \dot{Q}$ compartments. In contrast, the pattern of high $\dot{V}_{A} / \dot{Q}$ is seen in Figure $2 \mathrm{~B}$. Here most of the perfusion is distributed around $\dot{V}_{A} / \dot{Q}=1$ and the bimodal pattern is seen for ventilation, with a normal and a high $\dot{V}_{A} / \dot{Q}$ peak.

In a more recent study, the quantity of $\dot{V} A / Q$ mismatch was compared to the progression in disease as described by the four GOLD stages. Here, it was found that low $\dot{V}_{A} / \dot{Q}$ is present in the earliest stage and often 
more abnormal than the decline in FEV1, and that the overall $\dot{V}_{A} / \dot{Q}$ distribution of the lungs worsen with progression in disease, with the largest increase seen in high $\dot{V}_{A} / \dot{Q}[41]$.

Allthough MIGET is capable of describing abnormalities in patient's gas exchange before significant decrease in FEV1 can be seen, and it can be used to differentiate between different patterns of $\dot{V}_{A} / \dot{Q}$ mismatch often seen in these patients, its use in clinical practice is very limited. This may be because of its high complexity and the duration of the procedure, and that only a few centers round the world possess the technology and expertise to perform the maneuver [42].

In contrast, attempts to describe pulmonary gas exchange properties with simpler models has been made prior to the introduction of MIGET $[43,44]$ and also in recent years [45-47]. Focusing on the latter of these, the model proposed by Kjaergaard et al., it has been shown to reproduce retention-excretion data from MIGET [48] and be able to simulate similar arterial oxygenation [49]. The model is included in the Automatic Lung Parameter Estimator (ALPE), which will be described in the next section together with its refinement since first publication. This refinement is described in details in paper 1 of this thesis.

\subsubsection{ALPE}

ALPE was introduced in 2002 by Rees et al. [50]. The method is based upon variation of inspired oxygen fraction $\left(\mathrm{FIO}_{2}\right)$ in 3-5 steps to achieve a range of arterial oxygenation $\left(\mathrm{SpO}_{2}\right)$ between 92 to $100 \%$. At the end of each step oxygen steady state is allowed and measurements of ventilation, inspiratory and expiratory oxygen fractions and $\mathrm{SpO}_{2}$. Completing measurements at the varying levels of inspired oxygen takes 10-15 minutes in total and the measurements are then used to identify parameters of the previously mentioned mathematical model of pulmonary gas exchange. ALPE has been implemented in different versions, depended on the clinical situations. The three implementations are seen in Figure 3, where the originally proposed (ALPE1) is seen in panel 1. ALPE2 for spontaneously breathing patients (panel 2) and ALPE3 for mechanically ventilated patients 
(panel 3) are both validated for clinical use and are commercial available. In the following section the mathematical model of ALPE will be presented, where after each implementation of ALPE will be introduced shortly and the rationale for development of the dedicated versions is summarized.

\section{2: ALPE2 for spontaneous breathing patients}

ALPE1, experimental system for

1: spontaneous breathing and

mechanically ventilated patients, 2002 version.
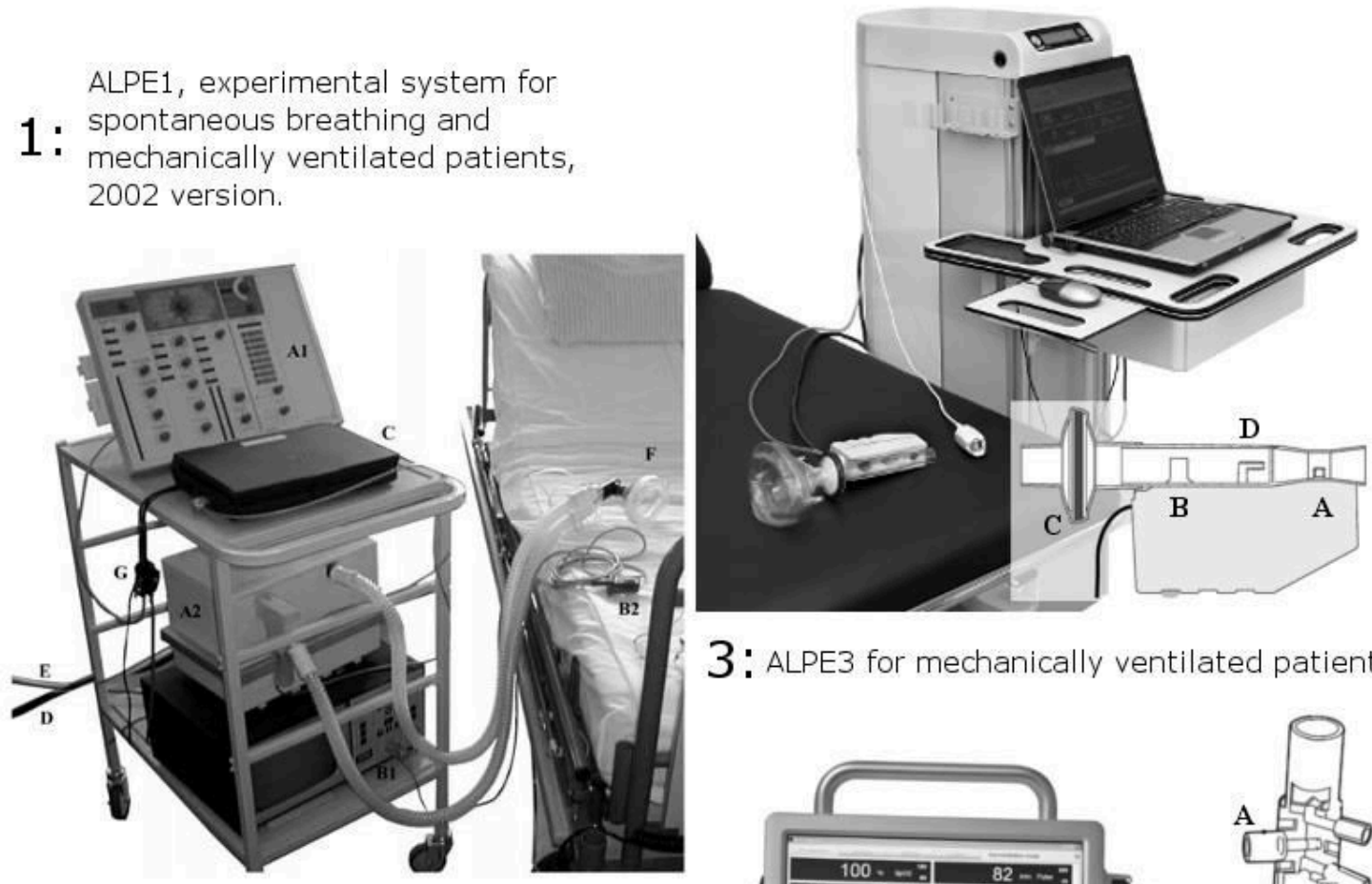

3: ALPE3 for mechanically ventilated patients

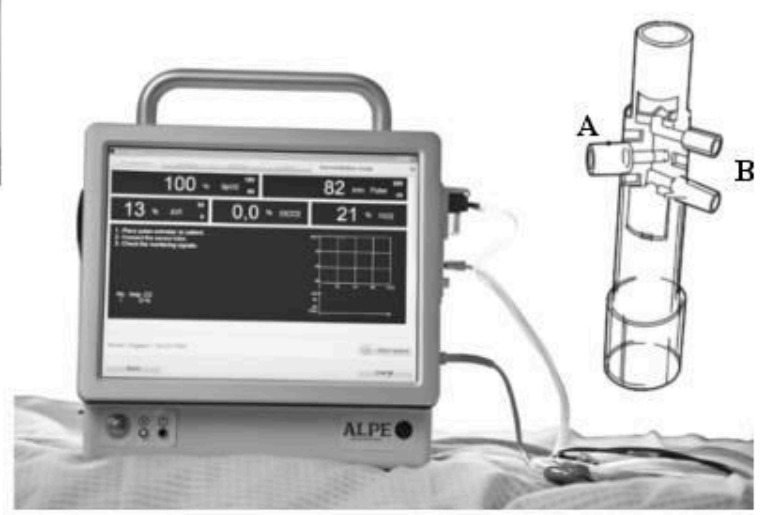

Figure 3: Implementations of the ALPE system, from [51] with permission. Panel 1: ALPE1, the 2002 experimental implementation of the $A L P E$ method including a ventilator (A1\&A2), a gas analyser with oximeter (B1\&B2), a computer (C) collecting the data, the gas-inlet (D\&E), and the face mask (F). Panel 2: ALPE2, the implementation for spontaneously breathing patients, consisting of the main unit including gas tanks and a respiration unit where the patient breathes freely through. A schematic drawing of the respiration unit (inset) where flow ( $A$ ) and oxygen fraction (B) are measured by mainstream sensors and proper mixing of oxygen or nitrogen is ensured by infusion of the gasses occurring against the inspiratory stream and being distributed via a mixing lattice (D). The disposable tube also has an antibacterial and humidity filter (C). Panel 3: ALPE3, the implementation for mechanically ventilated patients, showing the main unit to the left, consisting of a touchscreen displaying ALPE results and hardware for side stream measurement of $\mathrm{O}_{2}, \mathrm{CO}_{2}$, flow and pressure. The inset to the right shows the airway adapter that slots into the existing respiratory circuit, with side stream gas sampling port (A) and pressure difference flow sensor (B). 


\subsubsection{Mathematical model of ALPE}

The mathematical model of ALPE is a steady state description of oxygenation in the whole body such that oxygen transported into the blood from ventilation is equivalent to oxygen consumptions at the tissues $\left(\mathrm{V}_{2}\right)$. As a function of inspired oxygen fractions the model can be used to simulate arterial oxygenation. This can be used to describe how the model can differentiate between levels of pulmonary shunt and low VA/Q். In patients, quantification of these problems is achieved when the model is fitted to clinical data. 


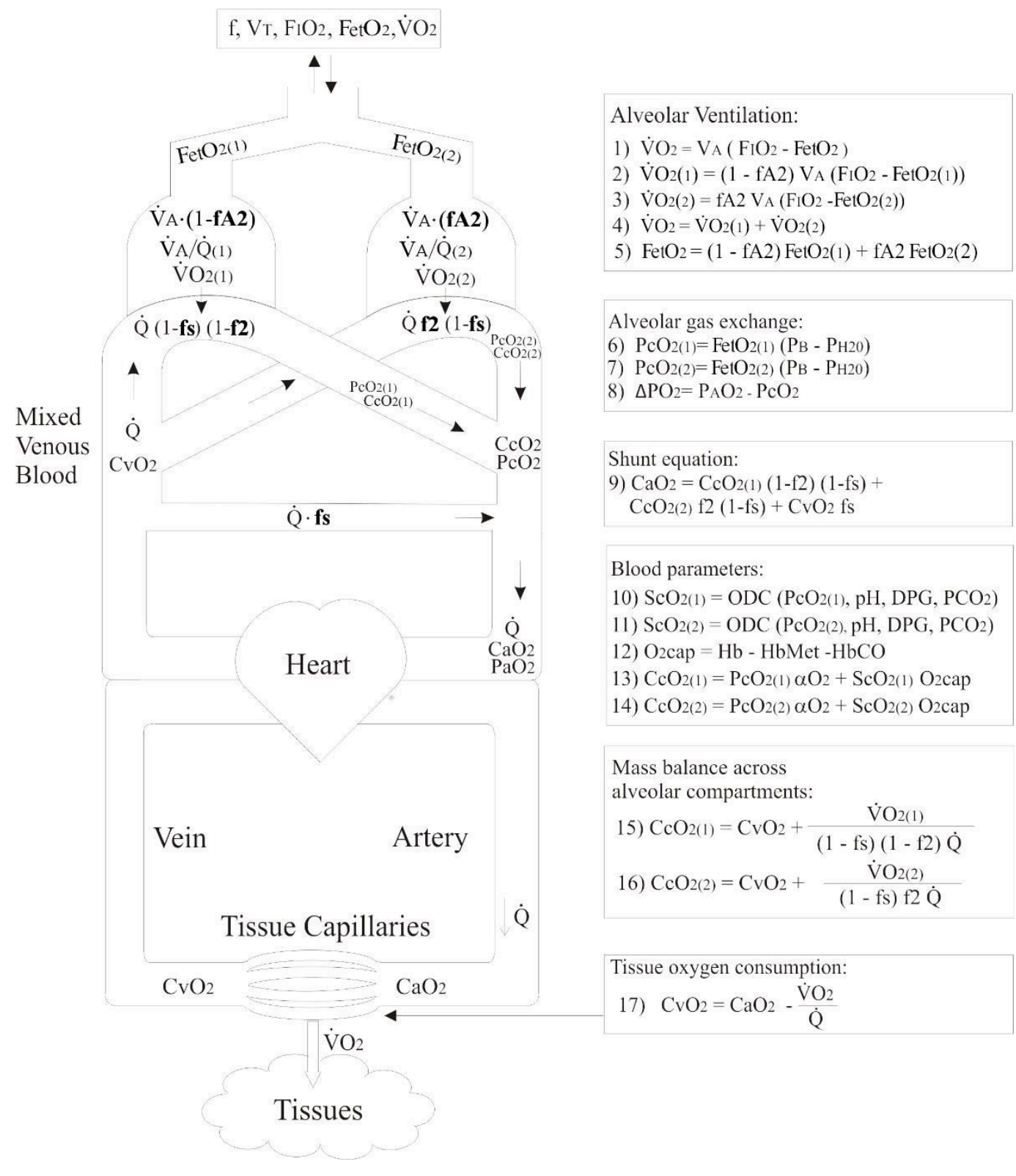

Figure 4: The mathematical model of oxygen transport, modified slightly (from [52] with permission). The model consist of three compartments, where two are ventilated and perfused representing gas exchange in the lungs, and the third representing pulmonary shunt. The equations describe the transport of oxygen at steady state from the a ventilator or air into the tissues: 1-4) oxygen flow into the alveoli and blood $\left(\mathrm{VO}_{2}\right)$ in total and addition from each compartment; 5) total expired oxygen fraction (FEO 2 ); 6-7) Oxygen partial pressure $\left(\mathrm{PcO}_{2(1)}, \mathrm{PcO}_{2(2)}\right)$ in the compartments; 8) drop in $\mathrm{O}_{2}$ partial pressure from expired gas to capillary blood; 9) mixed concentration of arterial blood $\left(\mathrm{CaO}_{2}\right) ; 10$-14) relationship between oxygen partial pressure $\left(\mathrm{PO}_{2}\right)$, saturation $\left(\mathrm{SO}_{2}\right)$ and concentration $\left(\mathrm{CO}_{2}\right)$ in the capillary compartments calculated from the oxygen dissociation curve (ODC) and blood variables; 15-16) concentration of oxygen in the lung capillary compartments $\left(\mathrm{CcO}_{2(1)}, \mathrm{CcO}_{2(2)}\right)$ combining venous concentration $\left(\mathrm{CvO}_{2}\right)$ and the increase in oxygen concentration resulting from alveolar equilibration; 17) venous oxygen concentration $\left(\mathrm{CvO}_{2}\right)$ combining arterial oxygen concentration $\left(\mathrm{CaO}_{2}\right)$ and the drop in oxygen concentration as a result of consumption in the tissues. 
The model, shown in Figure 4, includes a three compartment representation of gas exchange in the lungs, with pulmonary shunt, and two compartments with uniquely adjustable ventilation/perfusion ratios $\dot{V}_{A} / \dot{Q}_{(1)}$ and $\dot{V}_{A} / \dot{Q}(2)$. The parameters of the model are shunt (fs), the fraction of cardiac output not contributing to gas exchange; the fractional alveolar ventilation to the $\dot{V} / \dot{Q}$ compartments ( $\mathrm{fA} 2$ ); and the fraction of non-shunted perfusion to the $\dot{\mathrm{V}} / \dot{\mathrm{Q}}$ compartments (f2). The inputs for the model are oxygen consumption $\left(\mathrm{V}_{2}\right)$ obtained from measurement of respiratory gasses $\left(\mathrm{FetO}_{2}, \mathrm{FIO}_{2}\right)$ at steady state conditions; cardiac output (Q்), obtained using invasive or non-invasive techniques or approximated; the acid base characteristics of blood which are used to describe the position of the oxygen dissociation curve (using a model of blood [53]); and the alveolar ventilation obtained from frequency, tidal volume, and serial dead space (VDs). In most of the published studies using ALPE, the parameter $\mathrm{f} 2$ was locked at 0.9 meaning that one compartment received $90 \%$ of the nunshunted pulmonary perfusion and the other $10 \%$. In doing so, $\dot{V}_{A} / \dot{Q}_{(2)}$ becomes a low $\dot{V}_{A} / \dot{Q}$ compartment and $\dot{V}_{A} / \dot{Q}(1)$ a normal to high $\dot{V} A / \dot{Q}$ compartment. A further discussion of the parameter $f 2$ and the potential for estimating it from experimental data can be found on page 33. Parameterization of the low $\dot{V} / \dot{Q}$ compartment can be expressed as the parameter $\triangle \mathrm{PO}_{2}$ which describes an oxygen drop from end tidal to the mixed blood leaving aerated compartments. The equations describing the model are explained in details in the legend to Figure 4.

\subsection{Model simulations}

The model can be used to simulate changes in arterial oxygen saturation $\left(\mathrm{SaO}_{2}\right)$ due to changes in inspired oxygen fraction. By fixing values of model parameters and inputs, simulations can be performed on changes of $\mathrm{FIO}_{2}$ to new steady state conditions. In Figure 5A and Figure 5B examples of this is shown. Figure 5A illustrates how pulmonary shunt flattens the curve. The shunted blood flow through collapsed alveoli does not receive any ventilation and thus oxygen, resulting in only small increases in saturation as oxygen fractions is raised. The simulated curve flatten further on increasing shunt. In contrast, Figure 5B illustrates the effect of low $\dot{V} / \dot{Q}$ 
$\left(\triangle \mathrm{PO}_{2}\right)$. With increasing low $\dot{\mathrm{V}} \mathrm{A} / \mathrm{Q}$ the curves are shifted to the right, which is not surprising as blood passing through regions of the lung with little ventilation can be oxygenated further on increasing inspired oxygen levels.

As can be seen on the figure, shunt and low $\dot{V} A / Q$ behave different to changes in $\mathrm{FIO}_{2}$ and can therefore be estimated from changes in $\mathrm{FIO}_{2}$ and measurement of $\mathrm{SpO}_{2}$ response. Upon variations in inspired oxygen fraction, and measurement of inputs, the model can be parameterized with the level of shunt and low $\dot{V}_{A} / \dot{Q}$ determined for the individual patient, as explained in the following section.
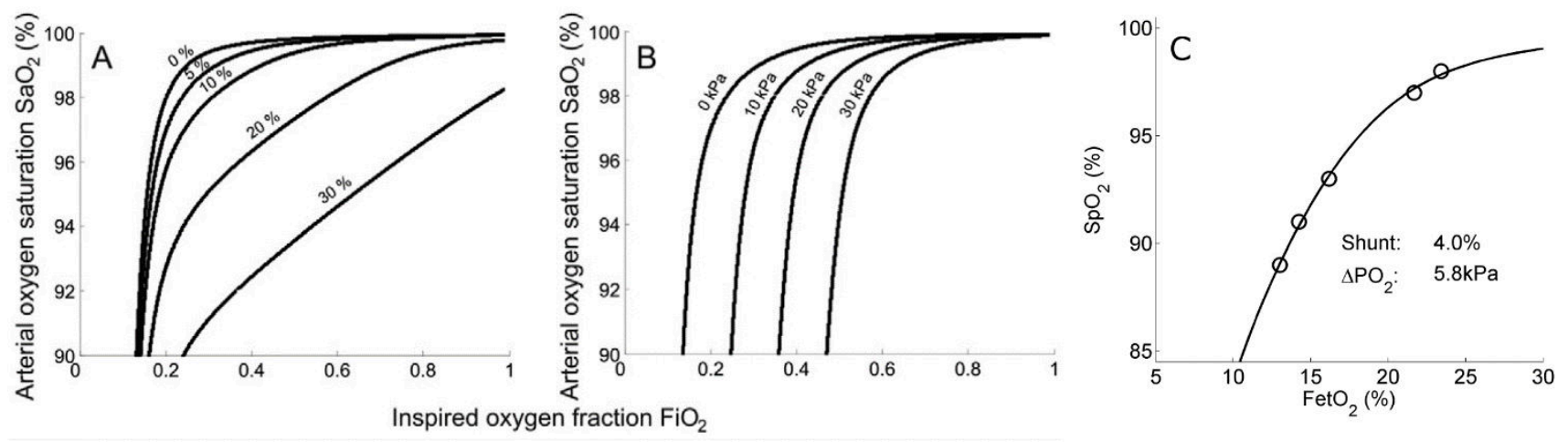

Figure 5: Model simulations and fit to data, part A and B with permission from [52]. Part A showing model simulation of pulmonary shunt at different levels. Part $B$ shows model simulations of deltaPO ${ }_{2}$. Part $C$ shows the best fit of the model (curve) to the data measured at steady state (circles).

\subsection{Estimation of model parameters}

The description of gas exchange problems in a patient is achieved by fitting the model to the measured data and estimating model parameters. Figure 5C illustrate an example where the model was fitted to measurements of steady state $\mathrm{FetO}_{2}$ versus $\mathrm{SpO}_{2}$ (circles), with the full data set given in Table 1 . For each oxygenation steady state (circles in figure, columns in table) several variables are measured. If arterial blood gas is available at each level this can also be included. $\mathrm{FetO}_{2}$ and $\mathrm{SpO}_{2}$ are given to the model in pairs whereas all other measurements are mean values for all inspired oxygen levels. In Figure 5C, the curve shows the "best" fit of the model to the data using least-squared fitting techniques, where the error between the simulated $\mathrm{SaO}_{2}$ 
and the measured $\mathrm{SpO}_{2}$ is optimized. These techniques will not be explained further here, as they have been described in details elsewhere [54].

Table 1: Typical dataset for usage with the mathematical model of ALPE, patient 1. $\mathrm{FIO}_{2}$, inspired oxygen fraction; FetO ${ }_{2}$, end-tidal carbon dioxide fraction; $\mathrm{SpO}_{2}$, pulse oximetry arterial oxygen saturation; $R F$, respiration frequency; Vt, tidal volume; $\mathrm{V}_{2}$, oxygen consumption; $\dot{V} \mathrm{CO}_{2}$, carbon dioxide production; $\mathrm{FetCO}_{2}$, end-tidal carbon dioxide fraction; VDs, serial deadspace; $\mathrm{pHa}$, arterial $\mathrm{pH}$; $\mathrm{PaO}$, arterial oxygen pressure; $\mathrm{SaO}_{2}$, arterial oxygen saturation; $\mathrm{PaCO}_{2}$, arterial carbon dioxide pressure; ctHb, total haemoglobin; FCOHb, carboxyhaemoglobin fraction; FMetHb, methaemoglobin fraction; $\dot{Q}$, cardiac output.

\begin{tabular}{|c|c|c|c|c|c|}
\hline & \multicolumn{5}{|c|}{ Oxygenation steady state } \\
\hline $\mathrm{FIO}_{2}$ & 0.21 & 0.18 & 0.15 & 0.30 & 0.25 \\
\hline $\mathrm{FetO}_{2}$ & 0.16 & 0.14 & 0.12 & 0.23 & 0.22 \\
\hline $\mathrm{SpO}_{2}(\%)$ & 93 & 91 & 88 & 98 & 97 \\
\hline RF (Breath/min) & 19 & 20 & 18 & 19 & 20 \\
\hline$\dot{\mathbf{V}} \mathbf{t}(\mathrm{L} / \mathrm{min})$ & 0.688 & 0.626 & 0.758 & 0.669 & 0.681 \\
\hline$\dot{\mathrm{V}}_{2}(\mathrm{~L} / \mathrm{min})$ & 0.334 & 0.340 & 0.317 & 0.378 & 0.361 \\
\hline VDS (L) & 0.317 & & & & \\
\hline $\mathrm{pHa}$ & 7.467 & & & & \\
\hline $\mathrm{PaO}_{2}(\mathrm{kPa})$ & 8.28 & & & & \\
\hline $\mathrm{SaO}_{2}(\%)$ & 92.5 & & & & \\
\hline $\mathrm{PaCO}_{2}(\mathrm{kPa})$ & 4.93 & & & & \\
\hline ctHb (mmol/L) & 9 & & & & \\
\hline FCOHb & 0.013 & & & & \\
\hline FmetHb & 0.011 & & & & \\
\hline$\dot{\mathbf{Q}}(\mathrm{L} / \mathrm{min})$ & 6.17 & & & & \\
\hline
\end{tabular}

\subsubsection{ALPE1}

ALPE1 was introduced as a research tool and designed around a ventilator (Servo 300, Siemens, Sweden)

(Figure 3.1, A1 and A2) and a gas analyzer with pulse oximeter (BK104, Bruel and Kjær, Denmark) (Figure 3.1, B1 and B2), coupled to a computer (Figure 3.1, C) with the ability to automatically collect data from the experiment. The ventilator was replaced by that ventilating the patient when the system was used in mechanically ventilated patients. For use in spontaneously breathing patients, the patient was ventilated using CPAP mode with zero pressure support and the patient breathed normally through the system. The ventilator was used to control the inspired gas fraction, where oxygen was supplied on super-atmospheric levels and nitrogen during sub-atmospheric level. 
Clinical use of ALPE1 has led to a refinement of the system, which is described in details in paper 1 . One of the major improvements to the system is the addition of two dedicated implementations of ALPE. In a pre- or postoperative setup patients often breathe spontaneously without the need for mechanical ventilation. In this case a simpler ALPE system could be developed excluding the functionality of a mechanical ventilator, but including gas mixing so as to allowing variation of inspired oxygen fraction. As pre-and post-operative patients often suffer from relatively minor respiratory abnormalities in relation to ICU patients, gas mixing was designed to deliver sub-atmospheric levels of $\mathrm{FIO}_{2}$, in order to draw the characteristic $\mathrm{FIO}_{2}$ versus $\mathrm{SpO}_{2}$ curves introduced in the previous section. The second dedicated version of the system was designed for patients in the ICU who typically are already on mechanical ventilation. In this case a system was designed which exploited the patients existing mechanical ventilator for gas delivery and mixing, providing only measurement functionality.

\subsubsection{ALPE2}

ALPE2 is the version designed for spontaneously breathing patients not on mechanical ventilation, see Figure 3.2. The primary part of the system is a respiratory unit, where flow and oxygen fraction is measured, and supplementary gas is injected during inspiration to ensure correct inspiratory oxygen fraction (Figure 3.2, inset). During measurement the patient breathes freely through the respiratory unit, and the system administers oxygen fraction and measures respiratory data needed by the ALPE model automatically. Oxygen saturation is measured with a standard pulse oximetry probe from the patient's finger. The main body of the transportable system hold gas tanks with supplementary gases oxygen and nitrogen, and serves as the workstation for the operator of the system. The system has been described in more detail in paper 1.

\subsubsection{ALPE3}

ALPE3 is the version for mechanically ventilated patients and is designed as an add-on for the mechanical ventilator. A small airway adapter slots into the existing respiratory circuit and measures respiratory $\mathrm{O}_{2}$ and $\mathrm{CO}_{2}$ fractions, pressures and flow, see inset of Figure 3.3. Pulse oximetry arterial saturation is measured with a 
standard finger probe. The system measures automatically and inspired gas fractions are controlled by the operator on the patient's ventilator, with the ALPE system providing advice as to the correct settings.

\subsubsection{Summary}

The potential of MIGET to provide a detailed description of gas exchange properties of the lung has been demonstrated in several studies. It has been shown, that patients suffering from COPD have different patterns of $\dot{V} A / \dot{Q}$ mismatch and that correlation between the stages of disease to total $\dot{V}_{A} / \dot{Q}$ abnormality can be established. The technique however, is experimental, time consuming and requires a high level of expertise. In contrast, an approach using a simpler mathematical model which can be identified from routinely available clinical data was presented, i.e. ALPE. The mathematical model of ALPE enables the description of pulmonary shunt and $\dot{V} A / Q$ mismatch. The model has previously been shown to reproduce MIGET results and it could therefore be interesting to investigate whether this technique could be used in the diagnosis of patients suffering from COPD. The ALPE method has been implemented in three versions, where the ALPE2 designated for spontaneously breathing patients will be suitable for patients suffering from COPD. 


\subsection{Challenges for ALPE in COPD}

ALPE has been used in different clinical settings. Based on the experience gained from these studies and characteristics of patients suffering from COPD, the challenges for using ALPE for patients suffering from COPD are identified in the following section.

\subsubsection{Clinical use of ALPE}

Hypoxaemia caused by respiratory complications is often seen in patients following major surgery [55], and is considered "the main cause of increased hospital stay" [56]. Therefore, ALPE has been applied as a tool for assessing post-operative lung function in patients following gynecological laparotomy [57], cardiopulmonary bypass [58], and abdominal surgery [47]. In these studies it has been shown that patients' gas exchange problems can be described satisfactorily by shunt and $\dot{V} / \dot{Q}$ mismatch, see Figure 6 , panel A. Typically in these patients, values of shunt increased immediately following surgical intervention whereas low $\dot{V} / \dot{Q}$ tended to peak 2-3 days following surgery. The increase in shunt is consistent with immediate atelectasis due to surgical procedure and anaesthesia [59], where the peak in low $\dot{V} / \dot{Q}$ is consistent with elevated risk of post-operative hypoxaemia [60]. 
A: Pre/post abdominal surgery

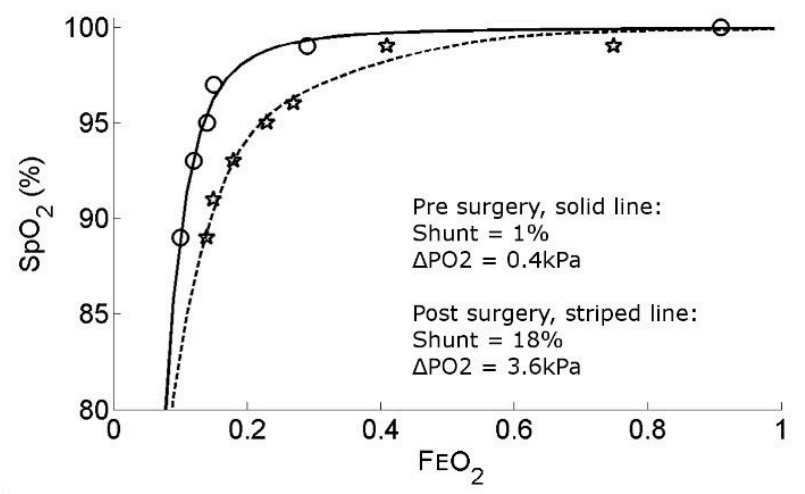

B: ARDS, effect of changing PEEP

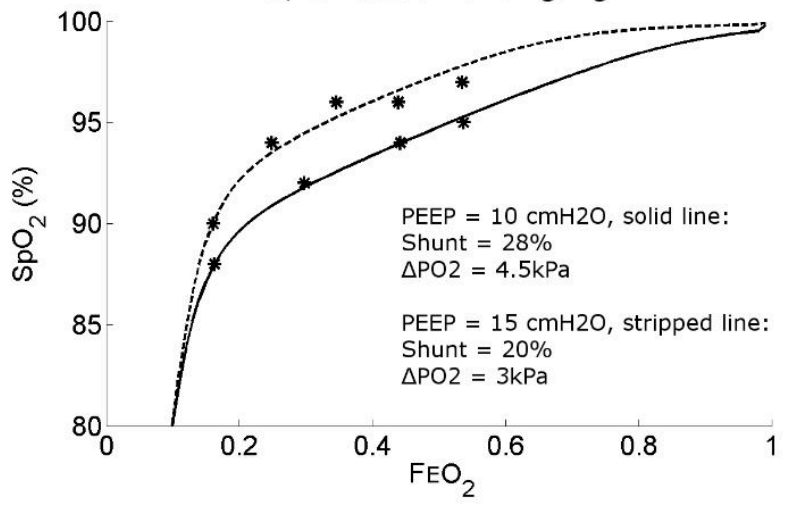

Figure 6: ALPE simulations (curves) of $\mathrm{FEO}_{2}$ versus $\mathrm{SpO}_{2}$ from patient data (stars) in disease, from [51] with permissions. Panel A shows simulations pre-(solid curve, circles) and post- (striped curve, stars) abdominal surgery. Gas exchange problems post-surgery is described by the model as an increase in shunt to $18 \%$ and $\triangle P \mathrm{P}_{2}=3.8 \mathrm{kPa}$. Panel $\mathrm{B}$ shows simulations of data at $\mathrm{PEEP}$ levels $10 \mathrm{~cm} \mathrm{H}_{2} \mathrm{O}$ (solid curve) and $15 \mathrm{cmH}_{2} \mathrm{O}$ (striped curve) from a patient suffering from ARDS. The improvement in gas exchange resulting from increased PEEP is described by the model included in ALPE as reduction in shunt and $\triangle P \mathrm{O}_{2}, 28 \%$ to $20 \%$ and $4.5 \mathrm{kPa}$ to $3 \mathrm{kPa}$, respectively.

ALPE has also been applied to patients in the ICU where diagnostic classification of Acute Lung Injury (ALI) and Acute Respiratory Distress Syndrome (ARDS) is based on several variables including the value of the $\mathrm{PaO}_{2} / \mathrm{FIO}_{2}$ ratio [61]. ALPE was used to investigate the adequacy of this ratio and it was showed that misclassification can occur in as much as $30 \%$ of patients [62]. It was shown here again, that the mathematical model of ALPE could describe the gas exchange problems of the patient's satisfactorily using shunt and $\dot{V}_{A} / \dot{Q}$ mismatch. Figure 6 , panel B, shows example of the model describing a patients with ARDS at two different levels of PEEP. For this patient the increase in PEEP by $5 \mathrm{cmH}_{2} \mathrm{O}$ benefits the patient, as shunt is reduced by $8 \%$ and $\triangle \mathrm{PO}_{2}$ by $1.5 \mathrm{kPa}$.

Up until now, ALPE has been shown to describe a variety of patients both mechanically ventilated and spontaneously breathing, where the primary gas exchanges problems was caused by high fractions of pulmonary shunt and areas of low $\dot{V} A / Q$. None of the existing implementation of ALPE has been systematically used in patients suffering from COPD, and possibly the differences these patients may exhibit can lead to 
challenges for the application of ALPE. In the following section the characteristics of a COPD patient that may be seen as a challenge for application of ALPE in COPD are described.

\subsubsection{Identification of challenges in relation to application of ALPE in COPD}

Patients suffering from COPD are defined by GOLD criteria as having a FEV1\% below $80 \%$ and a FEV1/TLC ratio below 0.7 [6]. The obstructive nature of the disease and the often chronic dyspnea can as a consequence lead to difficulties in any measurement that challenges the ability of the patient to breathe freely. Previous studies report that patients suffering from COPD are often claustrophobic $[20,21]$ and can be unable to co-operate because of anxiety [21] due to usage of facemasks or ventilation mouth pieces. Furthermore, the addition of any external resistance will cause a load that needs additional work of breathing from the patient. As the patients respiratory muscles may be fatigued, this increased work of breathing may cause irregular breathing patterns like for instance rapid shallow breathing [63]. If ALPE is to be used in patients suffering from COPD, it is important that the mouthpiece and airway adapter introduces minimal resistance and that duration of the measurement is as short as possible to avoid discomfort for the patient. Furthermore, the sub- or superatmospheric inspired gas fractions needs to be stable even as respiration patterns change widely.

It has previously been established, that the principal contributor to hypoxaemia in patients suffering from COPD is mismatch of pulmonary ventilation and perfusion $[36,64,65]$. This is either seen as areas of low $\dot{V} A / \dot{Q}$ with substantial perfusion to under ventilated areas or high $\dot{V}_{A} / \dot{Q}$ with increased ventilation to under perfused areas and thus increased physiological dead space. The increase in very high $\dot{V}_{A} / \dot{Q}$ or physiological dead space is associated with elevated levels of arterial carbon dioxide [66]. Rapid shallow breathing may also be a contributor to high $\dot{V}_{A} / \dot{Q}[67,68]$. If ALPE is to be used in patients suffering from COPD, description of high $\dot{V}_{A} / \dot{Q}$ must be included. The implementation of the mathematical model currently used with ALPE2, i.e. the fraction $\mathrm{f} 2$ is fixed at 0.9 , is not capable of describing high $\dot{V}_{A} / \dot{Q}$ and this represents a challenge to the application of ALPE. 
During a measurement with ALPE inspired oxygen fraction is varied. As such, changes in oxygen are used as a tracer to identify $\dot{V} A / \dot{Q}$ mismatch. After each variation, oxygen is allowed to equilibrate which is assessed by monitoring end-tidal oxygen fraction plateau. Typically one to two minutes is waited before end-tidal plateau occurs, however this may not be sufficient. This has been investigated for patients with COPD in a PhD study running parallel to this, concluding that the time to steady state in $\mathrm{PaO}_{2}$ and $\mathrm{SaO}_{2}$ after changes in $\mathrm{FIO}_{2}$ was up to 10 - 15 minutes [69]. This means an ALPE measurement with 3 changes in inspired oxygen could last more than 45 minutes, which is unacceptable in a clinical setting and especially in these patients. If ALPE is to be used in patients suffering from COPD, the need for measurements to be taken at steady state conditions needs to be relaxed, allowing a faster examination procedure than is possible with the current version of ALPE.

The use of oxygen as a tracer to investigate pulmonary gas exchange raises other issues. The appropriate use of any tracer implies that the underlying system is not perturbed by the tracer. As the mathematical model is a steady-state description of gas exchange in the lungs, this assumption implies that model inputs $\left(\dot{\mathrm{V}} \mathrm{O}_{2}, \dot{\mathrm{V}} \mathrm{A}, \dot{\mathrm{Q}}\right.$, and acid-base status) remain constant for all $\mathrm{FIO}_{2}$ levels. In patients suffering from COPD where arterial level of $\mathrm{CO}_{2}$ are permanently elevated, this may not be true. In these patients respiratory drive may be controlled primarily by changes in oxygen pressure rather than carbon dioxide pressure [70] and as such lowering $\mathrm{FIO}_{2}$ may increase total ventilation and increasing $\mathrm{FIO}_{2}$ may decrease ventilation. The latter of these may lead to hypercapnia and respiratory failure $[71,72]$. If ALPE is to be used in patients suffering from COPD, the impact of changing $\mathrm{FlO}_{2}$ in these patients should be considered carefully.

In summary, ALPE can potentially be used for description of lung function in COPD given, the above mentioned challenges can be solved. The techniques however, may need to be integrated with other available clinical measures to enable a meaningful clinical description COPD that can aid in diagnosis and follow-up of patients. 
In the following section, it is investigated how description of gas exchange may aid in a combined description of COPD.

\subsubsection{Integration of ALPE with clinical available measurements}

The current clinical standard for measuring gas exchange in patients with COPD is the measurement of DLCO. To understand the potential need for ALPE requires consideration of the limitations of DLCO. DLCO can be criticized for lumping all causes of gas exchange abnormalities into one, and thus possibly missing descriptive information regarding the underlying cause of disease. In contrast to this, the description of patient's pulmonary gas exchange with MIGET has shown, that different $\dot{V} A / \dot{Q}$ distribution patterns exist in these patients. Furthermore it has been shown that patient's oxygenation problems can be explained solely by $\dot{V}_{A} / \dot{Q}$ mismatch, without the need for resistance to diffusion. In some studies using MIGET a correlation between specific patterns and sub-types of disease has been shown, for example a pattern of increased high $\dot{V}_{A} / \dot{Q} n$ emphysema.

A combined assessment of the patient's lung may provide a more complete description of the impairment of disease and could lead to a deeper understanding of the underlying causes. As quantification of $\dot{V} A / Q$ mismatch is a description of pulmonary gas exchange and therefore a functional description, a combination with a description of the mechanical properties of the lungs such as FEV1\% might be appropriate. It is possible that a combined assessment of the impact of disease on functional and mechanical properties of the lungs may help to determine the underlying cause of disease, i.e. the pathoanatomical subtype of COPD, emphysema or airway disease. Both emphysema and or airway disease present as obstruction, measurable by FEV\%1, but may have different patterns of $\dot{V} A / Q$ mismatch. If such an assessment is made, it could be compared to a radiologic classification of COPD, where the pathoanatomical subtypes are determined by visual inspection. This may provide a radiologic classification using simpler clinical measurements. 


\subsubsection{Summary}

ALPE has been shown to describe gas exchange problems in different clinical setting in patients undergoing therapy with mechanical ventilation and those with spontaneous breathing alone. The gas exchange abnormalities seen in patients previously studies with ALPE have been due mainly to shunt and low VA/Q. In contrast, the principal contributor to gas exchange abnormalities in patients suffering from COPD is $\dot{V}_{A} / \dot{Q}$ mismatch, where both areas of low $\dot{V}_{A} / \dot{Q}$ and high $\dot{V}_{A} / \dot{Q}$ contribute to poor gas exchange. Therefore, the mathematical model of ALPE need to incorporate a description of high $\dot{V} A / \dot{Q}$.

In addition, achieving oxygenation steady state within a few minutes following a change in inspired oxygen fraction could be a problem in these patients, and hypoxia may change their breathing patterns. The use of oxygen as a tracer is not therefore straightforward in these patients and the effects of changing inspired oxygen should be considered carefully, including the need to eliminate the need for measurements to be taken a steady state conditions.

A further issue associated with the application of ALPE in these patients is the combined effect of obstruction, hypoxia and changes in breathing patters that nay make reliable measurements with an airway adapter problematic. Investigation is therefore required to see: if the airway adapter of ALPE2 is suitable for use in COPD; if the measurement can be performed within a reasonable time; and if the gas mixing system is capable of delivering stabile fractions of inspired gas.

Assuming that the challenges identified above can be addressed adequately, the question remains as to whether an ALPE description of pulmonary gas exchange can be combined with other readily available measurements, and whether such combination could result in an improved description of the disease. A combined description might be able to characterize patients according to their pathoanatomical subtypes emphysema and airway disease identified from radiological images. 


\subsection{Aim of the thesis}

The previous section has identified a number of challenges for using ALPE in measuring pulmonary gas exchange in patients suffering from COPD. These challenges have led to the following questions and it is the consideration of these which constitutes the aim of this thesis:

- How can the current version of ALPE be modified to be applicable for use in patients suffering from COPD?

To address this question requires consideration of a number of sub questions. These points are the basis of paper 1 and paper 2 .

- How can the current ALPE model be modified to enable description of high $\dot{V}_{A} / \dot{Q}$ units of the lung which often present in COPD?

- Can the current ALPE equipment be used in the often unstable breathing patterns seen in these patients?

- Is it possible to design a strategy for measurement and model fitting which does not require steady state conditions for oxygen?

Do the effects of hypoxic drive prevent the use of oxygen as a tracer in patients with COPD?

- How can the ALPE measurements be integrated with other measurements to provide an integrated clinical picture of the lungs, and if so can such a description provide similar classifications as radiologic descriptions of the lungs? This question is the basis for paper 3.

The following chapter will present the methods and result of the thesis. The thesis is structures according to the research questions presented above, with chapters divided into sections each describing a question or subquestion. Each section will present specific methods and results from the papers, and the discussion of these and relation to the aims of the thesis will be summarized in the synthesis. 


\section{Application of ALPE in patients suffering from COPD}

The previous chapter introduced the diagnosis of COPD, the use of functional and mechanical measurements of the lung, and criticized the current functional description of the lungs, DLCO. Alternatives to DLCO include ALPE, where gas exchange abnormalities are explained by shunt and $\dot{V} A / \dot{Q}$ mismatch, which have been shown by the reference experimental technique MIGET to be the main problems associated with poor oxygenation in COPD. ALPE could potentially be used as a functional description of COPD, but challenges of using the technique in this range of patients has been identified. In this chapter the challenges will be investigated. Furthermore, the integration of ALPE with other clinical measures to provide a better description of the lung is investigated.

\subsection{How can the current ALPE model be modified to enable description of high $\dot{V}_{A} / \dot{Q}$ units of the lung?}

The mathematical model of ALPE describes transport of oxygen into the tissues and inefficient gas exchange is quantified as shunt and low $\dot{V}_{A} / \dot{Q}$. In patients suffering from COPD fractions of high $\dot{V}_{A} / \dot{Q}$ has been shown to contribute to the abnormalities, and thus the model need to incorporate a description of high $\dot{V}_{A} / \dot{Q}$.

\subsubsection{Three parameter model with description of high VंA/Q}

As described earlier (see page 19) the model can be uniquely identified from its three parameters: shunt (fs), the fraction of cardiac output not contributing to gas exchange; the fractional alveolar ventilation to the $\dot{V} / \dot{Q}$ compartments (fA2); and the fraction of non-shunted perfusion to the $\dot{V} / \dot{Q}$ compartments (f2). Currently, as the models parameters should be identifiable from the available oxygenation data, the parameter $\mathrm{f} 2$ determining the fraction of non-shunted cardiac output reaching the two compartment is fixed. Through repeated analysis of data it was shown that the models description of shunt and $\dot{V}_{A} / \dot{Q}$ mismatch was independent of $f 2$, and as a result setting $f 2$ at 0.9 was adopted [47]. This means $f A 2$ determines the fraction of alveolar ventilation reaching a compartment with either $10 \%\left(\dot{V}_{A} / \dot{Q}(1)\right)$ or $90 \%\left(\dot{V}_{A} / \dot{Q}(2)\right)$ of non-shunted 
perfusion. When $\mathrm{fA}_{2}$ is set at $0.9(90 \%)$ this gives equal $\dot{\mathrm{V}} \mathrm{A} / \dot{\mathrm{Q}}$ ratios in both compartments i.e. an optimal $\dot{\mathrm{V}} \mathrm{A} / \dot{\mathrm{Q}}$ relationship. Decreasing $f A 2$ below 0.9 increases $\dot{V}_{A} / \dot{Q}(1)$ and decreases $\dot{V}_{A} / \dot{Q}(2)$, i.e. $\dot{V}_{A} / \dot{Q}(2)$ is a low $\dot{V}_{A} / \dot{Q}$ compartment and $\dot{V}_{A} / \dot{Q}(1)$ a normal to high $\dot{V} A / \dot{Q}$ compartment.

In a previous study by Karbing et al. [54], the minimal model complexity able to describe clinical data was examined. Three mathematical models with increasing complexity were compared in their ability to fit data describing $\mathrm{O}_{2}$ and $\mathrm{CO}_{2}$ in patients residing in intensive care. A one parameter model describing pulmonary shunt, a two parameter model describing pulmonary shunt and ventilation varied to a fixed perfusion in two compartments (the model used with ALPE1 and ALPE2, described on page 19), and a three parameter model describing pulmonary shunt and both ventilation and perfusion varied in two compartments. Here it was shown that the shunt only model could not describe the patient sufficiently. The two and the three parameter model where able to describe most patients satisfactorily, although the three parameter model proved better in patients with significant fractions of very high $\dot{V}_{A} / \dot{Q}$ problems. This is due to the fixed perfusion ratio, as discussed above, where very high $\dot{V} A / \dot{Q}$ fractions are unachievable. This is because the high $\dot{V} A / \dot{Q}$ compartment received $10 \%$ of the total non-shunted perfusion, which is too much to reach very high $\dot{V}_{A} / \dot{Q}$.

Going from the two parameter model of ALPE to the three parameter model is in essence the unlocking of $\mathrm{f} 2$. To do so, requires additional data to be able to uniquely identify the three parameters and therefore equations describing the transport and storage of $\mathrm{CO}_{2}$ have been incorporated into the model. The three parameter model thus describes transport and storage of both oxygen and carbon dioxide from the lung and into the tissues. In addition to the inputs of the current ALPE model $\left(\dot{V}_{2}, \dot{Q}, \dot{V} A\right.$, acid-base status) carbon dioxide production $\left(\mathrm{VCO}_{2}\right)$ is added. Arterial carbon dioxide pressure $\left(\mathrm{PaCO}_{2}\right)$ is simulated by the model and a measured value is therefore needed in the fitting routine. Thus, to use the three parameter model with ALPE2 additional measurement of volumetric capnography are needed to calculate $\dot{\mathrm{V}} \mathrm{CO}_{2}$. $\mathrm{PaCO}_{2}$ can be measured 
from arterial blood. The fitting procedure for the three parameter model is, for oxygen, the same as to the two parameter model, i.e. least-squared fitting technique, where the error between the simulated $\mathrm{SaO}_{2}$ and the measured $\mathrm{SpO}_{2}$ is optimized. For $\mathrm{CO}_{2}$, the error between the simulated $\mathrm{PaCO}_{2}$ and the measured $\mathrm{PaCO}_{2}$ is optimized. Figure 7 illustrates the fit of the three parameter model to four patients with different subtypes of COPD. The model is fit to oxygenation data as shown in the previous chapter, but also to end tidal and arterial $\mathrm{CO}_{2}$ levels at baseline conditions. 

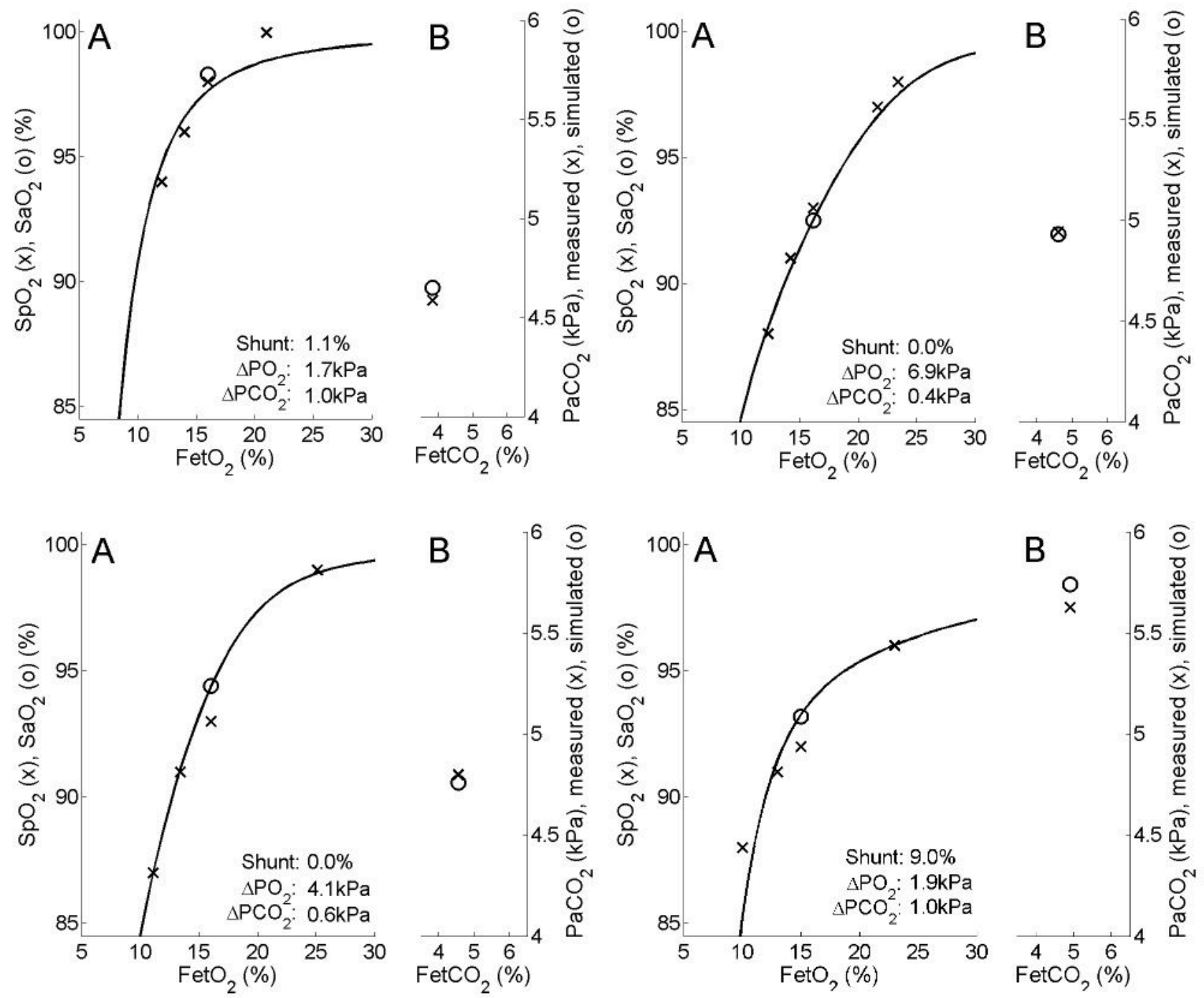

Figure 7: Examples of fitting the three parameter model to measured values of $\mathrm{SaO}_{2} / \mathrm{SpO}_{2}$ vs FetO $\mathrm{F}_{2}$ and FetCO2 vs PaCO in four patients. Part A: Measured end-tidal fraction of oxygen $\left(\mathrm{FetO}_{2}\right)$ and pulse oximetry arterial saturation $\left(\mathrm{SpO}_{2}\right)(x)$ or FetO $\mathrm{O}_{2}$ and arterial saturation $\left(\mathrm{SaO}_{2}\right)(\mathrm{o})$. The solid line shows the best fit of the model. Part B: Measured end-tidal carbon dioxide fraction (FetCO2) and arterial carbon dioxide pressure $\left(\mathrm{PaCO}_{2}\right)(\mathrm{o})$ and best model simulation $(x)$.

As described previously, model parameters can be used to calculate surrogate parameters which are useful for clinical interpretation. $\triangle \mathrm{PO} 2$ describes the oxygen drop from capillary blood to end tidal values and provides a clinical quantification of low $\dot{\mathrm{V}} \mathrm{A} / \dot{\mathrm{Q}}$ in the model. Similarly, high $\dot{\mathrm{V}} \mathrm{A} / \mathrm{Q}$ can be quantified by $\triangle \mathrm{PCO}{ }_{2} . \triangle \mathrm{PCO}_{2}$ describes the increase in carbon dioxide pressure from ventilated alveoli $\left(\mathrm{FetCO}_{2}\right)$ to pulmonary capillary blood 
before admixture of shunted venous blood. High values of $\triangle \mathrm{PCO}_{2}$ indicate insufficient $\mathrm{CO}_{2}$ removal and need for increased alveolar ventilation if $\mathrm{CO}_{2}$ retention due to $\dot{V}_{A} / \dot{Q}$ mismatch is to be avoided.

\subsubsection{Measurement of data required for the three parameter model}

This thesis is focused on the technical aspects of ALPE and mathematical modeling. While the focus has not been on clinical investigation, both retrospective and prospectively collected data has been used in the evaluation of the methods presented. In papers 1 to 3 data from a prospective controlled study of 25 patients suffering from COPD. This study was completed between spring 2010 and summer 2011 at our local outpatient clinic. All patients gave their informed consent and the study was approved by the local Ethics Committee and in agreement with the declaration of Helsinki. In addition to this, in paper 1 analysis of retrospective and prospectively collected data was performed. In this section the measurements taken in the retrospective study used in all papers is further explained, with special focus on the data specific for the ALPE model.

\subsubsection{Measurements}

In summary, the following measurements were taken on all patients:

- Pulmonary HRCT (Discovery CT750HD, GE, USA)

- Whole body plethysmography (Master Screen Body Pletysmograph, Jaeger Medical, USA)

- DLCO (Master Screen PFT, Jaeger Medical, USA)

- ALPE (ALPE Essential, Mermaid Care A/S, Denmark)

- Capnography (CO2SMO+, Respironics, USA)

○ Arterial blood gas (ABL725, Radiometer, Denmark)

The HRCT scan was conducted at a separate occurrence, typically the day following the visit to at the outpatient clinic, but within 48 hours of all other measurements. In accordance with the recommendations of Dirksen et al. [73] the same scanner was used for all patients, and a scanning protocol targeted at this study was used. The scans were all done with $1.25 \mathrm{~mm}$ slice thickness, as is proposed for optimal COPD assessment quality $[74,75]$. 
During a scheduled visit at the out-patient clinic, the standard clinical measures whole body plethysmography and DLCO were conducted for all patients. Here plethysmography, total lung volume, functional residual capacity, and standard spirometry was measured. DLCO was measured subsequently and the patient was allowed to rest for at least 5 minutes prior to the ALPE measurement, to ensure that CO was washed out properly.

To measure data for the three parameter ALPE model, the previously described ALPE2 implementation (see Figure 3.2) was used to record ventilatory volumes and oxygen-fractions, and to control the inspired oxygen level. The equipment was slightly modified in that a carbon dioxide monitor was slotted in with the airways adapter. This was done in order to allow recording of end-tidal $\mathrm{CO}_{2}$ fractions and $\mathrm{CO}_{2}$ production required by the mathematical model. The ALPE2 implementation and the capnograph were both connected to a laptop through standard RS-232 serial connection, from where all data were sampled with $100 \mathrm{~Hz}$. This allowed us to calculate all input parameters for the model using custom build software. In this setup, the automatic algorithm of ALPE2 to select and administer appropriate levels of inspired oxygen fraction was omitted and everything was controlled by the operator (Inspired gas levels, length of each oxygen level, and number of levels with different inspired oxygen fraction). During the initial $\mathrm{FIO}_{2}$ step, an arterial blood gas sample was drawn from a. radialis, while the patient was breathing though the mouthpiece. The procedure continued hereafter without the patient being disconnected from the mouthpiece, and the blood gas sample was analyzed within minutes by an assistant. 


\subsection{Can the current ALPE equipment be used in in the often unstable breathing patterns seen in these patients?}

If ALPE is to be used in patients suffering from COPD, it is important that the mouthpiece and airway adapter produce minimal resistance and that duration of the measurement is as short as possible to avoid discomfort for the patient. Furthermore, the sub- or super-atmospheric inspired gas fractions need to be stable even though respiration patterns change widely. In this section selected results from paper 1 are presented in relation to these points.

\subsubsection{Airway adapter}

Introducing ALPE2 in patients suffering from COPD, it is important that the equipment does not hinder the normal spontaneous breathing of the patient, as this may trigger claustrophobia and cause the patient to discontinue the maneuver. The airway adapter of ALPE2 responsible for infusion of supplementary gas and measurement of flow and oxygen fraction (see Figure 3.2, inset) was designed with a low resistance to flow so as to make it comfortable for the patient. In the clinical trial using ALPE in patients suffering from COPD, 25 patients were included and all patients were able to complete the measurement procedure. During recording of data no complaints were received regarding claustrophobia or wishes to exit the procedure.

The duration of the maneuver may also be important in respect to patient comfort, with shorter periods of time at increased effort of breathing being beneficial. In paper 1 it was investigated how efficiently ALPE2 can select and administer appropriate levels of $\mathrm{FIO}_{2}$. A rule-based automatic algorithm selects levels of $\mathrm{FIO}_{2}$ and to evaluate the algorithm, 287 completed measurements of ALPE in 224 patients were investigated. The system selected and administered $\mathrm{FIO}_{2}$ levels automatically and this resulted in an average duration of $7.2+-2.4$ minutes. In these patients the algorithm used on average 3.9 levels of $\mathrm{FIO}_{2}$ to adequately describe the patient's pulmonary gas exchange. 


\subsubsection{Gas-mixing}

The changes in breathing patterns often associated with COPD could be a challenge for the gas-mixing system of ALPE2. It is important, that elevated or lowered inspired gas fractions are stable, so that a steady state can be reached at each level. This could prove difficult on variation of breathing pattern if the inspired fraction vary widely. The precision of the gas-mixing system in ALPE2 has been evaluated by investigating the standard deviation of 1332 delivered inspirations with an $\mathrm{FIO}_{2}$ above or below $21 \%$ in 20 patients from the clincial study. This analysis was limit to 20 out of the 25 patients, as the necessary $100 \mathrm{~Hz}$ sampled curvedata was unavailable in these patients. For each patient a number of $\mathrm{FIO}_{2}$ steps were delivered and for each a standard deviation was calculated. The mean of the standard deviation across all delivered inspirations in all patients was $0.3 \%$. Figure 8 illustrates an example of 5 different levels of $\mathrm{FIO}_{2}$ in a patient, where the inspiratory volume is plotted against the oxygen fraction measured at the mouth. Each line in the figure represents an inspiration. The middle line shows the inspirations at $21 \%$ oxygen, where no supplementary gasses are added. The line thus represents data with no error due to gas mixing. At the beginning of the $21 \%$ inspiration the oxygen fraction equals the end-tidal value of the former expiration. The first flat part represents rebreathing the dead-space in the airway adapter and the slow rise up till $21 \%$ mixing of dead-space and fresh air combined with the impulse response of the chemical oxygen sensor in the system. After reaching $21 \%$ the curve flattens out and at this point the standard deviation can be measured. Following the flat part of the inspirations sub- and superatmospheric, a small overshoot of the infused gas is seen. That is a negative dip when nitrogen is infused and a positive peak when oxygen is infused. 


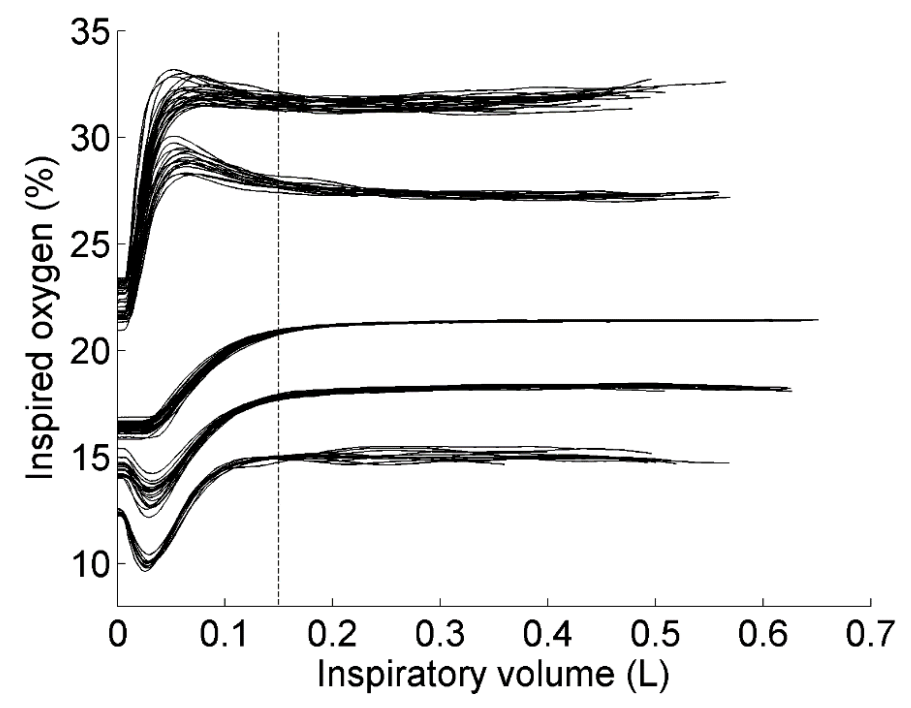

Figure 8: Inspired gas volume vs. inspired oxygen plot, showing all inspirations during a measurement using ALPE2 with 5 different FIO 2 levels, from [51] with permission. The vertical striped line indicates where the plateau is reached. Over shoot of supplementary gas by the gas mixing system in ALPE2 seen below volumes of $0.15 \mathrm{~L}$ is explained in details in the text.

\subsubsection{Summary}

This section has highlighted areas where introduction of ALPE in COPD could be challenging as seen from a technical perspective. A patient suffering from COPD may not tolerate a lengthy examination where their breathing is challenged by a restrictive mouthpiece. The low resistance airways adapter of ALPE2 and an examination period well under 10 minutes did not seem to challenge the 25 patients examined in our studies. Furthermore, the spontaneous variations in breathing patterns could be challenging when considering delivery of inspired gas fraction. If the inspired gas fraction is not stable it may be difficult to complete measurements at a steady state oxygen level. The gas mixing system of ALPE2 was shown to be able to deliver stable fractions in our study. 


\subsection{Is it possible to design a strategy for measurement and model fitting which does not require steady state conditions for oxygen?}

As shown previously, oxygen can take 10-15 minutes to reach steady state in patients with COPD [69]. For ALPE to be a useful clinical tool in these patient it is necessary then to relax the constraint of using oxygen steady state data in estimating pulmonary gas exchange. This section presents and evaluates a method for using breath by breath oxygen data as input to the ALPE model. This method and the results are presented in paper 2 and this section is a summary of that paper.

\subsubsection{Method for correction of breath by breath data to approximate ALPE data}

The method of using breath by breath data to estimate pulmonary gas exchange parameters is presented here using a patient example, illustrated in Figure 9. Figure 9A, presents the results of an ALPE experiment using steady state data. This was described earlier on page 22. Circles represent measurements at steady state and are numbered in the order in which the oxygen steps were taken, and the curve the resulting model fit. Figure 9B illustrates the breath by breath data (crosses) plotted along with the steady state data (circles) again numbered according to their respective steps. It can be seen in these data (crosses) that pulse oximetry $\mathrm{SpO}_{2}$ responds more slowly that end tidal $\mathrm{O}_{2}$ levels. This is best exemplified when stepping from $\mathrm{FIO}_{2}$ level 3 to 4 , i.e. from the lowest to the highest level. Initially, $\mathrm{FetO}_{2}$ increases with little change in $\mathrm{SpO}_{2}$ (arrow marked A). Subsequently $\mathrm{SpO}_{2}$ increases until at steady state point 4 is reached (arrow marked B). 

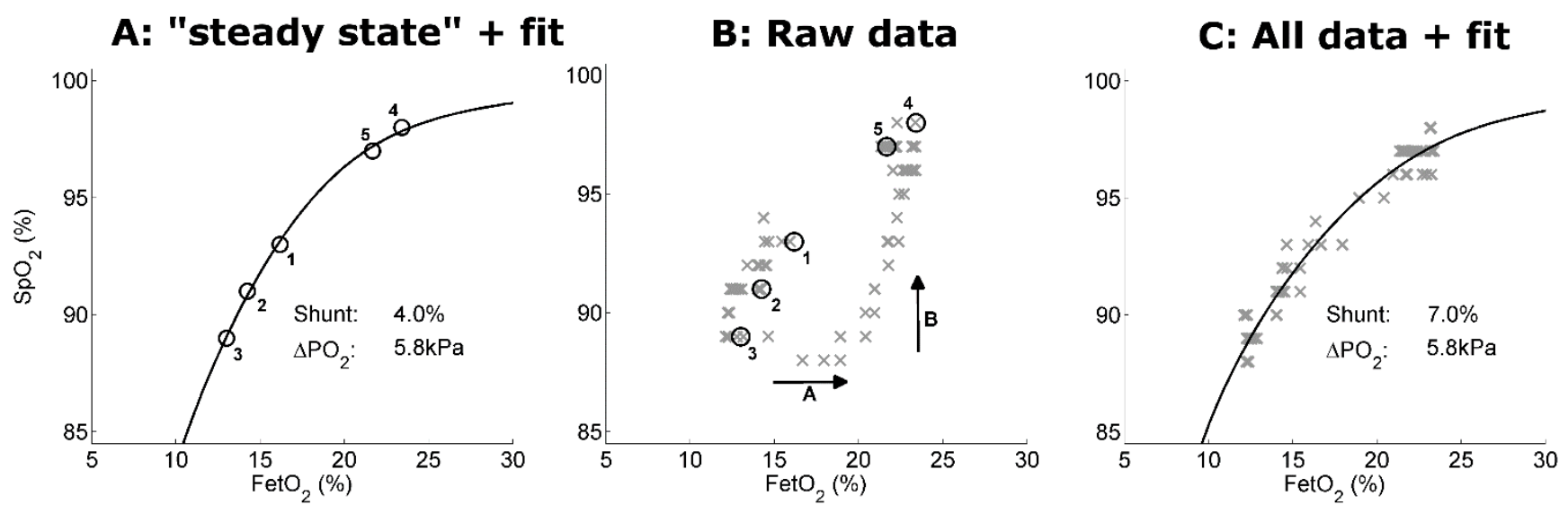

Figure 9: ALPE model fit and raw data. Part A shows the best model fit (curve) to data usually collected with ALPE (black circles). Part B shows the raw data (grey crosses) and points recorded by ALPE (black circles). Numbers indicate the order in which data were measured. Part C shows the best model fit (curve) for all breath by breath data points (grey crosses) corrected for delay in $\mathrm{SpO}_{2}$.

To correct for this effect, the delay in $\mathrm{SpO}_{2}$ can be estimated using a plot of $\mathrm{SpO}_{2}$ and $\mathrm{FIO}_{2}$ over time for the entirety of the experiment (Figure 10). Delay is estimated as the duration from the first change in $\mathrm{FlO}_{2}($ Figure 10, dashed vertical line labeled A) to the beginning of response of $\mathrm{SpO}_{2}$ (Figure 10, dashed vertical line labeled B). In the case of the patient illustrated in Figure $9 \mathrm{C}$ and Figure 10 this delay was 28 seconds. Correction is then performed by shifting all $\mathrm{SpO}_{2}$ values 28 seconds forward in time relative to $\mathrm{FetO}_{2}$ values. The resulting corrected breath by breath data is shown on Figure $9 \mathrm{C}$ (crosses). The corrected data can then be used to estimate pulmonary gas exchange parameters, with estimated parameter values and a model simulated curve given in Figure 9C. When the model is fitted to breath by breath data, each breath is treated as a steady state measurement. The estimation of model parameter values was described earlier on page 22 .

Strictly speaking it may not be correct to fit a steady state model to breath by breath data, although oxygen and carbon dioxide pressures are assumed to be in equilibrium end-tidal. However it is postulated here that, within experimental noise, calibrated breath by breath data follow the same curve as described by steady state measurements, and thus these can be assumed to be equivalent. 


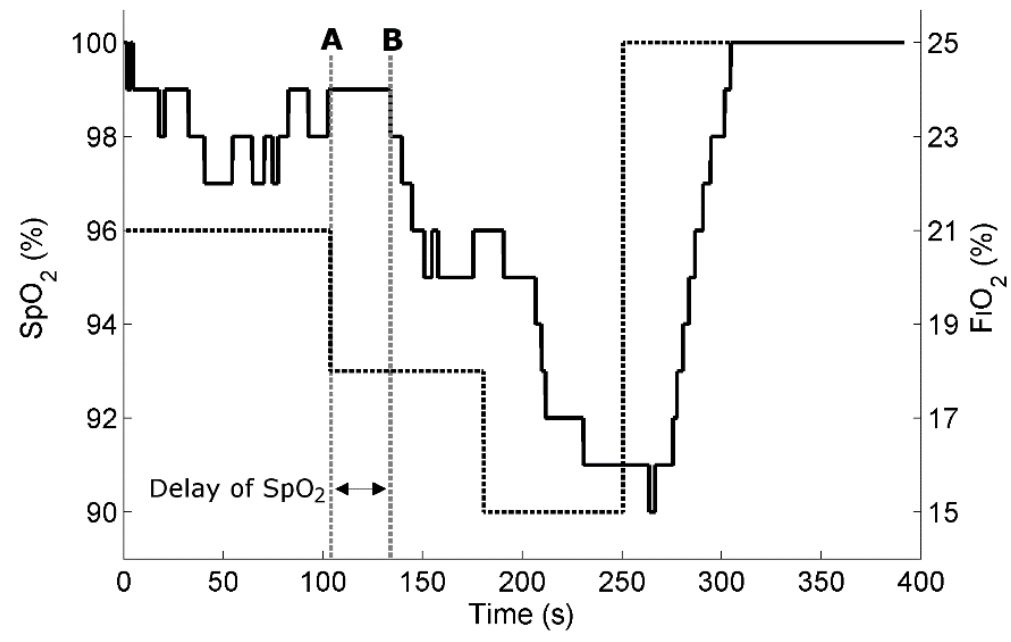

Figure 10: Pulse oximetry arterial oxygenation $\left(\mathrm{SpO}_{2}\right)$, solid line, left axis, and inspired oxygen fraction $\left(\mathrm{FlO}_{2}\right)$, dashed line, right axis, plotted against time for patient 1 . The grey vertical dashed line labeled A marks the first change in $\mathrm{FIO}_{2}$. The grey vertical dashed line marked $B$ shows the beginning of response of $\mathrm{SpO}_{2}$. Duration from $A$ to $B$ is the estimate of delay in $\mathrm{SpO}_{2}$, as indicated by the double arrow. The delay is estimated 28 seconds.

\subsubsection{Comparison of results from normal steady state and breath by breath data}

The method was evaluated in 14 patients suffering from COPD. This analysis was limit to 14 out of the 25 patients, due necessary data was unavailable in some patients. The correction for delay in $\mathrm{SpO}_{2}$ was performed for the 14 patients and the results are seen in table 2 . To enable correction, it was necessary that a sufficiently large signal was seen in $\mathrm{SpO}_{2}$ so as to determine the start of $\mathrm{SpO}_{2}$ change from noise. In 6 of the 14 patients this was not the case for the first step change in $\mathrm{FIO}_{2}$ and a subsequent step was therefore used. The average delay was 40.9 seconds, a value which is in accordance with the previously reported 30 seconds for finger probe pulse oximeters [76] where hyperthermia was absent.

Table 2: Estimated delay in pulse oximetry readings.

\begin{tabular}{|l|l|l|l|l|l|l|l|l|l|l|l|l|l|l|l|l|l|l|}
\hline Patient & 1 & 2 & 3 & 4 & 5 & 6 & 7 & 8 & 9 & 10 & 11 & 12 & 13 & 14 & avg & std & min & $\begin{array}{l}\text { Ma } \\
\mathrm{x}\end{array}$ \\
\hline Delay (s) & 28 & 23 & 38 & 38 & 41 & 42 & 29 & 47 & 45 & 40 & 37 & 40 & 55 & 70 & 40.9 & 11.6 & 23 & 70 \\
\hline
\end{tabular}


After delay of $\mathrm{SpO}_{2}$ was estimated and corrected, the same mathematical model was fitted to the two types of data, i.e. normal steady state measurements and breath by breath measurements corrected for delay in $\mathrm{SpO}_{2}$. Figure 11 Figure 11and Figure 12 shows model fit to all 14 patients. 

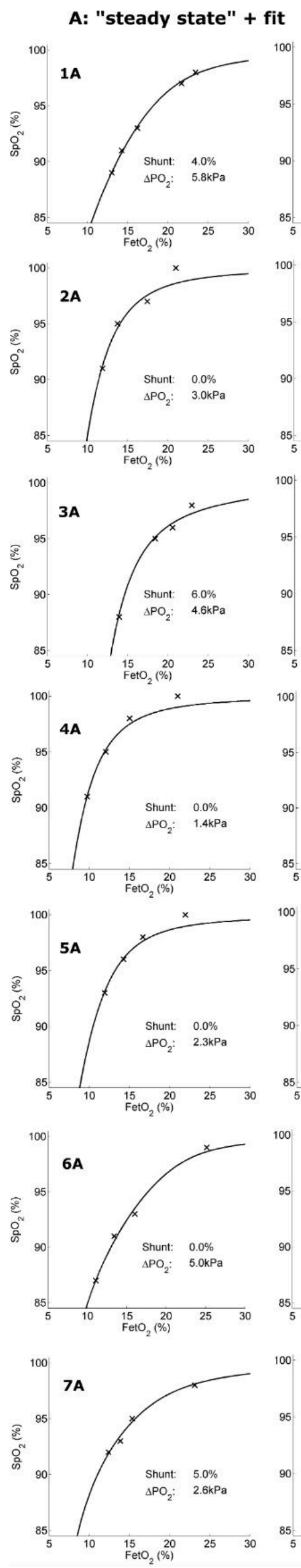

B: Raw data

C: All data + fit
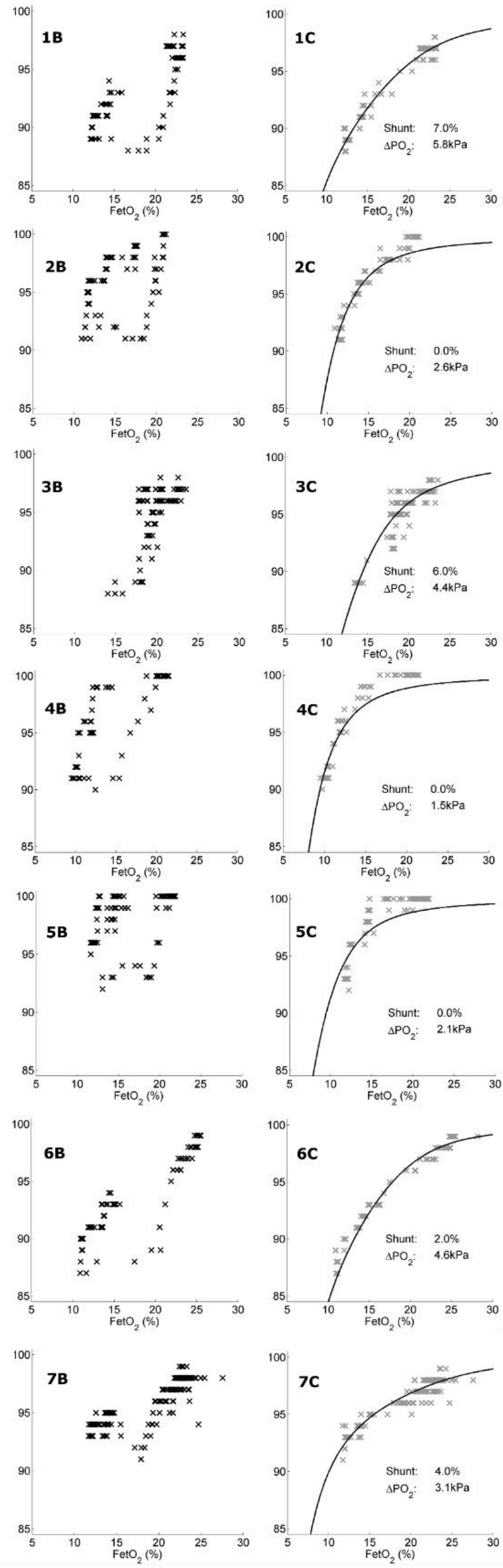

Figure 11: ALPE model fit and raw data in all patients. Part $A$ shows the best model fit (curve) to data usually collected with ALPE (crosses). Part B shows the raw data (grey crosses) and points recorded by ALPE (black circles). Part $C$ shows the best model fit (curve) for all breath by breath data points (grey crosses) corrected for delay in $\mathrm{SpO}_{2}$. 

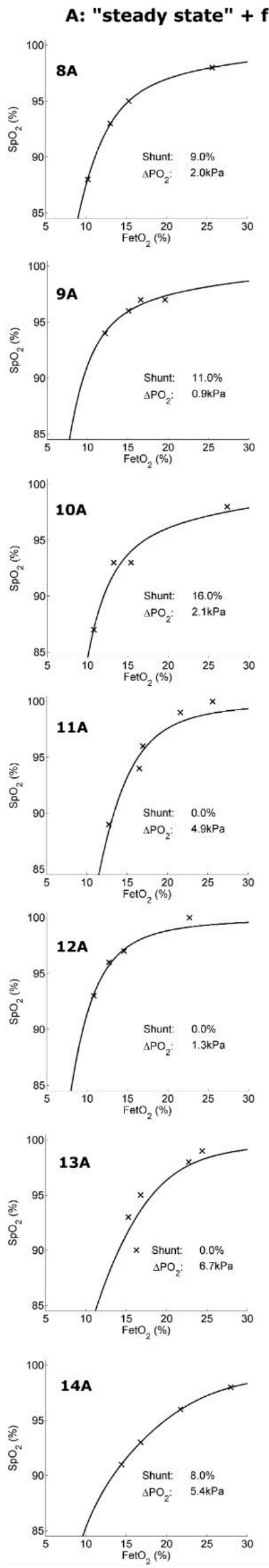

B: Raw data

100
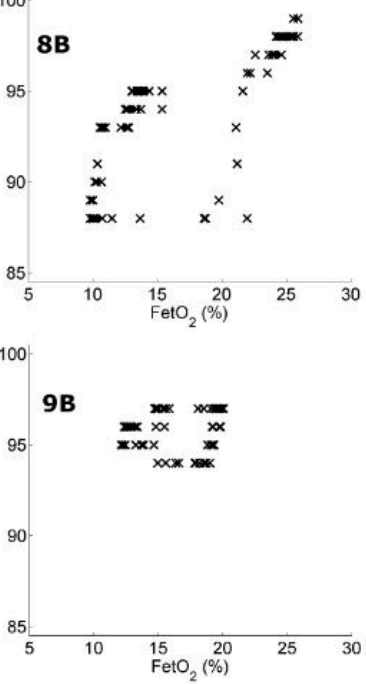

100
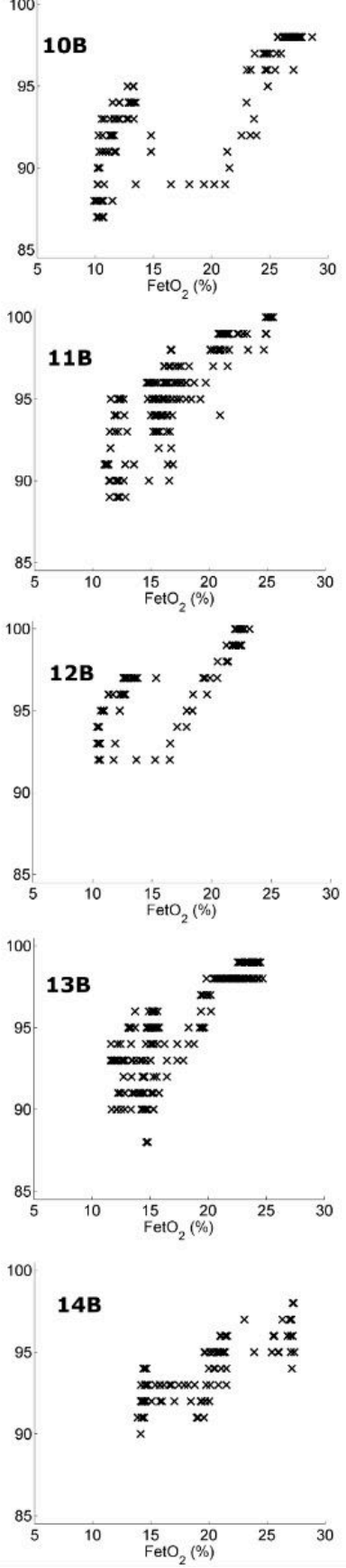

C: All data + fit
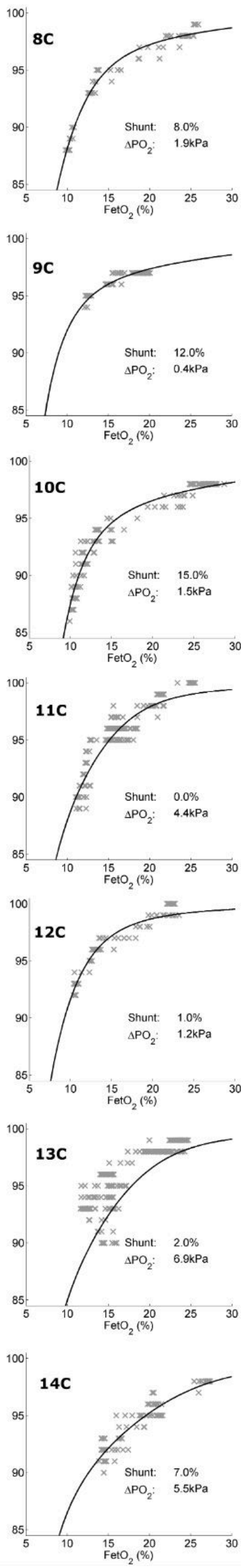

Figure 12: ALPE model fit and raw data in all patients. Part A shows the best model fit (curve) to data usually collected with ALPE (crosses). Part B shows the raw data (grey crosses) and points recorded by ALPE (black circles). Part $C$ shows the best model fit (curve) for all breath by breath data points (grey crosses) corrected for delay in $\mathrm{SpO}_{2}$

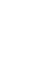


To investigate if the parameters shunt and $\Delta \mathrm{PO}_{2}$ calculated using the two methods where equal within acceptance of clinical measurements, two Bland-Altman plot were drawn, see Figure 13. The mean difference (bias) for shunt is $-0.4 \%$ with limits of agreement ranging from -3.0 to $2.2 \%$. For $\Delta \mathrm{PO}_{2}$, the mean bias is $0.17 \mathrm{kPa}$ with limits of agreement ranging from -0.47 to $0.81 \mathrm{kPa}$.
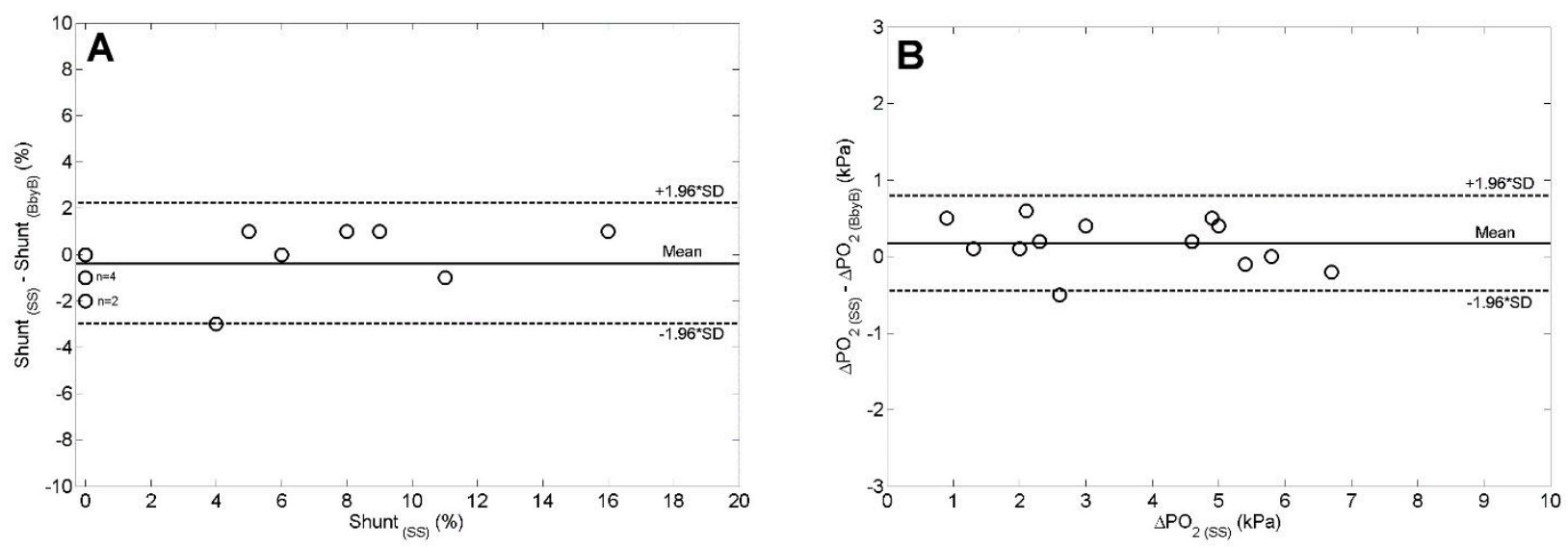

Figure 13: Bland-Altman plot comparing model parameter values calculated by fitting the mathematical model to data usually collected by ALPE and breath by breath data corrected for delay.

\subsubsection{Summary}

In summary, this section has presented a new and novel method that may allow oxygen to be used as a tracer in patients suffering from COPD, without the need for measurements at steady state. The principle of the method is to use breath by breath data, corrected for delay in $\mathrm{SpO}_{2}$, instead of measurements achieved at oxygenation steady state. In doing so it is assumed that model inputs vary little during the procedure, which will be investigated further in the next section.

It has been shown that the delay of $\mathrm{SpO}_{2}$ due to circulation time can be estimated from continuous $\mathrm{SpO}_{2}$ curves, and that the estimated values are in line with literature. The comparison of parameters from best model fits to steady state data and breath by breath data where delay in $\mathrm{SpO}_{2}$ was calibrated out, showed that the two method are, for practical purposes, equivalent. 


\subsection{Do the effects of hypoxic drive prevent the use of oxygen as a tracer in patients with COPD?}

An assumption for using the novel method where delay in $\mathrm{SpO}_{2}$ is corrected, is that the inputs of the model

$\left(\dot{\mathrm{VO}}_{2}, \dot{\mathrm{V}} \mathrm{CO}_{2} \dot{\mathrm{V}} \mathrm{min}, \dot{\mathrm{Q}}\right.$, and acid-base status) vary little during the procedure. With the existing steady state method, the input for the model will be a mean value of the measurements made at each step in $\mathrm{F}_{1} \mathrm{O}_{2}$, which for example could be the mean of four measurement of $\dot{\mathrm{V}} \mathrm{O}_{2}$. If small variations in $\dot{\mathrm{VO}}_{2}$ occurs during the procedure, these will be averaged out. On the contrary when breath by breath data is used, only the measurements at the initial $\mathrm{FIO}_{2}$ (atmospheric air) are used and thus variations in measurements during the procedure is not reflected in the input. The purpose of this section is to investigate whether the model input change during the measurement procedure and if these changes are significant for this application.

\subsubsection{Method for validation of model input variation}

As has been described earlier, an elevated hypoxic drive in patients suffering from COPD may mean that even minor changes in $\mathrm{FlO}_{2}$ change ventilation. To investigate this, two factors were examined: changes in $\dot{\mathrm{V}}$ min and FetCO $\mathrm{C}_{2}$ were explored on lowering $\mathrm{FIO}_{2}$ to evaluate the possibility of increase respiratory drive on lowering $\mathrm{FIO}_{2}$ and to assess whether acid-base status was changed. Another mechanism that could be responsible for changes in respiration is stress of the procedure and this could cause changes in patients' metabolism. Therefore changes in $\mathrm{VO}_{2}$ were also explored on lowering $\mathrm{FIO}_{2}$ to assess possibility of stress-related changes in metabolism, or other factors.

To assess a possible change in the three parameters as a result of changes in $\mathrm{FIO}_{2}$, the difference between the steady state measurements at the initial $21 \%$ level and at the lowest $15 \%$ level ( $16 \%$ for one patient) was compared. This comparison is summarized in Figure 14. 


\subsubsection{Evaluation of changes in model inputs}

Figure 14 illustrates changes in $\dot{\mathrm{V}} \mathrm{min}(\Delta \dot{\mathrm{V}} \mathrm{min})$, end tidal $\mathrm{CO}_{2}(\Delta \mathrm{etCO})$ and $\dot{\mathrm{VO}}_{2}\left(\Delta \dot{\mathrm{VO}}_{2}\right)$ on lowering $\mathrm{FIO}_{2}$ during the procedure. The difference is calculated as the initial value (21\%) minus the lowest value (15\%). The average values, marked as vertical lines on Figure 14 , were $\Delta \dot{\mathrm{V}} \min 0.78 \mathrm{~L} / \mathrm{min}, \Delta \mathrm{etCO}{ }_{2} 0.09 \mathrm{kPa}$ and $\Delta \dot{\mathrm{VO}}_{2}-0.03 \mathrm{~L} / \mathrm{min}$.

A

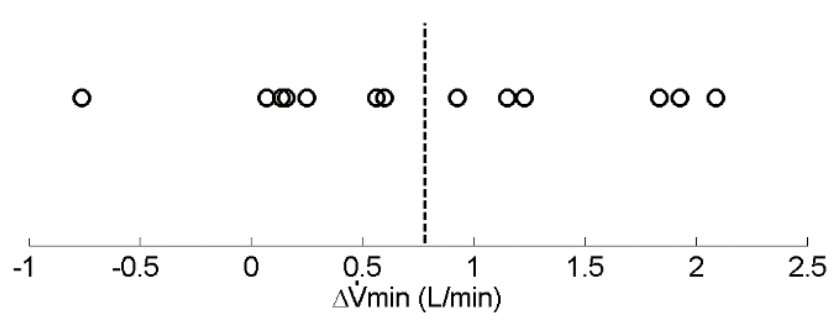

B

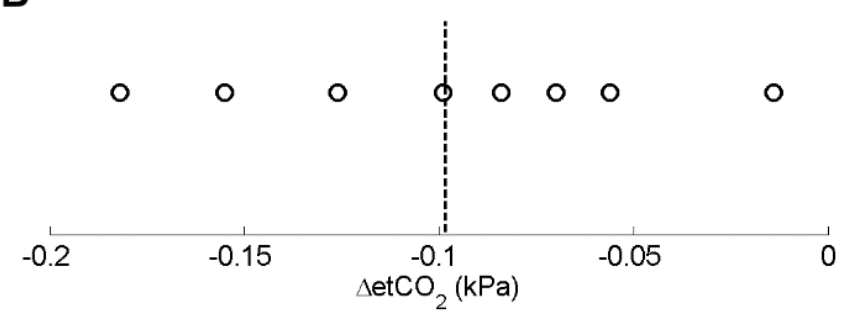

C

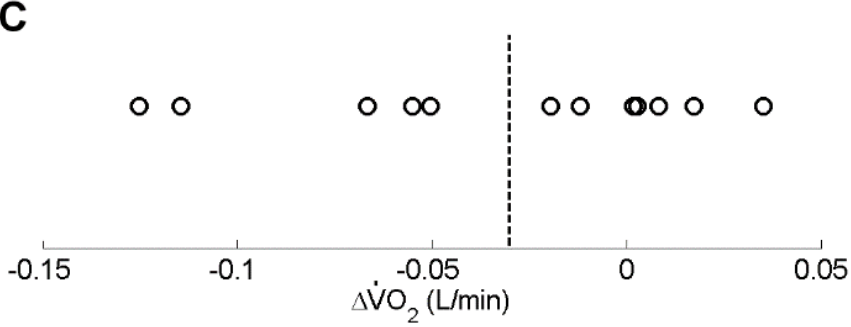

Figure 14: Change in steady state measurements of $\dot{V}$ min (Part A), $\mathrm{FetCO}_{2}$ (Part B) and $\dot{\mathrm{VO}}_{2}$ (PartC) on lowering $\mathrm{FIO}_{2}$. Measured as difference from initial steady state at $21 \%$ inspired oxygen to steady state at $18 \%$ and $15 \%$ (16\% for one patient). Average difference is shown with a vertical stripped line, and where: $\Delta \dot{V} \min 0.78 \mathrm{~L} / \mathrm{min}, \Delta e t \mathrm{CO}_{2} 0.098 \mathrm{kPa}$ and $\Delta \dot{\mathrm{V}} \mathrm{O}_{2}-0.03 \mathrm{~L} / \mathrm{min}$. 


\subsubsection{Summary}

To investigate if the assumption that inputs for the model are constant during the ALPE procedure, changes in $\dot{\mathrm{V}} \min$ and $\mathrm{FetCO}_{2}$ and $\dot{\mathrm{VO}}_{2}$ were evaluated. It was seen for all, that the input variables changes during the procedure, and this will be discussed in the context of appropriate usage of oxygen as a tracer in the discussion (Section 3.3). Also in that section, possible causes for changes in the remaining model inputs will be discussed. 


\subsection{How can ALPE measurements be integrated with other measurements to provide an integrated clinical picture of the lungs, and if so can such a description provide similar classifications as radiologic descriptions of the lungs?}

ALPE may provide a functional description of the lung in patients suffering from COPD as seen in figure 7 section 2.1. For this to be useful in clinical practice it should be investigated if combining the ALPE description of pulmonary gas exchange with other readily available measurements could result in an improved description of disease. Therefore, a combined description of the lung, integrating ALPE with clinically readily available data, will be presented in this section. The methods and results from paper 3 are presented here.

Several causal mechanisms can be postulated which link radiological, physiologic and clinical data. For instance, airway disease presenting on computed tomography (CT) as airway remodeling and bronchial wall thickening is more likely to cause sputum production than emphysema [77]. Similarly, using data from CT, emphysema can be described by grade, location and size of bullae, with each of these classifications perhaps related causally to profiles of pulmonary gas exchange, lung mechanics or clinical parameters. Causal Probabilistic Networks (CPN) allows causal reasoning to be integrated with measurements in a model [78] and has been shown applicable in other fields $[79,80]$. In this section, a CPN model is formulated from causal relations and as a proof of concept, the model is used to categorize patient cases in four well defined situations: Small airway disease; emphysema with diffuse central bullae; emphysema with concentrated central bullae; and emphysema with diffuse peripheral bullae.

\subsubsection{Causal probabilistic network for classification of COPD}

The constructed causal probabilistic network is seen in Figure 16. In constructing the network a number of assumptions regarding causal relations between disease patterns, physiological concepts and clinical measurements were made. The most important of these will be mentioned, following an overall description of 
the network. However, firstly, a short introduction to the basics and construction of causal probabilistic networks is provided.

\subsubsection{Causal probabilistic networks}

A causal probabilistic network is designed and constructed from nodes and links. The nodes represent explanations/hypothesis or probable causes, and they describe two or more states. For instance, presence of airway disease in a patient can be represented with the states yes or no. The link between nodes is defined by conditional probabilities. In the example of airway disease presence in a patient, a link could exist to a node describing patients' sputum production i.e. productive cough binary in two stages, yes or no. Here, the link will be a table of conditional probabilities, where presence of productive cough will have a higher conditional probability of airway disease being the cause than no productive cough. In a simple network, a third node could represent emphysema with two stages, yes or no. In the link from emphysema to productive cough the conditional probabilities would be so that, presence of productive cough has a much lower likelihood of being causing by emphysema than by airway disease. To illustrate this is example, the described network is seen in figure 15. Here, the three nodes along with their states are seen, and their causal relations. In this example, both airways disease and emphysema can be the cause of productive cough, but as was will be explained in details shortly, the differences in conditional probabilities favors airway disease as the cause. As a general rule for this type of network in a clinical domain, going from the bottom and up is towards diagnosis, i.e. the cause of the disease. Going from the top and down, is moving towards the symptoms caused by the disease, measurable by for instance productive cough. 


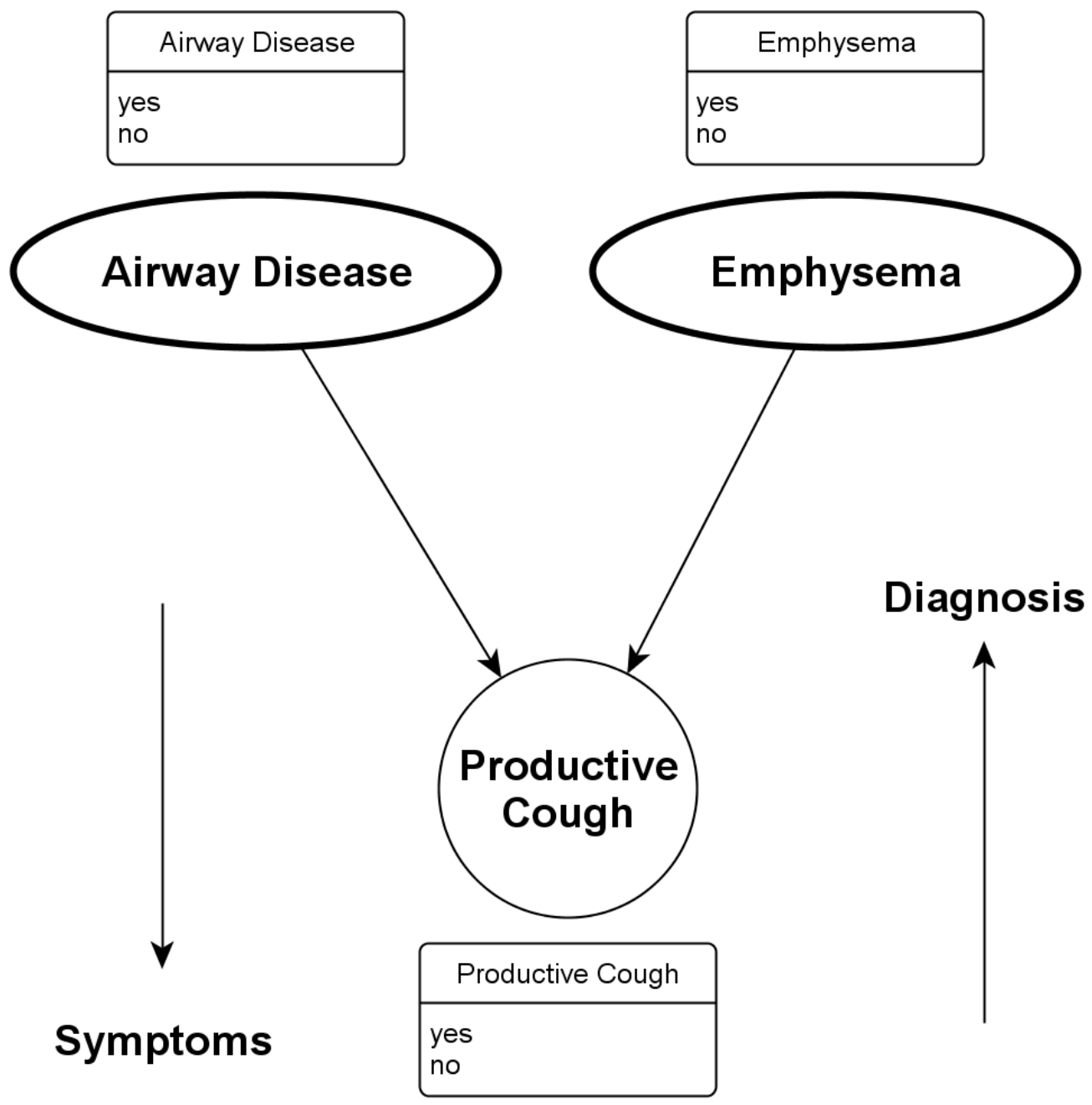

Figure 15: Causal probabilistic network modelling airway disease, emphysema, and productive cough

Behind the graphical model in figure 15 showing the causal relations and states, are the conditional probability tables, where the actual knowledge about the domain is entered. For the above described case, table 3 shows the conditional probabilities for the node Productive Cough. 
Table 3: Conditional probability table

\begin{tabular}{|l|l|l|l|l|l|}
\hline Airway disease & \multicolumn{2}{|c|}{ Yes } & \multicolumn{2}{c|}{ No } \\
\hline Emphysema & \multicolumn{2}{|c|}{ Yes } & \multicolumn{2}{c|}{ No } & \multicolumn{2}{c|}{ No } \\
\hline Yes & 1 & 0.95 & 0.05 & 0 \\
\hline No & 0 & 0.5 & 0.95 & 1 \\
\hline
\end{tabular}

To illustrate the usage of the table, we can look at the situation where productive cough is present. This is marked by 'Yes' in the first column and thus the third row shows the probabilities for the four different combinations of presence/no presence of emphysema and airway disease. In this example here, presence of both emphysema and airway disease has a probability of 1 that productive cough is present. Airway disease alone is believed to cause productive cough in $95 \%$ of cases and emphysema alone only in $5 \%$ of cases. None of the diseases present causes no productive cough.

Dependent on which information/evidence is available, the network can be updated either in the direction of diagnosis or symptoms. If for instance, a patient has productive cough, and this is entered in the network, then the probability of airway disease being the cause will increase to $98 \%$ (in the case of this network). But information can also propagate the other direction. If it is known, that a certain patient has airway disease, then the probability that the patient also has productive cough will increase and from this, the probability of presence of emphysema decrease (as we are quiet certain productive cough is presence and this not often caused by emphysema). In this way, evidence is said to propagate through the network and this is the fundamental method of the causal network. 


\subsubsection{Constructed causal network}

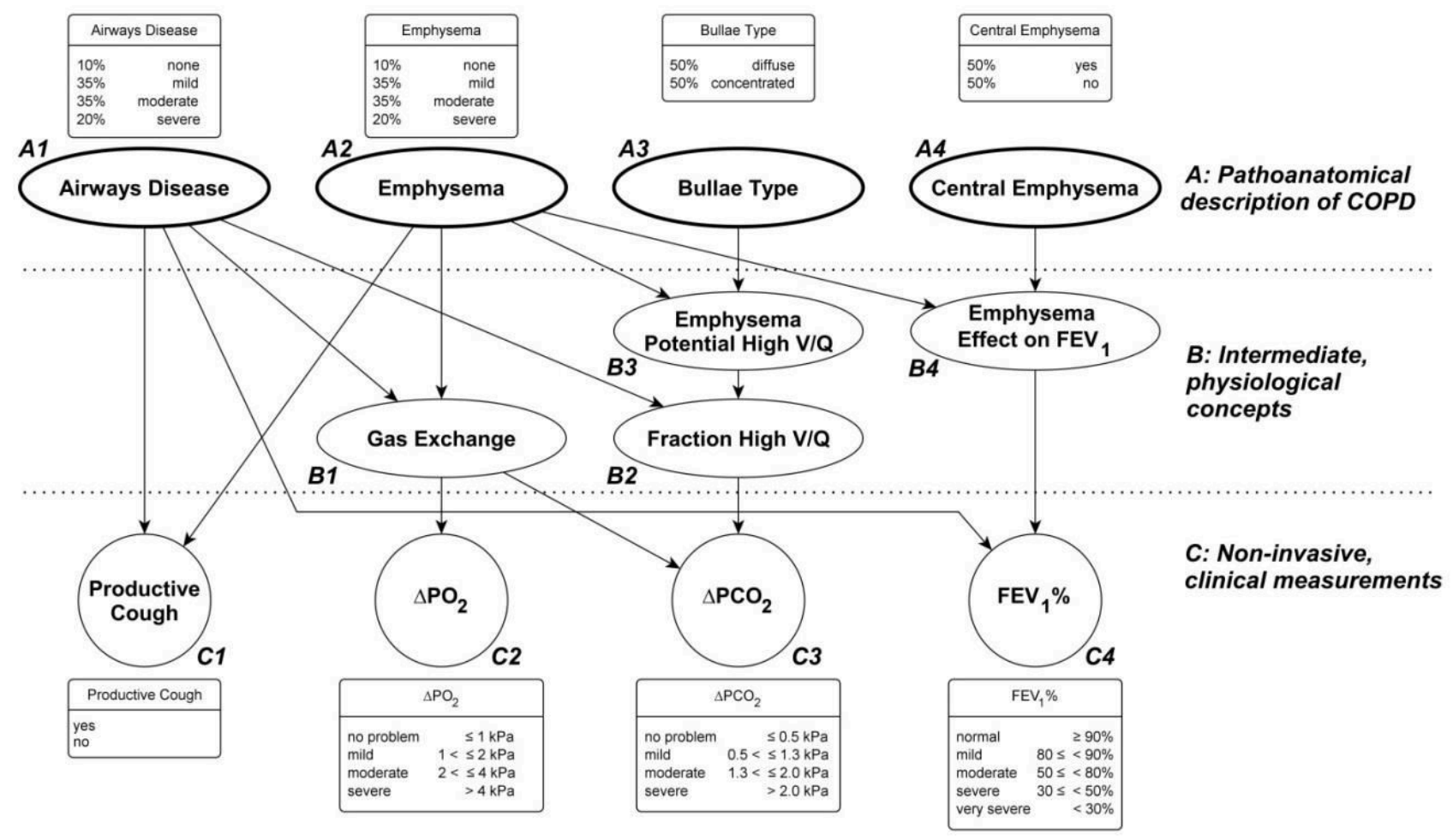

Figure 16: The causal probabilistic network, from [81] with permission. The network is divided into three horizontal layers, A, B, and C, with directed arrows showing causal relation explained further in the text. The network includes three layers describing the pathoanatomy of COPD based on CT/HRCT (A), intermediate physiological concepts (B) and non-invasive clinical measurements (C), with details of the individual variables given in the text.

In the top layer of the network $(A)$ the four nodes describe the pathoanatomy of a patient suffering from COPD. The two nodes Airway Disease (A1) and Emphysema (A2) describe the main disease categories of COPD and these are staged in four severities; none, mild, moderate, and severe. The nodes Bullae Type (A3) and Central Emphysema (A4) are only considered when emphysema is the main cause of disease, i.e. when the most possible cause of disease is emphysema. Bullae Type (A3) describes the distribution of parenchymal destruction in the lungs, being either diffusely spread or concentrated in regions. Central Emphysema (A4) described the presence of emphysema in the central regions of the lungs.

The two main categories emphysema and airway disease were chosen, as studies have shown that present and extend of both airway disease and emphysema can be found reliably from CT scans [82, 83]. It is also well 
known that both disease patterns contribute independently to airflow obstruction in COPD [84]. The pattern emphysema distribution, i.e. Bullae Type, is assumed to affect $\dot{V} A / Q$ distributions in the lung differently. If emphysema is diffusely spread across the lungs with small bullae, then these areas will typically be cyclically ventilated during breathing with ventilation typically exceeding perfusion resulting in high $\dot{V} A / \dot{Q}$. In contrast, if emphysema is concentrated in regions of the lung, either as large bullae or dense areas of small bullae, cyclic ventilation will not be sufficient to replenish these relatively large areas of gas with fresh air and they will present either as regions of the lung with neither ventilation nor perfusion, or if perfused, as regions with low $\dot{V} \mathrm{~A} / \mathrm{Q}$. Centrally located emphysema has been shown to cause major changes in FEV1\% reductions [85]. This is in contrast to peripheral emphysema which is usually assumed [86] to cause only minor reduction in FEV1\%. In this situation the site of parenchymal destruction is at the most distal parts of the bronchial tree which are not usually assumed to empty during the first second of forced expiration, even in health [13].

In the middle layer (B) variables describe intermediate physiological concepts of the network. The node Gas Exchange (B1) describes the causal effects of Airway Disease (A1) and Emphysema (A2) on the patient's pulmonary gas exchange. The node Emphysema Potential High $\dot{V}_{A} / \dot{Q}$ (B3) describes whether emphysema, on the basis of the previously discussed distribution of parenchymal destruction (A3), introduces areas of high $\dot{V} A / \dot{Q}$ in the lung. The combination of high $\dot{V} A / Q$ caused by Airway Disease (A1) and potentially from Emphysema (B3) is described by node B2. The node Emphysema Effect on FEV1 (B4) describes, by using the previously discussed Central Emphysema (A4), whether emphysema contributes to airway obstruction.

In the bottom layer $(C)$ the variables describe non-invasive clinical measurements used to instantiate the network. The causal nature of the network dictates that the top row contains the causes and the bottom row the effects, i.e. the measured clinical variables. The variables are Productive Cough (C1), $\triangle \mathrm{PO}_{2}(\mathrm{C} 2), \triangle \mathrm{PCO} \mathrm{C}_{2}(\mathrm{C} 3)$, 
and FEV1\%(C4). Assessment of cough and measurement of FEV1\% are standard clinical measurements in diagnosing COPD and $\triangle \mathrm{PO}_{2} / \triangle \mathrm{PCO} \mathrm{O}_{2}$ are measured with ALPE.

\subsubsection{Clinical data for the network and assessment of HRCT}

This section describes the clinical measurements used as input for the network and the High Resolution Computed Tomography (HRCT) datasets used for comparison in four patients with different radiologic representations of COPD. The four patients represents the four patients also shown in Figure 7.

The inputs for the network are summarized in Table 4. Information regarding productive cough was available from the standard COPD-anamnesis. FEV1\% was measured as previously described, $\triangle \mathrm{PO}_{2}$ and $\triangle \mathrm{PCO} \mathrm{C}_{2}$ was measured using ALPE. The best fit of the mathematical model of ALPE for the four patients are seen in Figure 7.

Table 4: Clinical measurements used in the network in the four patient cases

\begin{tabular}{|l|l|l|l|l|}
\hline Case \# & $\begin{array}{l}\text { Cough } \\
\text { (yes/no) }\end{array}$ & $\begin{array}{l}\Delta \mathrm{PO}_{2} \\
(\mathrm{kPa})\end{array}$ & $\begin{array}{l}\Delta \mathrm{PCO}_{2} \\
(\mathrm{kPa})\end{array}$ & $\begin{array}{l}\mathrm{FEV} 1 \% \\
(\%)\end{array}$ \\
\hline 1 & No & 1.7 & 1.0 & 46 \\
\hline 2 & No & 6.9 & 0.4 & 67 \\
\hline 3 & No & 4.1 & 0.6 & 93 \\
\hline 4 & Yes & 1.9 & 1.0 & 20 \\
\hline
\end{tabular}

As part of the comparison, patients underwent a HRCT scan within 48 hours of all other measurements. Each scan was assessed independently by three experienced physicians, two radiologists and a pulmonologist. The physicians where blinded to any details about the patients. The assessment was inspired Aziz et al. [85] , where evaluation of texture, core/rind distribution, grade and type was performed. Before the assessment the methods were presented to physicians, including visual reference material adapted from the COPDGene group [83]. Emphysema was graded for the entire lung and for the three regions (above carina, between carina and inferior pulmonary vein, and below inferior pulmonary vein), with the primary site of parenchymal destruction 
being either central or peripheral. Presence of airway disease was evaluated as bronchial wall thickening, as changes in bronchioles and bronchi are a representative measure of airway disease from CT [83].

\subsubsection{Classification of patients}

The four patient cases, with their clinical data shown Table 4, are presented here as they were described in paper 3. The cases are: emphysema with central diffuse bullae, emphysema with central concentrated bullae, emphysema with peripheral diffuse bullae, and airway disease.

\subsubsection{Case one - emphysema with central diffuse bullae}

This patient was a 75 year old female and former smoker with 50 pack years (a pack-year is an average of 1 pack of cigarette smoked per day for a year). The lung function test showed FEV1\% of 46 and FEV1/FVC $<0.7$, severe COPD according to GOLD diagnostic classification [87]. Body Mass Index (BMI) was $21 \mathrm{~kg} / \mathrm{m}^{2}$ and there were no known co-morbidities. The patient's main complaint was dyspnea and MRC-score was 4 . The patient had an arterial oxygen saturation $\left(\mathrm{SaO}_{2}\right)$ of $96 \%$ at rest, and the distance of 6 minute walk test (6MWT) was 180 meters.

\section{Network description}

The clinical measurements are instantiated into the network (Figure 17, Case 1 ) as no productive cough, mild $\triangle P O_{2}$, mild $\triangle P C O_{2}$, and severe $F E V 1 \%$. These propagate through the network and describe the patient in the following way: suffering from emphysema with moderate to severe grade. The bullae type is diffuse and central emphysema is present.

\section{Radiologic description}

An illustrative example from the CT data set for this patient is seen in Figure 17, Case 1. The radiologists described the primary presentation of the disease as severe emphysema with bullae diffusely spread in lungs, including the central regions. 


\subsubsection{Case two - Emphysema with central concentrated bullae}

This patient was a 70 year old male and former smoker with 100 pack years. The lung function test showed FEV1\% of 67 and FEV1/FVC $<0.7$, moderate COPD according to GOLD classification. BMI was $30 \mathrm{~kg} / \mathrm{m}^{2}$ and there were no known co-morbidities. The patient's main complaint was dyspnea and MRC-score was 3 . The patient had an $\mathrm{SaO}_{2}$ of $93 \%$ at rest, and the $6 \mathrm{MWT}$ distance was 490 meters.

\section{Network description}

The clinical measurements are instantiated into the network (Figure 17, Case 2) as severe $\triangle P O_{2}$, no $\triangle P C O_{2}$ problem, and moderate FEV1\%. Productive cough was not instantiated in this case. These propagate through the network and describe the patient in the following way: suffering from emphysema with a moderate grade. The bullae type is concentrated and central emphysema is present. Productive cough is predicted present.

\section{Radiologic description}

An illustrative example from the CT data set is seen in Figure 17, Case 2. The radiologists described the primary presentation of the disease as moderate emphysema with primarily concentrated bullae in the central regions of the lungs. 


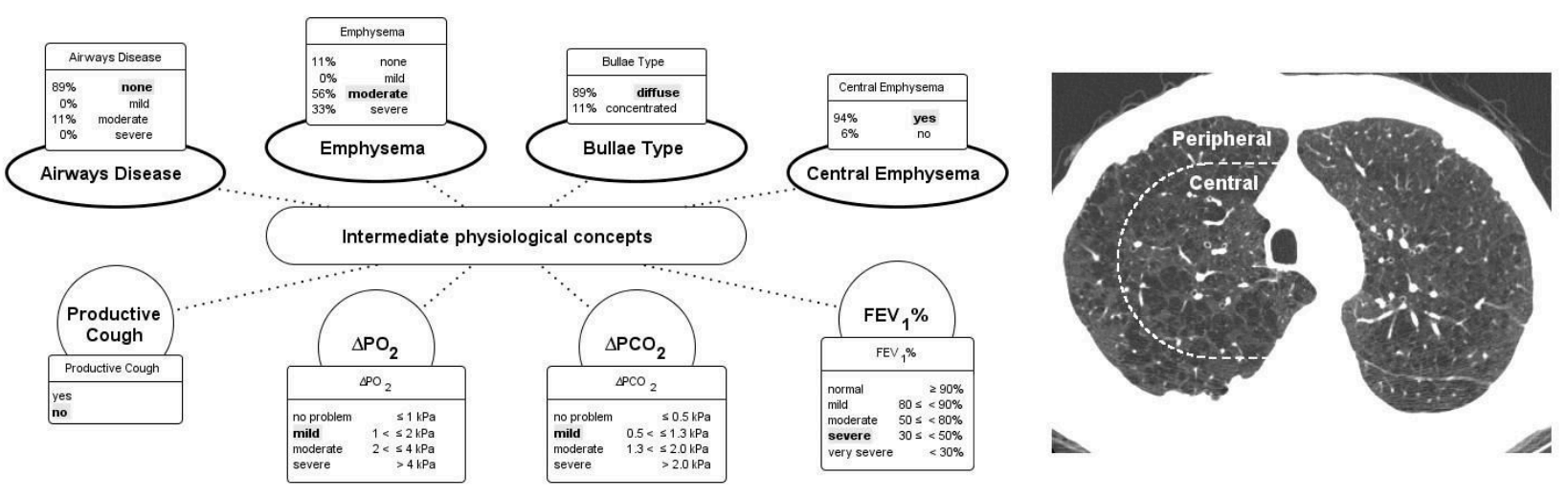

Case 2: Emphysema with central concentrated bullae

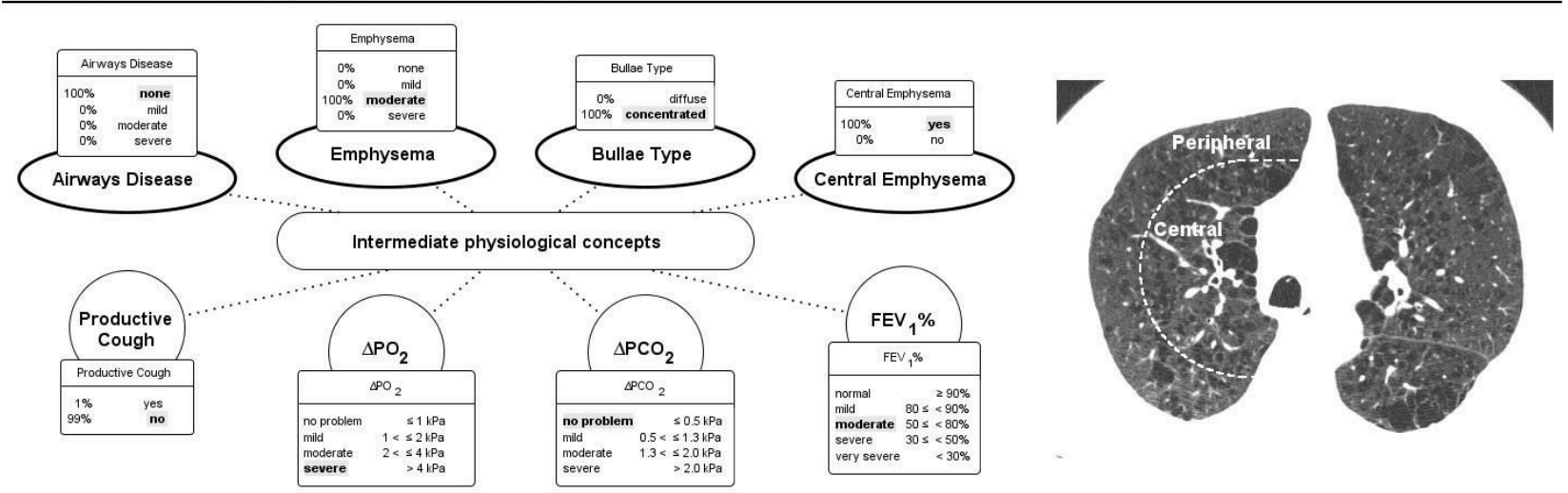

Figure 17: Patient cases 1 and 2 with network description (left) and CT scan (right), from [81] with permission. In the network, the input from clinical data is marked in the bottom row with bold text and gray color. In the top row the outcome with the highest probability from the network is marked with bold text and gray color. In the CT scan, a dotted line is used to divide the left lung into a central and a peripheral part. This line is according to Aziz et al. [85], i.e. placed at 0.7 times radius of the lung, resulting in equal areas on each side of the line. CT scans are presented with window width $800 \mathrm{HU}$ and level $-800 \mathrm{HU}$.

\subsubsection{Case three - Emphysema with peripheral diffuse bullae}

This patient was a 52 year old female and current smoker with 35 pack years. The lung function test showed FEV1\% of 93 and FEV1/FVC $=0.7$, not categorized as suffering from COPD according to GOLD classification (FEV1\% should be below $80 \%$ and FEV1/FVC below 0.7 ). BMI was $20 \mathrm{~kg} / \mathrm{m}^{2}$ and there were no known comorbidities. The patient's main complaint was dyspnea and MRC-score was 2. The patient had an $\mathrm{SaO}_{2}$ of $94 \%$ at rest, and the 6MWT distance was 400 meters. 


\section{Network description}

The clinical measurements are instantiated into the network (Figure 18, Case 3 ) as no productive cough, severe $\triangle P O_{2}$, mild $\triangle P C O_{2}$, and normal $F E V 1 \%$. These propagate through the network and describe the patient in the following way: suffering from emphysema with moderate to severe grade. The bullae type is diffuse and emphysema is absent in the central regions of the lungs.

\section{Radiologic description}

An illustrative example from the CT data set is seen in Figure 18, Case 3. The radiologists described the primary presentation of the disease as moderate emphysema, diffusely spread mainly in the peripheral regions of the lungs.

\subsubsection{Case four - Airway disease}

This patient was a 53 year old male and former smoker with 30 pack years. The lung function test showed FEV1\% of 20 and FEV1/FVC < 0.7, very severe COPD according to GOLD classification. BMI was $27 \mathrm{~kg} / \mathrm{m}^{2}$ and there were no known co-morbidities. The patient's main complaint was dyspnea and MRC-score was 5 . The patient had an $\mathrm{SaO}_{2}$ of $93 \%$ at rest, and the $6 \mathrm{MWT}$ distance was 300 meters.

\section{Network description}

The clinical measurements are instantiated in the network (Figure 18, Case 4) as productive cough, mild $\triangle P \mathrm{O}_{2}$, mild $\triangle P C O_{2}$ and very severe $F E V 1 \%$. These propagate through the network and describe the patient as suffering from severe airway disease.

\section{Radiologic description}

An illustrative example from the CT data set is seen in Figure 18, Case 4. The radiologists describe the patient as suffering from severe airway disease. 


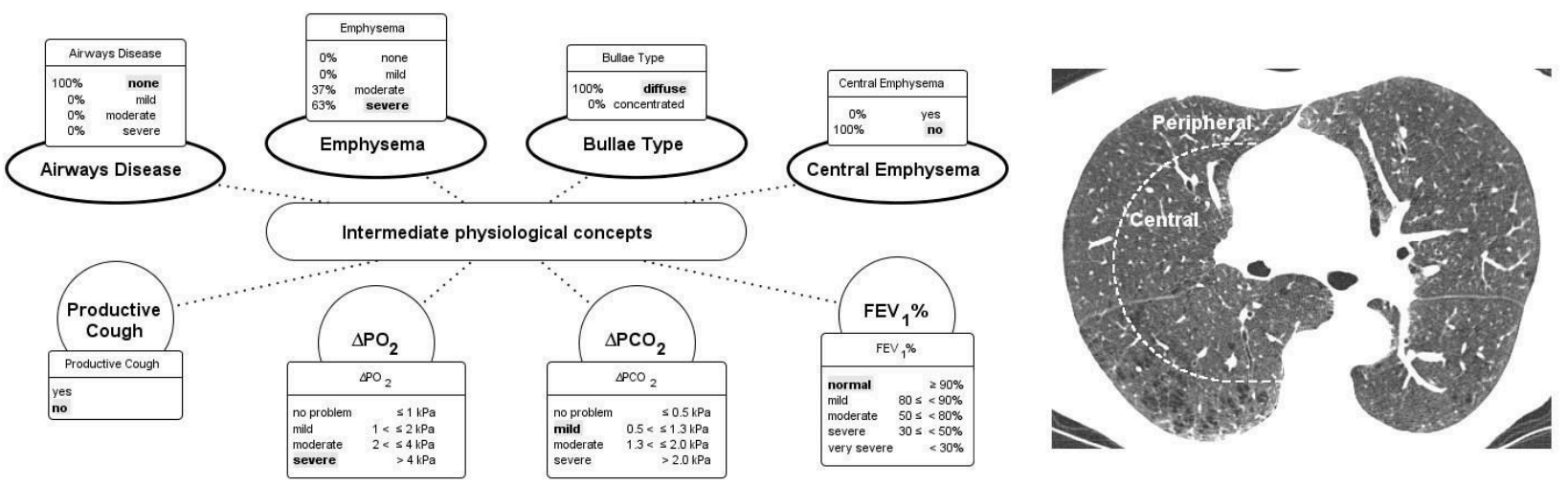

Case 4: Airways disease

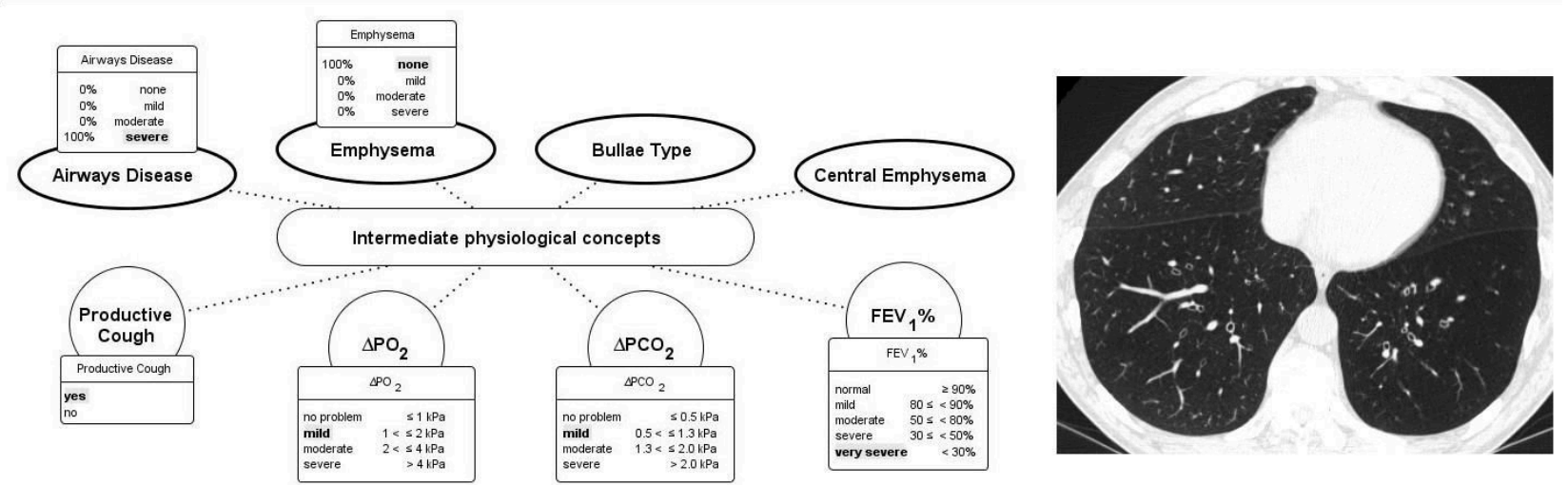

Figure 18: Patient cases 3 and 4 with network description (left) and CT scan (right), from [81] with permission. In the network, the input from clinical data is marked in the bottom row with bold text and gray color. In the top row the outcome with the highest probability from the network is marked with bold text and gray color. In the CT scan for patient 3, a dotted line is used to divide the left lung into a central and a peripheral part. This line is according to Aziz et al. [85], i.e. placed at 0.7 times radius of the lung, resulting in equal areas on each side of the line. For patient 3 the CT scan is presented with a window width $800 \mathrm{HU}$ and level $-800 \mathrm{HU}$. In patient 4 the CT scan is presented with a window width 1200 and level -500, as necessary for description of airway disease according to Collins et al. [88].

\subsubsection{Summary}

The functional lung description by ALPE has been integrated into a causal probabilistic network together with measurement of FEV1\% and information of productive cough. The constructed network uses causal assumption to relate airway disease and emphysema with the clinical measures. The main assumptions are: grading severity of disease is a combination of mechanical obstruction (FEV1\%) and oxygenation problems $\left(\triangle \mathrm{PO}_{2}\right)$; airway disease and emphysema given diffuse bullae introduce high $\dot{V}_{A} / \dot{Q}$ in the patients. Emphysema mainly affects FEV1\% when it is present centrally. With four descriptive patient cases, the network was shown to classify patients according to their radiologic assessment. 


\section{Discussion}

The diagnosis and classification of COPD can be seen as the difficult task of describing a heterogeneous disease affecting a complex organ, using relatively simple measurements. Combining these measurements and thus describing the impact of disease on the lung and its functional capacity can provide additional information enabling the clinician to succeed in this task. In this context, this thesis has investigated the clinical description of pulmonary gas exchange abnormalities, the current standard (DLCO), the reference experimental technique (MIGET), and a new alternative (ALPE). It has been described how DLCO simplifies the well-known intrapulmonary causes of hypoxaemia (V்/Q mismatch, shunt, $\mathrm{O} 2$ diffusion) into only one parameter and how in contrast MIGET has shown that $\dot{V} A / Q$ mismatch is the major contributor to hypoxaemia in COPD and furthermore that different patterns of $\dot{V} \mathrm{~A} / \dot{Q}$ mismatch exist in different patients. Unfortunately MIGET is not applicable in daily clinical practice. A contribution of this thesis is thus, highlighting the need for a more comprehensive and physiological sound description of pulmonary gas exchange in daily clinical practice. In the light of this, ALPE may offer "the happy medium" as the method is clinical applicable and can describe VA/Q mismatch (and shunt) [89].

The ALPE system was originally published in 2002 and has been used in clinical studies to describe patients with ALI/ARDS and in pre- and post-operative environments. ALPE has been implemented in a version for spontaneously breathing patients (ALPE2), which is approved for clinical use, but has never been applied in COPD. Another contribution of this thesis has been the description of the currently available versions of ALPE and the included mathematical models, and from this identifying challenges in relation to applying ALPE in COPD. In short, these challenges are: Description of high $\dot{V}_{A} / \dot{Q}$, measurement of reliable data in unstable breathing, relaxing the constraint of measurement at steady state, and use of oxygen as a tracer in patients with hypoxic drive. 
To investigate the possibility of integrating ALPE into the daily diagnostic process of managing COPD, the quantification of $\dot{V} A / Q$ mismatch measured by ALPE has been integrated with other clinical data in a causal network. In doing so, it is hoped to target classification of sub-disease available primarily from CT, but using simpler measurements.

In the following section the findings from the three papers presented in the thesis will be discussed in turn. The findings are related to the questions listed in the aims of the thesis and the following sections are organized to address these questions as follow: "What complexity is necessary to describe pulmonary gas exchange in COPD?", "Can measurement at steady state be relaxed?", "Can oxygen be used as a tracer in COPD?", and "Can radiologic profiles be classified using both ALPE and other routine measurements in a causal network".

\subsection{What complexity is necessary to describe pulmonary gas exchange in COPD?}

DLCO is the clinical standard for measuring pulmonary gas exchange abnormalities in COPD and has been the focus of many studies. Correlations have been shown between DLCO and functional capacity [90, 91], dyspnea [92], post-operative risk [93], and survival [94]. DLCO is used to grade the severity of COPD and among other

uses for finding candidates for lung reduction surgery [95] and for differentiating COPD from asthma [96]. Although DLCO is well established in clinical practice, the measurement is a lumped description of $\dot{V}_{A} / \dot{Q}$ mismatch, pulmonary shunt and $\mathrm{O}_{2}$ diffusion. This means that important information is unavailable for the clinician. The experimental reference technique for describing pulmonary gas exchange, MIGET, has shown that in COPD the main reason for hypoxemia is $\dot{V}_{A} / \dot{Q}$ mismatch, and that neither shunt nor diffusion limitations contribute significantly [25]. Furthermore, studies has shown that different patterns of $\dot{V}_{A} / \dot{Q}$ mismatch exist, and thus a one-parameter quantification will fail to describe these variations. MIGET is however a time consuming experimental approach, and although efforts has been made to further simplify the technique (MMIMS-MIGET [97]), it remains an experimental tool. 
The focus in this thesis, and in the presented papers, has therefore been the application of a method simpler than MIGET but with the ability to describe $\dot{V} A / \dot{Q}$ mismatch using a mathematical physiological model. This model, the mathematical model used in ALPE, has previously been applied in severely ill patients in the ICU and in pre- and post-operative patients. In these patients the impairment of gas exchange can be explained by shunt and low $\dot{V}$ A/Q. A previous effort has included transport and storage of $\mathrm{CO}_{2}$ into the model [54]. This enables identification of the third parameter in the model and thus description of high $\dot{\mathrm{V}} \mathrm{A} / \dot{\mathrm{Q}}$. In this thesis, this three parameter model has been used in patients suffering from COPD. This has included decisions on inspired oxygen levels during measurement, calculations of model-input from curve data, and adjustments of leastsquare weights in the fitting routine. The model has been used both with data measured at steady state and with the proposed method using breath by breath data corrected for delay in $\mathrm{SpO}_{2}$. In all cases the model was able to fit data and provide measures of shunt, low $\dot{V}_{A} / \dot{Q}$ and high $\dot{V}_{A} / \dot{Q}$ in this group of patients.

It has also been possible to show, that with the equipment (ALPE2+capnograph) measurements could be made in these patients, indicating that the added airway resistance is tolerable and that the examination time is not too long. The gas mixing capability of the system was shown to provide stable inspired oxygen fractions in the range $15 \%$ to $30 \%$. These results are essential as they show that reliable data for the mathematical model of ALPE can be measured even in COPD.

The ALPE model quantifies low and high $\dot{\mathrm{V}} \mathrm{A} / \mathrm{Q}$ as the measures $\triangle \mathrm{PO}_{2}$ and $\triangle \mathrm{PCO}_{2}$, respectively. An assumption here, however, has been that the two parameter quantification of low and high $\dot{V}_{A} / \dot{Q}$ is comparable to the 50 compartment description used with MIGET. This represents the necessary trade-off between complexity and usability; as the model ALPE is designed with clinical usage in mind, the experimental procedure only includes simple clinical available date. As was described earlier, the ALPE model has been shown to reproduce retention-excretion data from MIGET and to describe oxygenation in a comparative study, albeit in a rather 
homogeneous model of lung damage. Therefore, the ALPE model might represents a good alternative to MIGET, for the clinical setting.

The results of using ALPE may provide a deeper understanding of the patient, but will also have similarities to DLCO. The quantification of low $\dot{V} A / \dot{Q}$ will most likely correlate well with $D L C O$, as low $\dot{V}_{A} / \dot{Q}$ mainly is responsible for oxygenation problems and DLCO has been shown to correlate well with hypoxemia. The high $\dot{V}_{A} / Q$ quantification, is less likely to correlate with DLCO. In future research, it could be interesting to assess how ALPE quantification correlates with DLCO and other clinical parameters often used in the diagnosis of COPD. Ultimately, an analysis exploring predictive value of for instance mortality would be very interesting, but these studies require the method to be accepted and implemented at multiple centers.

It is the author's belief, that description of pulmonary gas exchange using a mathematical model approach can aid the clinician in diagnosing and treating patients suffering from COPD. In the case of ALPE, the mathematical model may allow the clinician to learn more about the underlying cause of the patient's disease. As is discussed later, this could, for example, be used to categorize patients according to their radiologic profile. In addition ALPE may have certain practical advantages compared to DLCO. The measurement procedure of ALPE requires the patient to breath normally through a mouth piece for up to 10 minutes. DLCO requires at least two consecutive successful measurements, with both rapid inspiration and breath holding at volumes close to vital capacity for 8 to 12 seconds, and there after constant exhalation to clear anatomic and equipment dead space [98]. Even though ALPE takes longer than DLCO, it may be both less stressful for the patient and providing more information.

\subsection{Can measurement at steady state in COPD be relaxed?}

The mathematical model of ALPE applies assumptions of steady state oxygenation, continuous ventilation and perfusion, and that end-tidal and mixed alveolar gases are equal. During the parameter estimation procedure, 
inspired oxygen fractions are changed in steps, and when oxygenation steady state is reached, a measurement is taken. In the ALPE2 implementation, oxygenation steady state is defined as a plateau in end-tidal oxygen fractions, which typically occurs after 1 to 2 minutes. The assumption here is that transport of oxygen across the alveolar membrane reaches an equilibrium and that end-tidal oxygen fraction can be used as a measure for alveolar equilibrium fraction. In COPD however, 1 to 2 minutes might not be sufficient to reach steady state, as a recent study has shown - co-authored by myself but outside the scope of this thesis - that up to 15 minutes should be waited following a change in inspired oxygen before arterial oxygen saturation and pressure is in equilibrium [69]. This thesis has investigated whether the constraint of measuring model inputs at steady state can be relaxed by using breath per breath measurements.

In the second paper, a novel method was postulated where delay in $\mathrm{SpO}_{2}$ due to circulation time is estimated and calibrated out. This method results in dataset of $\mathrm{FetO}_{2}$ versus $\mathrm{SpO}_{2}$ pairs that follow an ALPE curve. The calibrated dataset with the mathematical model of ALPE was used In 14 patients, and Bland-Altman analysis showed that the identified parameter values are equal to those obtained using steady state data in the same patients. Bias and limits of agreement were small for both pulmonary shunt and $\Delta \mathrm{PO}_{2}$. This means that the two methods give similar clinical picture of the patients' pulmonary gas exchange. Though it may not be strictly correct to fit a steady state model to breath by breath data, the comparison performed in paper 2 showed that within experimental noise, calibrated breath by breath data follow the same curve as described by steady state measurements. This indicated, that measurement at steady state may not be necessary, in patients suffering from COPD.

The basic principle of the method is in calibrating out the delay in $\mathrm{SpO}_{2}$ due to circulation. This allows per breath matching of $\mathrm{SpO}_{2}$ and end-tidal oxygen fraction. For each patient the delay has been estimated retrospectively and only one delay was estimated and used per patient. It has been assumed, that the delay is 
patient specific and that the delay does not change during the measurement procedure. It is thought that circulation time of arterial blood from the pulmonary capillaries to the point of measurement and sensor averaging are the main reasons for delay, as this has been reported earlier $[99,100]$. It is well-known, that vasoconstriction can affect the circulation time [101] and that local hypothermia contributes to this effect [76]. For all patients measured with ALPE in this $\mathrm{PhD}$ project, $\mathrm{SpO}_{2}$ has been measured at the finger tip, where hypothermia more likely occurs than at the ear or the patient's forehead. The changes in inspired oxygen fraction during the measurement with ALPE is not though to induce changes to the local vasoconstriction or to the averaging in the sensors. On a further note, it could thus be interesting to evaluate the method using delay in $\mathrm{SpO}_{2}$ measurements from the forehead, as this may give a better matching of $\mathrm{SpO}_{2}$ and end-tidal oxygen fraction. Another contributor to the circulation time is cardiac output. It is however a limitation of this study that cardiac output was not measured. Cardiac output has been approximated per patient using a cardiac index of $2.8[102,103]$ and body surface area calculated from height and weight using DuBois formula $[104,105]$.

The delay in $\mathrm{SpO}_{2}$ is determined from identifying a response in $\mathrm{SpO}_{2}$ to an increase or decrease in inspired oxygen. The change in oxygen is thus required to result in a change in oxygen saturation larger than the resolution of the $\mathrm{SpO}_{2}$ measurement (typically 1\%) and should also be larger than 2 standard deviations (typically $2 \%$ [106]). Dependent on the patient, the typical decrease of $3 \%$ oxygen from the initial $21 \%$ to $18 \%$, may not result in a decrease in $\mathrm{SpO}_{2}$ of more than $2 \%$. This was the case in 6 out of the 14 patients in this study and the delay was determined from subsequent reductions in inspired oxygen. It is a limitation of this method that the change in inspired oxygen needs to be sufficiently large, as it is difficult prior to the change to foresee how the patient reacts. To aid in selecting an appropriate inspired oxygen fraction that results in at least $2 \%$ change in saturation, the Bayesian method for choosing $\mathrm{FIO}_{2}$ proposed by Murley et al. [107] and described in paper 1 could be used. Based on the a priori knowledge of the specific group of patients and the current inspired oxygen level, this method advises on appropriate levels using the ALPE model. 
In summary, it has been shown that the proposed breath by breath method can be applied with the mathematical model of ALPE, and that calculated parameters compare well with the steady state method. Using the breath by breath method it is assumed that model inputs remain constant during the procedure. This assumption and the theory behind the use of oxygen as a tracer will be discussed in the following section.

\subsection{Can oxygen be used as a tracer in COPD?}

To be able to describe pulmonary gas exchange, ALPE uses changes in inspired oxygen to estimate parameters of the mathematical model, meaning that oxygen is used as a tracer. As has been discussed previously, an appropriate tracer is one that does not perturbe the system it is used to investigate.

ALPE and the new method presented in paper 2 for using breath by breath data, apply the assumption that model inputs $\left(\dot{\mathrm{VO}}_{2}, \dot{\mathrm{V}} \mathrm{CO}_{2}, \dot{\mathrm{V}} \min , \dot{\mathrm{Q}}\right.$, and acid-base status) remain constant for all $\mathrm{FIO}_{2}$ levels. This relies on the assumption oxygen is a good tracer, i.e. the values of the model do not change in varying $\mathrm{FIO}_{2}$. When using the steady state method it is possible to measure model inputs following each change in inspired oxygen and in the end use a mean value of the measurements to minimize the inherent variability in the data. When using the breath by breath method the model inputs must be measured at the initial oxygen level. To evaluate whether it is reasonable to assume these input values to be constant during the ALPE measurement procedure, changes in $\dot{\mathrm{V} m i n}, \mathrm{FetCO}_{2}$ and $\dot{\mathrm{VO}}_{2}$ were explored on lowering $\mathrm{FIO}_{2}$. Results showed that, $\dot{\mathrm{V}}$ min systematically increased by, on average $0.8 \mathrm{l} / \mathrm{min}$ on reducing $\mathrm{FIO}_{2}$ from $21 \%$ to $15 \%$, end-tidal $\mathrm{CO}_{2}$ decreased on average less than $0.1 \mathrm{kPa}$ and $\mathrm{d} \dot{V}_{2}$ decreased on average $30 \mathrm{ml}$. This change in $\dot{V}$ min is clinically relevant and is perhaps due to an increase in respiratory drive on lowering oxygen. It is noticeable however, that this resulted in very little change in end tidal $\mathrm{CO}_{2}(<0.1 \mathrm{kPa})$ and minor differences in estimated model parameters. It is important to note that the majority of patients studied here had FEV1\% levels in the more moderate range of COPD. Four, however, were classified as having severe COPD according to the GOLD criteria and no differences were seen in these compared to patients with less severe disease. 
A limitation to the investigation of changes in $\dot{\mathrm{V}} \mathrm{min}, \mathrm{FetCO}_{2}$ and $\dot{\mathrm{VO}}_{2}$ is that it was only performed during decreases in inspired oxygen. An analysis showing the effect of increases in oxygen could also be relevant, as COPD patients with hypoxic drive are known to decrease ventilation substantially at higher inspiratory levels $[108,109]$. The increasing oxygen fraction should be from a well-defined steady state, i.e. atmospheric air, and as this was the case for only one of our included patient, this investigation was not performed.

As has been described earlier, changes in inspired oxygen may cause redistribution of pulmonary blood flow by HPV. This could potentially have an impact on the model description of $\dot{V} A / \dot{Q}$ mismatch if local perfusion changes during the measurement procedure. HPV is mediated by a lowering of alveolar oxygen tension [110] and previously, studies has shown significant effect on pulmonary perfusion distribution in clamped lungs [111]. In a study of HPV in diseased animal lungs, it was shown that with maximal effect of HPV (maximal HPV response versus inhibited response), pulmonary shunt changed 13\% [112]. HPV can evidently alter pulmonary perfusion, but with the focus on ALPE it has not yet clearly been shown how the - in comparison to clamped studies and maximal HPV studies - relatively small changes in end-tidal oxygen tension affects pulmonary perfusion. It is likely, that the effect on pulmonary gas exchange is less significant with smaller changes and end-tidal $\mathrm{FIO}_{2}$ near or above $10 \mathrm{kPa}$. The effect on pulmonary perfusion of an ALPE measurement, has been evaluated as part of a PhD project running in parallel with this. In a submitted paper, it was investigated how mean arterial blood pressure and cardiac output measured with pulmonary arterial catheters changed during an ALPE manoeuvre. It was concluded that, the procedure is safe, as both pressures and cardiac output returned to the initial state immediately following the procedure. Furthermore, across the clinical range of reductions in $\mathrm{FIO}_{2}$ the average, non-significant change in pulmonary arterial pressure was merely $4 \mathrm{mmHg}$. This can be considered as a quiet small change, and as a comparison studies in exercise has shown changes in the magnitude of 13 to $21 \mathrm{mmHg}$ [113]. Supporting these finding are computer simulation studies [114, 115] and studies with MIGET [116, 117], where small changes in model parameter where following changes in $\mathrm{FIO}_{2}$. 
The use of oxygen as a tracer for describing pulmonary gas exchange has been investigated further in this PhD thesis. It should however also be recognized that other authors have also considered the use of oxygen as a tracer to describe pulmonary gas exchange or have been aiming to describe pulmonary gas exchange with minimal steady state models, with recent publications from these groups including Rowe et al. [118] and Melo et al. [119]. The question whether oxygen perturbs the system, i.e changes the underlying physiology of the lung was raised here, and the answer must be yes to some extent. It has been argued here, that for the application of ALPE these changes are minor and that the parameters of the mathematical model changed little. This leads to the conclusion, that oxygen may be a useful tracer in investigating gas exchange in patients suffering from COPD.

\subsection{Can radiologic profiles be classified using both ALPE and other routine measurements in a causal network?}

In paper three the integration of ALPE with other clinical measures was investigated. The main contribution from this paper, is that the constructed causal network may adequately describe radiological profiles of CT scans. It was shown that a causal probabilistic network can be built from causal relations between disease subtypes and clinical measures. The input for the network is presence of productive cough, quantification of low $\dot{V} A / \dot{Q}\left(\triangle P O_{2}\right)$, quantification of high $\dot{V} A / \dot{Q}\left(\triangle P C O_{2}\right)$, and airway limitation (FEV1\%). The CPN was validated in four typical and distinct patterns of COPD, showing this network could adequately describe the radiological profile in these CT scans. Furthermore, potential was shown to use the network to distinguish between peripheral and central bullae locations of emphysema, which cause different reductions in FEV1\% and to separate small bullae from large bullae subtypes of emphysema, in these cases.

To the authors' knowledge, this is the first attempt to use a CPN to combine clinical, physiological and radiological data in the description of COPD. If reproducible this may have several important consequences. CT and HRCT is expensive, places the patient at radiation risk, and is not available in all institutions. The use of a 
system such as that presented here may therefore enable more targeted application of HRCT. This might be seen as replacing the need for HRCT, but more likely as an additional diagnostic tool to monitor disease progression where frequent repeated HRCT would be problematic because of radiation exposure. This could for instance be monitoring of emphysema extend in patients with alpha- 1 antitrypsin deficiency, where CT is frequently used [120]. In addition, several studies have investigated COPD phenotypes from a combination of clinical, physiological and CT data, with patients evaluated iteratively including repeated HRCT [22, 23]. A clinical system which can translate the results of such studies to everyday practice without the need for repeated $\mathrm{CT}$ evaluation, as performed in the studies, may therefore be useful as new understanding of COPD phenotypes presents. The need for a clinical system like this was recognized and requested by James C. Hogg in the Lancet as a conclusion on specific treatment of emphysema and airway disease [121]:

"This step will require precise, safe, non-invasive quantitative methods of diagnosis that will allow both the airway-obstructive and emphysema phenotypes to serve as measurable endpoints in clinical trials."

However, before this can be considered appropriate for clinical use, there are limitations which require addressing. The network was designed to classify COPD into the primary components airway disease or emphysema, however it is known that both subtypes can occur simultaneously [84, 122]. In addition, this proof of concept study has focused on the technological possibility of this approach. While it has been shown that the CPN-model give a nice description of four well defined cases, it is clear that a much large patient group is required for adequate validation. Further patient's cases would allow validation of both the overall comparison of model results with $\mathrm{CT}$ and the causal mechanisms included in the model. 


\section{Acknowledgements}

I wish to express my sincere gratitude to:

Steve Rees, my supervisor, for his friendship, patience and valuable guidance during all aspects of my PhD project.

Steen Andreassen, co-supervisor, for inspiration and valuable discussion of the project.

Ulla Møller Weinreich, my "partner in crime", for her friendship, discussion of clinical perspectives, and for her substantial support in collecting data for the project.

Dan Stieper Karbing, for his friendship, never ending enthusiasm, support, and being a terrific "roommate".

All staff at department of pulmonary medicine, Aalborg University Hospital, for their understanding and help. Especially to Anita Hansen for help when things got critical.

Colleagues at MMDS, for their collaboration and support.

And - most of all - my wife Signe for her endless understanding and support, and for being a fantastic mother for Karl! 


\section{References}

\section{References}

1. Bousquet J, Kiley J, Bateman E, Viegi G, Cruz A, Khaltaev N, Khaled NA, Baena-Cagnani C, Barreto M, Billo N: Prioritised research agenda for prevention and control of chronic respiratory diseases. European Respiratory Journal 2010, 36(5):995-1001.

2. Soriano JB, Zielinski J, Price D: Screening for and early detection of chronic obstructive pulmonary disease. Lancet (London, England) 2009, 374(9691):721-732.

3. Mathers CD, Loncar D: Projections of global mortality and burden of disease from 2002 to 2030. PLoS medicine 2006, 3(11):e442.

4. Diette GB, Accinelli RA, Balmes JR, Buist AS, Checkley W, Garbe P, Hansel NN, Kapil V, Gordon $S$, Lagat DK: Obstructive lung disease and exposure to burning biomass fuel in the indoor environment. Global heart 2012, 7(3):265-270.

5. Vestbo J, Hurd SS, Agusti AG, Jones PW, Vogelmeier C, Anzueto A, Barnes PJ, Fabbri LM, Martinez FJ, Nishimura M: Global Strategy for the Diagnosis, Management, and Prevention of Chronic Obstructive Pulmonary Disease GOLD Executive Summary. American journal of respiratory and critical care medicine 2013, 187(4):347-365.

6. Global Strategy for the Diagnosis, Management and Prevention of COPD, Global Initiative for Chronic Obstructive Lung Disease (GOLD) 2011. Available from: [www.goldcopd.org]

7. Jones PW: Health status and the spiral of decline. Copd: Journal of Chronic Obstructive Pulmonary Disease 2009, 6(1):59-63.

8. Mahler D, Wells CK: Evaluation of clinical methods for rating dyspnea. CHEST Journal 1988, 93(3):580-586.

9. Jones P, Harding G, Berry P, Wiklund I, Chen W, Leidy NK: Development and first validation of the COPD Assessment Test. European Respiratory Journal 2009, 34(3):648-654.

10. Lange P, Marott JL, Vestbo J, Olsen KR, Ingebrigtsen TS, Dahl M, Nordestgaard BG: Prediction of the Clinical Course of Chronic Obstructive Pulmonary Disease, Using the New GOLD Classification A Study of the General Population. American journal of respiratory and critical care medicine 2012, 186(10):975-981.

11. Soriano JB, Alfageme I, Almagro P, Casanova C, Esteban C, Soler-Cataluña JJ, de Torres JP, Martinez-Camblor P, Miravitlles M, Celli BR: Distribution and Prognostic Validity of the New Global Initiative for Chronic Obstructive Lung Disease Grading ClassificationNew GOLD COPD Grading. CHEST Journal 2013, 143(3):694-702. 
12. Rennard SI: COPD: overview of definitions, epidemiology, and factors influencing its development. CHEST Journal 1998, 113(4_Supplement):235S-241S.

13. Hogg JC: Pathophysiology of airflow limitation in chronic obstructive pulmonary disease. The Lancet 2004, 364(9435):709-721.

14. Thomas F, Burke JP, Parker J, James F Orme J, Gardner RM, Clemmer TP, Hill GA, Macfarlane P: The risk of infection related to radial vs femoral sites for arterial catheterization. Crit Care Med 1983, 11(10):807-812.

15. Lacasse Y, Goldstein R, Lasserson T, Martin S: Pulmonary rehabilitation for chronic obstructive pulmonary disease. Cochrane Database Syst Rev 2006, 4(4).

16. Hernandes NA, Wouters E, Meijer K, Annegarn J, Pitta F, Spruit M: Reproducibility of 6-minute walking test in patients with COPD. European Respiratory Journal 2011, 38(2):261-267.

17. Celli B, MacNee W, Agusti A, Anzueto A, Berg B, Buist A, Calverley P, Chavannes N, Dillard T, Fahy B: Standards for the diagnosis and treatment of patients with COPD: a summary of the ATS/ERS position paper. European Respiratory Journal 2004, 23(6):932-946.

18. Coxson HO, Rogers RM: Quantitative computed tomography of chronic obstructive pulmonary disease. Acad Radiol 2005, 12(11):1457.

19. Shaker SB, Dirksen A, Bach KS, Mortensen J: Imaging in chronic obstructive pulmonary disease. COPD: Journal of Chronic Obstructive Pulmonary Disease 2007, 4(2):143-161.

20. Mansfield D, Naughton MT: Effects of continuous positive airway pressure on lung function in patients with chronic obstructive pulmonary disease and sleep disordered breathing. Respirology 1999, 4(4):365-370.

21. Barbe F, Togores B, Rubi M, Pons S, Maimo A, Agusti A: Noninvasive ventilatory support does not facilitate recovery from acute respiratory failure in chronic obstructive pulmonary disease. European Respiratory Journal 1996, 9(6):1240-1245.

22. Vestbo J, Anderson W, Coxson HO, Crim C, Dawber F, Edwards L, Hagan G, Knobil K, Lomas DA, MacNee W: Evaluation of COPD longitudinally to identify predictive surrogate end-points (ECLIPSE). European Respiratory Journal 2008, 31(4):869-873.

23. Regan EA, Hokanson JE, Murphy JR, Make B, Lynch DA, Beaty TH, Curran-Everett D, Silverman EK, Crapo JD: Genetic epidemiology of COPD (COPDGene) study design. COPD: Journal of Chronic Obstructive Pulmonary Disease 2011, 7(1):32-43.

24. Goldman M, Smith H, Ulmer W: Whole-body plethysmography. European Respiratory Monograph 2005, 31:15. 
25. Rodriguez-Roisin R, Wagner P: Clinical relevance of ventilation-perfusion inequality determined by inert gas elimination. European Respiratory Journal 1990, 3(4):469-482.

26. Macintyre N, Crapo R, Viegi G, Johnson D, Van der Grinten C, Brusasco V, Burgos F, Casaburi R, Coates A, Enright P: Standardisation of the single-breath determination of carbon monoxide uptake in the lung. European Respiratory Journal 2005, 26(4):720-735.

27. McCormack MC: Facing the Noise: Addressing the Endemic Variability in DLCO Testing. Respir Care 2012, 57(1):17-25.

28. Drummond MB, Schwartz PF, Duggan WT, Teeter JG, Riese RJ, Ahrens RC, Crapo RO, England $\mathrm{RD}$, MacIntyre NR, Jensen RL: Intersession variability in single-breath diffusing capacity in diabetics without overt lung disease. American journal of respiratory and critical care medicine 2008, 178(3):225-232.

29. Wagner PD, Saltzman HA, West JB: Measurement of continuous distributions of ventilationperfusion ratios: theory. J Appl Physiol 1974, 36(5):588-599.

30. Roca J, Wagner PD: Contribution of multiple inert gas elimination technique to pulmonary medicine. 1. Principles and information content of the multiple inert gas elimination technique. Thorax 1994, 49(8):815-824.

31. Wagner PD, Laravuso RB, Uhi RR, West JB: Continuous distributions of ventilation-perfusion ratios in normal subjects breathing air and 100\% O2. J Clin Invest 1974, 54(1):54.

32. Melot C: Contribution of multiple inert gas elimination technique to pulmonary medicine. 5. Ventilation-perfusion relationships in acute respiratory failure. Thorax 1994, 49(12):1251-1258.

33. Hedenstierna G: Contribution of multiple inert gas elimination technique to pulmonary medicine. 6. Ventilation-perfusion relationships during anaesthesia. Thorax 1995, 50(1):85-91.

34. Manier G, Castaing Y: Contribution of multiple inert gas elimination technique to pulmonary medicine--4. Gas exchange abnormalities in pulmonary vascular and cardiac disease. Thorax 1994, 49(11):1169-1174.

35. Rodriguez-Roisin R, Roca J: Contributions of multiple inert gas elimination technique to pulmonary medicine. 3. Bronchial asthma. Thorax 1994, 49(10):1027-1033.

36. Wagner PD, Dantzker DR, Dueck R, Clausen JL, West JB: Ventilation-perfusion inequality in chronic obstructive pulmonary disease. J Clin Invest 1977, 59(2):203-216.

37. Burrows B, Fletcher C, Heard B, Jones N, Wootliff J: The emphysematous and bronchial types of chronic airways obstruction. A clinicopathological study of patients in London and Chicago. Lancet 1966, 1(7442):830. 
38. Barbera JA, Ramirez J, Roca J, Wagner PD, Sanchez-Lloret J, Rodriguez-Roisin R: Lung structure and gas exchange in mild chronic obstructive pulmonary disease. American Journal of Respiratory and Critical Care Medicine 1990, 141(4 Pt 1):895-901.

39. Agustí A, Barbera JA: Contribution of multiple inert gas elimination technique to pulmonary medicine. 2. Chronic pulmonary diseases: chronic obstructive pulmonary disease and idiopathic pulmonary fibrosis. Thorax 1994, 49(9):924-932.

40. Sandek K, Bratel T, Hellstrom G, Lagerstrand L: Ventilation-perfusion inequality and carbon dioxide sensitivity in hypoxaemic chronic obstructive pulmonary disease (COPD) and effects of 6 months of long-term oxygen treatment (LTOT). Clin Physiol 2001, 21(5):584-593.

41. Rodríguez-Roisin R, Drakulovic M, Rodríguez DA, Roca J, Barberà JA, Wagner PD: Ventilationperfusion imbalance and chronic obstructive pulmonary disease staging severity. J Appl Physiol 2009, 106(6):1902-1908.

42. Wagner PD: The multiple inert gas elimination technique (MIGET). In Applied Physiology in Intensive Care Medicine. Edited by Anonymous Springer; 2009:29-36.

43. King TK, Briscoe WA: Bohr integral isopleths in the study of blood gas exchange in the lung. $\mathrm{J}$ Appl Physiol 1967, 22(4):659-674.

44. RILEY RL, COURNAND A: Analysis of factors affecting partial pressures of oxygen and carbon dioxide in gas and blood of lungs; theory. J Appl Physiol 1951, 4(2):77-101.

45. Jones JG, Jones SE: Discriminating between the effect of shunt and reduced VA/Q on arterial oxygen saturation is particularly useful in clinical practice. J Clin Monit Comput 2000, 16(56):337-350.

46. Loeppky JA, Caprihan A, Altobelli SA, Icenogle MV, Scotto P, Vidal Melo MF: Validation of a two-compartment model of ventilation/perfusion distribution. Respiratory physiology \& neurobiology 2006, 151(1):74-92.

47. Kjaergaard S, Rees S, Malczynski J, Nielsen JA, Thorgaard P, Toft E, Andreassen S: Non-invasive estimation of shunt and ventilation-perfusion mismatch. Intensive Care Med 2003, 29(5):727-734.

48. Rees SE, Kjaergaard S, Andreassen S, Hedenstierna G: Reproduction of MIGET retention and excretion data using a simple mathematical model of gas exchange in lung damage caused by oleic acid infusion. J Appl Physiol 2006, 101(3):826-832.

49. Rees SE, Kjaergaard S, Andreassen S, Hedenstierna G: Reproduction of inert gas and oxygenation data: a comparison of the MIGET and a simple model of pulmonary gas exchange. Intensive Care Med 2010, 36(12):2117-2124. 
50. Rees SE, Kjaergaard S, Thorgaard P, Malczynski J, Toft E, Andreassen S: The automatic lung parameter estimator (ALPE) system: non-invasive estimation of pulmonary gas exchange parameters in 10-15 minutes. J Clin Monit Comput 2002, 17(1):43-52.

51. Thomsen LP, Karbing DS, Smith BW, Murley D, Weinreich UM, Kjærgaard S, Toft E, Thorgaard $\mathrm{P}$, Andreassen S, Rees SE: Clinical refinement of the automatic lung parameter estimator (ALPE). J Clin Monit Comput 2013, 27(3):341.

52. Rees SE: The Intelligent Ventilator (INVENT) project: The role of mathematical models in translating physiological knowledge into clinical practice. Comput Methods Programs Biomed 2011, 104:S1-S29.

53. Rees SE, Andreassen S: Mathematical models of oxygen and carbon dioxide storage and transport: the acid-base chemistry of blood. Crit Rev Biomed Eng 2005, 33(3):209-264.

54. Karbing DS, Kjaergaard S, Andreassen S, Espersen K, Rees SE: Minimal model quantification of pulmonary gas exchange in intensive care patients. Med Eng Phys 2011, 33(2):240-248.

55. ROSENBERG J, OTURAI P, ERICHSEN CJ, PEDERSEN MH, KEHLET H: Effect of General Anesthesia and major versus Minor Surgery on Late Postoperative Episodic and Constant Hypoxemia. Surv Anesthesiol 1995, 39(1):43.

56. Ferreyra G, Long Y, Ranieri VM: Respiratory complications after major surgery. Curr Opin Crit Care 2009, 15(4):342-348.

57. Kjaergaard S, Rees SE, Nielsen JA, Freundlich M, Thorgaard P, Andreassen S: Modelling of hypoxaemia after gynaecological laparotomy. Acta Anaesthesiol Scand 2001, 45(3):349-356.

58. Kjaergaard S, Rees SE, Gronlund J, Nielsen EM, Lambert P, Thorgaard P, Toft E, Andreassen S: Hypoxaemia after cardiac surgery: clinical application of a model of pulmonary gas exchange. Eur J Anaesthesiol 2004, 21(4):296-301.

59. Edmark L, Kostova-Aherdan K, Enlund M, Hedenstierna G: Optimal oxygen concentration during induction of general anesthesia. Anesthesiology 2003, 98(1):28-33.

60. Rosenberg J, Wildschiødtz G, Pedersen M, Von Jessen F, Kehlet H: Late postoperative nocturnal episodic hypoxaemia and associated sleep pattern. Br J Anaesth 1994, 72(2):145-150.

61. Artigas A, Bernard GR, Carlet J, Dreyfuss D, Gattinoni L, Hudson L, Lamy M, Marini JJ, Matthay MA, Pinsky MR: The American-European Consensus Conference on ARDS, Part 2 Ventilatory, Pharmacologic, Supportive Therapy, Study Design Strategies, and Issues Related to Recovery and Remodeling. American journal of respiratory and critical care medicine 1998, 157(4):1332-1347. 
62. Karbing DS, Kjaergaard S, Smith BW, Espersen K, Allerod C, Andreassen S, Rees SE: Variation in the $\mathrm{PaO} 2 / \mathrm{FiO} 2$ ratio with $\mathrm{FiO} 2$ : mathematical and experimental description, and clinical relevance. Crit Care 2007, 11(6):R118.

63. Aubier M, Murciano D, Milic-Emili J, Touaty E, Daghfous J, Pariente R, Derenne JP: Effects of the administration of $\mathrm{O2}$ on ventilation and blood gases in patients with chronic obstructive pulmonary disease during acute respiratory failure. Am Rev Respir Dis 1980, 122(5):747-754.

64. Rodriguez-Roisin R, MacNee W: Pathophysiology of chronic obstructive pulmonary disease. European Respiratory Monograph 2006, 38:177.

65. Kent BD, Mitchell PD, McNicholas WT: Hypoxemia in patients with COPD: cause, effects, and disease progression. International journal of chronic obstructive pulmonary disease 2011, 6:199.

66. Liu Z, Vargas F, Stansbury D, Sasse SA, Light RW: Comparison of the end-tidal arterial PCO2 gradient during exercise in normal subjects and in patients with severe COPD. CHEST Journal 1995, 107(5):1218-1224.

67. Oliven A, Kelsen SG, Deal EC, Cherniack NS: Mechanisms underlying CO2 retention during flow-resistive loading in patients with chronic obstructive pulmonary disease. J Clin Invest 1983, 71(5):1442.

68. Gorini M, Misuri G, Corrado A, Duranti R, Iandelli I, De Paola E, Scano G: Breathing pattern and carbon dioxide retention in severe chronic obstructive pulmonary disease. Thorax 1996, 51(7):677-683.

69. Weinreich UM, Thomsen LP, Hansen A, Kjaergaard S, Wagner PD, Rees SE: Time to Steady State after Changes in FIO in Patients with COPD. COPD 2013, .

70. Dunn WF, Nelson SB, Hubmayr RD: Oxygen-induced hypercarbia in obstructive pulmonary disease. American Journal of Respiratory and Critical Care Medicine 1991, 144(3 Pt 1):526-530.

71. ROBINSON TD, FREIBERG DB, REGNIS JA, YOUNG IH: The role of hypoventilation and ventilation-perfusion redistribution in oxygen-induced hypercapnia during acute exacerbations of chronic obstructive pulmonary disease. American Journal of Respiratory and Critical Care Medicine 2000, 161(5):1524-1529.

72. Calverley P: Respiratory failure in chronic obstructive pulmonary disease. European Respiratory Journal 2003, 22(47 suppl):26s-30s.

73. Dirksen A: Monitoring the progress of emphysema by repeat computed tomography scans with focus on noise reduction. Proceedings of the American Thoracic Society 2008, 5(9):925-928. 
74. Madani A, Keyzer C, Gevenois P: Quantitative computed tomography assessment of lung structure and function in pulmonary emphysema. European Respiratory Journal 2001, 18(4):720730.

75. Coxson HO, Pare PD: Phenotyping COPD using High Resolution CT. Is it time to leave it for Watson? COPD 2012, 9(2):87-89.

76. MacLeod DB, Cortinez LI, Keifer JC, Cameron D, Wright DR, White WD, Moretti EW, Radulescu LR, Somma J: The desaturation response time of finger pulse oximeters during mild hypothermia. Anaesthesia 2005, 60(1):65-71.

77. Hansell D: Small airways diseases: detection and insights with computed tomography. European Respiratory Journal 2001, 17(6):1294-1313.

78. Jensen FV, Nielsen TD: Bayesian networks and decision graphs: Springer Verlag; 2007.

79. Andreassen S, Jensen FV, Olesen KG: Medical expert systems based on causal probabilistic networks. Int J Biomed Comput 1991, 28(1):1-30.

80. Leibovici L, Paul M, Nielsen AD, Tacconelli E, Andreassen S: The TREAT project: decision support and prediction using causal probabilistic networks. Int J Antimicrob Agents 2007, 30:93102.

81. Thomsen LP, Weinreich UM, Karbing DS, Helbo Jensen VG, Vuust M, Frøkjær JB, Rees SE: Can computed tomography classifications of chronic obstructive pulmonary disease be identified using Bayesian networks and clinical data? Comput Methods Programs Biomed 2013, 110(3):361.

82. Friedlander AL, Lynch D, Dyar LA, Bowler RP: Phenotypes of chronic obstructive pulmonary disease. COPD: Journal of Chronic Obstructive Pulmonary Disease 2007, 4(4):355-384.

83. Barr CC, Berkowitz EA, Bigazzi F, Bode F, Bon J, Bowler RP, Chiles C, Crapo JD, Criner GJ, Curtis JL, Dass C, Dirksen A, Dransfield MT, Edula G, Erikkson L, Friedlander A, Galperin-Aizenberg M, Gefter WB, Gierada DS, Grenier PA, Goldin J, Han MK, Hanania NA, Hansel NN, Jacobson FL, Kauczor HU, Kinnula VL, Lipson DA, Lynch DA, Macnee W, Make BJ, Mamary AJ, Mann H, Marchetti N, Mascalchi M, McLennan G, Murphy JR, Naidich D, Nath H, Newell JD,Jr, Pistolesi M, Regan EA, Reilly JJ, Sandhaus R, Schroeder JD, Sciurba F, Shaker S, Sharafkhaneh A, Silverman EK, Steiner RM, Strange C, Sverzellati N, Tashjian JH, Beek EJ, Washington L, Washko GR, Westney G, Wood SA, Woodruff Deceased PG: A Combined Pulmonary-Radiology Workshop for Visual Evaluation of COPD: Study Design, Chest CT Findings and Concordance with Quantitative Evaluation. COPD 2012, .

84. Patel BD, Coxson HO, Pillai SG, Agustí AGN, Calverley PMA, Donner CF, Make BJ, Müller NL, Rennard SI, Vestbo J: Airway wall thickening and emphysema show independent familial 
aggregation in chronic obstructive pulmonary disease. American journal of respiratory and critical care medicine 2008, 178(5):500-505.

85. Aziz ZA, Wells AU, Desai SR, Ellis SM, Walker AE, MacDonald S, Hansell DM: Functional impairment in emphysema: contribution of airway abnormalities and distribution of parenchymal disease. Am J Roentgenol 2005, 185(6):1509-1515.

86. Hoesein FAAM, van Rixkoort E, van Ginneken B, de Jong PA, Prokop M, Lammers JWJ, Zanen P: CT-quantified emphysema distribution is associated with lung function decline. European Respiratory Journal 2012, .

87. Pauwels RA, Buist AS, Calverley PMA, Jenkins CR, Hurd SS: Global strategy for the diagnosis, management, and prevention of chronic obstructive pulmonary disease. American journal of respiratory and critical care medicine 2001, 163(5):1256-1276.

88. Collins J, Stern EJ, Franquet TC: Bronchiolar disease: A spectrum of causes and CT findings. Appl Radiol 2002, 31(1):20-28.

89. Wagner PD: Assessment of gas exchange in lung disease: balancing accuracy against feasibility. Crit Care 2007, 11(6):182.

90. Miniati M, Catapano GA, Monti S, Mannucci F, Bottai M: Effects of emphysema on oxygen uptake during maximal exercise in COPD. Internal and emergency medicine 2013, 8(1):41-47.

91. Carter R, Holiday DB, Nwasuruba C, Stocks J, Grothues C, Tiep B: 6-minute walk work for assessment of functional capacity in patients with COPD. CHEST Journal 2003, 123(5):1408-1415.

92. Mahut B, Chevalier-Bidaud B, Plantier L, Essalhi M, Callens E, Graba S, Gillet-Juvin K, ValckeBrossollet $\mathrm{J}$, Delclaux $\mathrm{C}$ : Diffusing capacity for carbon monoxide is linked to ventilatory demand in patients with chronic obstructive pulmonary disease. COPD: Journal of Chronic Obstructive Pulmonary Disease 2012, 9(1):16-21.

93. Ferguson MK, Lehman AG, Bolliger CT, Brunelli A: The role of diffusing capacity and exercise tests. Thoracic surgery clinics 2008, 18(1):9-17.

94. Boutou AK, Shrikrishna D, Tanner RJ, Smith C, Kelly JL, Ward SP, Polkey MI, Hopkinson NS: Lung function indices for predicting mortality in chronic obstructive pulmonary disease. European Respiratory Journal 2013, .

95. Celli BR: Update on the management of COPD. CHEST Journal 2008, 133(6):1451-1462.

96. Chang J, Mosenifar Z: Differentiating COPD from asthma in clinical practice. J Intensive Care Med 2007, 22(5):300-309. 
97. Baumgardner JE, Choi IC, Vonk-Noordegraaf A, Frasch HF, Neufeld GR, Marshall BE:

Sequential V(A)/Q distributions in the normal rabbit by micropore membrane inlet mass spectrometry. J Appl Physiol 2000, 89(5):1699-1708.

98. Ruppel GL, Enright PL: Pulmonary function testing. Respir Care 2012, 57(1):165-175.

99. Young D, Jewkes C, Spittal M, Blogg C, Weissman J, Gradwell D: Response time of pulse oximeters assessed using acute decompression. Anesth Analg 1992, 74(2):189-195.

100. Zubieta-Calleja GR, Zubieta-Castillo G, Paulev PE, Zubieta-Calleja L: Non-invasive measurement of circulation time using pulse oximetry during breath holding in chronic hypoxia. J Physiol Pharmacol 2005, 56 Suppl 4:251-256.

101. Ding ZN, Shibata K, Yamamoto K, Kobayashi T, Murakami S: Decreased circulation time in the upper limb reduces the lag time of the finger pulse oximeter response. Can J Anaesth 1992, 39(1):87-89.

102. Brent BN, Berger HJ, Matthay RA, Mahler D, Pytlik L, Zaret BL: Physiologic correlates of right ventricular ejection fraction in chronic obstructive pulmonary disease: a combined radionuclide and hemodynamic study. Am J Cardiol 1982, 50(2):255-262.

103. Biernacki W, Flenley D, Muir A, MacNee W: Pulmonary hypertension and right ventricular function in patients with COPD. CHEST Journal 1988, 94(6):1169-1175.

104. Du Bois D, Du Bois EF: A formula to estimate the approximate surface area if height and weight be known. 1916. Nutrition 1989, 5(5):303-11; discussion 312-3.

105. Wang Y, Moss J, Thisted R: Predictors of body surface area. J Clin Anesth 1992, 4(1):4-10.

106. Webster J: Medical instrumentation: application and design: John Wiley \& Sons; 2009.

107. Murley D, Rees S, Rasmussen B, Andreassen S: Decision support of inspired oxygen selection based on Bayesian learning of pulmonary gas exchange parameters. Artif Intell Med 2005, 34(1):53-63.

108. Gelb A, Klein E, Schiffman P, Lugliani R, Aronstam P: Ventilatory response and drive in acute and chronic obstructive pulmonary disease. Am Rev Respir Dis 1977, 116(1):9.

109. Berry R, Mahutte C, Kirsch J, Stansbury D, Light R: Does the hypoxic ventilatory response predict the oxygen-induced falls in ventilation in COPD? CHEST Journal 1993, 103(3):820-824.

110. Moudgil R, Michelakis ED, Archer SL: Hypoxic pulmonary vasoconstriction. J Appl Physiol 2005, 98(1):390-403. 
111. Hambraeus-Jonzon K, Bindslev L, Mellgard AJ, Hedenstierna G: Hypoxic pulmonary vasoconstriction in human lungs. A stimulus-response study. Anesthesiology 1997, 86(2):308-315.

112. Brimioulle S, Julien V, Gust R, Kozlowski JK, Naeije R, Schuster DP: Importance of hypoxic vasoconstriction in maintaining oxygenation during acute lung injury. Crit Care Med 2002, 30(4):874-880.

113. Kovacs G, Berghold A, Scheidl S, Olschewski H: Pulmonary arterial pressure during rest and exercise in healthy subjects: a systematic review. European Respiratory Journal 2009, 34(4):888894.

114. Marshall BE, Marshall C, Frasch F, Hanson CW: Role of hypoxic pulmonary vasoconstriction in pulmonary gas exchange and blood flow distribution. 1. Physiologic concepts. Intensive Care Med 1994, 20(4):291-297.

115. Marshall BE, Hanson CW, Frasch F, Marshall C: Role of hypoxic pulmonary vasoconstriction in pulmonary gas exchange and blood flow distribution. 2. Pathophysiology. Intensive Care Med 1994, 20(5):379-389.

116. Domino KB, Hlastala MP, Eisenstein BL, Cheney FW: Effect of regional alveolar hypoxia on gas exchange in dogs. $\mathrm{J}$ Appl Physiol 1989, 67(2):730-735.

117. Delcroix M, Melot C, Vermeulen F, Naeije R: Hypoxic pulmonary vasoconstriction and gas exchange in acute canine pulmonary embolism. J Appl Physiol 1996, 80(4):1240-1248.

118. Rowe L, Jones JG, Quine D, Bhushan SS, Stenson BJ: A simplified method for deriving shunt and reduced VA/Q in infants. Archives of Disease in Childhood-Fetal and Neonatal Edition 2010, 95(1):F47-F52.

119. Melo M, Loeppky J, Caprihan A, Luft U: Alveolar ventilation to perfusion heterogeneity and diffusion impairment in a mathematical model of gas exchange. Computers and biomedical research 1993, 26(2):103-120.

120. Shaker S, Stavngaard T, Stolk J, Stoel B, Dirksen A: a1-Antitrypsin deficiency• 7: Computed tomographic imaging in a1-antitrypsin deficiency. Thorax 2004, 59(11):986.

121. Hogg JC, Chu F, Utokaparch S, Woods R, Elliott WM, Buzatu L, Cherniack RM, Rogers RM, Sciurba FC, Coxson HO: The nature of small-airway obstruction in chronic obstructive pulmonary disease. $\mathrm{N}$ Engl J Med 2004, 350(26):2645-2653.

122. Gelb AF, Hogg JC, Müller NL, Schein MJ, Kuei J, Tashkin DP, Epstein JD, Kollin J, Green RH, Zamel N: Contribution of emphysema and small airways in COPD. Chest 1996, 109(2):353-359. 


\section{Summary}

Chronic Obstructive Pulmonary Disease (COPD) is a major respiratory disease that is characterized by progressive and irreversible decline in lung function. This leads to high rates of morbidity and mortality, and COPD is predicted to be the fourth most likely cause of death in 2030. The diagnosis and classification of COPD can be seen as the difficult task of describing a heterogeneous disease affecting a complex organ, using relatively simple measurements. Traditionally, diagnosis of COPD has been based on patients' expiratory efforts measured by spirometry and graded in four stages. This however often fails to describe the heterogeneity of disease, why clinicians use additional diagnostic tools.

In the first part of this thesis, the currently available tools for diagnosis of COPD has been described and evaluated. Special interest has been taken in tools for description of pulmonary gas exchange abnormalities, as it is the authors' believe alternative solutions are needed. With the reference experimental technique for assessing pulmonary gas exchange, the Multiple Inert Gas Elimination Technique (MIGET), it has been shown that mismatch of pulmonary ventilation and perfusion is the major contributor to oxygenation problems in COPD. The currently clinically available single breath diffusion capacity for carbon monoxide (DLCO) however fails to describe this property, as it is lumped together with other possible causes diffusion resistance and intra pulmonary shunt. As MIGET is an experimental technique and thus not suitable for routine clinical practice, other tools could be interesting. In this light, investigation of whether a new technique capable of describing $\dot{V} A / \dot{Q}$ mismatch from clinical available measurement is applicable in COPD, has been the main topic of this thesis.

The Automatic Lung Parameter Estimator (ALPE) is a relatively new technique for describing pulmonary gas exchange at the bedside. ALPE has however up until now never been used systematically in patients suffering from COPD, and potentially a number of challenges exists if this technique is to be applied in COPD. This thesis describes challenges that should be solved in order to successfully allow ALPE to describe pulmonary gas 
exchange in COPD, these relate to: The mathematical model included in ALPE, the measurement of reliable data in unstable breathing, relaxation of the need to measure at steady state, and integration of ALPE description with other clinically available measurements.

In the second part of the thesis, the methods and results from the thesis' three papers are presented, describing solutions to the identified challenges. It is shown, that a three parameter model of pulmonary gas exchange can adequately describe gas exchange in patients suffering from COPD. The model of pulmonary gas exchange needs to incorporate both description of low and high $\dot{V} A / \dot{Q}$ in order to describe COPD. Moreover, it has been experimentally shown, that ALPE equipment available for clinical practice, can measure input variables for the mathematical model satisfactorily. In relation to measurement at steady state, a novel method has been presented, where breath by breath measurements can be used to parameterize the model. This method uses an estimated circulation delay of measured pulse oximetry arterial oxygen saturation to calibrate data and construct a new dataset suitable for the model. It was shown experimentally, that the new method could describe patients as well as the traditionally steady state method. Integration of the ALPE description of gas exchange together with standard spirometry measurement and clinical description of sputum production was investigated by mean of causal relation. A causal probabilistic network was constructed, and it was shown capable of categorizing patients according to pathoanatomical subgroups normally only available using CT-scans.

In summary, this thesis has identified challenges for the application of ALPE in COPD and has presented novel solutions to these. The primary outcome is a novel method allowing steady state mathematical model of pulmonary gas exchange to be parameterized using breath per breath data, and a causal probabilistic network capable of targeting CT categorization of COPD. 


\section{Danish summary}

Kronisk obstruktiv lungesygdom (KOL) er en alvorlig respiratorisk sygdom, der er karakteriseret ved fremadskridende og irreversibel nedgang i lungefunktionen. Dette medfører høj morbiditet og mortalitet, og KOL forventes at være den fjerde mest sandsynlige dødsårsag i 2030. Diagnosticering og klassificering af KOL kan ses som den vanskelige opgave, at beskrive en heterogen sygdom, der påvirker et komplekst organ, ved hjælp af relativt simple målinger. Traditionelt har diagnosen af KOL været baseret på patienternes ekspiratoriske kunnen målt ved spirometri, klassificeret i fire niveauer. Oftest formår dette dog ikke at beskrive heterogeniteten i sygdommen, og derfor benytter klinikere sig ofte af yderligere diagnostiske værktøjer.

I den første del af denne afhandling, bliver de i øjeblikket tilgængelige værktøjer til diagnosticering af KOL beskrevet og vurderet. Der er lagt særlig fokus på værktøjer til beskrivelse af abnormal pulmonal gasudveksling, da det er forfatterens overbevisning, at alternative løsninger er nødvendige her. Den eksperimentielle reference teknik til vurdering af pulmonal gasudveksling, Multiple Inert Gas Elimination Technique (MIGET), har påvist at misforholdet mellem pulmonal ventilation og perfusion er den primære årsag til iltnings problemer i KOL. Den aktuelle klinisk tilgængelig måling, single breath diffusion capacity for carbon monoxide (DLCO), kan ikke beskrive denne årsag, da den er slået sammen med andre mulige årsager som diffusionsmodstand og intra pulmonær shunt. Da MIGET er en eksperimentel teknik og derfor ikke egnet til rutinemæssig klinisk praksis, kunne andre værktøjer være interessant. På denne baggrund har undersøgelse af, om en ny teknik kan beskrive $\dot{V}_{A} / \dot{Q}$ mismatch ud fra klinisk tilgængelige måling i KOL, været det primære fokus i denne afhandling.

The Automatiske Lung Parameter Estimator (ALPE) er en relativt ny teknik til at beskrive pulmonal gasudveksling i klinisk praksis. ALPE er dog aldrig anvendt systematisk i patienter, der lider af KOL, og potentielt eksisterer der en række udfordringer, hvis denne teknik skal anvendes i KOL. Denne afhandling beskriver udfordringer, der bør løses for at ALPE kan benyttes til at beskrive pulmonal gasudveksling i KOL, de vedrører: 
Den matematiske model der indgår i ALPE, måling af pålidelige data i ustabil vejrtrækning, afhængighed af målinger i steady state, og integration af ALPE beskrivelsen med andre klinisk tilgængelige målinger.

I anden del af afhandlingen præsenteres metoder og resultater fra de tre artikler tesen er baseret på og løsninger på de identificerede udfordringer bliver beskrevet. Det er vist, at en tre parameter model af pulmonal gasudveksling kan beskrive gasudveksling i patienter der lider af KOL. Modellen af pulmonal gasudveksling skal både kunne beskrive $h ø j$ og lav $\dot{V} A / Q$ for at være tilstrækkelig i KOL. Endvidere er det eksperimentelt blevet vist, at det kommercielt tilgængelig ALPE, tilfredsstillende kan måle input variablene til den matematiske model. I forhold til steady state måling er en ny metode blevet præsenteret, hvor per åndedrag målinger kan bruges til at parameterisere modellen. Denne metode bruger en estimeret forsinkelse i målt puls oximetritil at kalibrere data og konstruere et nyt datasæt, der er egnet til modellen. Det er blevet eksperimentelt vist, at den nye metode kan beskrive patienterne tilsvarende den traditionelle steady state metode. Integration af ALPE beskrivelsen af gasudveksling med standard spirometri og klinisk beskrivelse af produktiv hoste blev unders $\varnothing \mathrm{gt}$ ved hjælp af kausale relationer. Et kausalt probabilistisk netværk blev konstrueret og det blev vist at være i stand til at kategorisere patienter i henhold til patoanatomisk undergrupper normalt kun tilgængelige via CTscanninger.

Sammenfattende har denne afhandling identificeret udfordringer for anvendelse af ALPE i KOL og har fremlagt løsninger til disse. De primære resultater er en ny metode der tillader at parameterisere en steady state matematisk model af pulmonal gasudveksling ved hjælp af per åndedrag målinger, samt et kausal probabilistiske netværk der er i stand til at karakterisere KOL på samme måde som CT-skanninger. 


\section{List of papers}

This thesis is bases on the following papers, which will be referred to in the text by their Arabic numeral 1-3:

1. Thomsen, L. P., Karbing, D. S., Smith, B. W., Murley, D., Weinreich, U., Kjærgaard, S., Toft, E., Thorgaard, P., Andreassen, S., \& Rees, S. E. (2013). Clinical refinement of the automatic lung parameter estimator (ALPE). Journal of Clinical Monitoring and Computing, 27(3):341, doi: 10.1007/s10877-013-9442-9

2. Thomsen, L. P., Weinreich, U. M., Karbing, D. S., Wagner, P. D. \& Rees, S. E. Measuring gas exchange with step changes in inspired oxygen: an analysis of the assumption of oxygen steady state. Invited paper for a Journal of Clinical Monitoring and Computing special issue: IFAC BMS 2012: Modeling in Anaesthesia and Intensive Care. In revision.

a. Bases on the following peer-reviewed conference paper:

Thomsen, L. P., Weinreich, U. M., Karbing, D. S., \& Rees, S. E. (2012). Measuring gas exchange with step changes in inspired oxygen: an analysis of the assumption of oxygen steady state. I Benyo, B., Andreasen, S., Feng, D. D., Carson, E., Chase, J. G., \& Kovács, L. (red.), 8th IFAC Symposium on Biological and Medical Systems (2012). (s. 507-511). Elsevier Science. (Elsevier IFAC Publications / IFAC Proceedings series, Vol. 8). doi: 10.3182/20120829-3-HU-2029.00048

3. Thomsen, L. P., Weinreich, U. M., Karbing, D. S., Jensen, V. G. H., Vuust, M., Frøkjær, J. B., \& Rees, S. E. (2013). Can computed tomography classifications of chronic obstructive pulmonary disease be identified using Bayesian networks and clinical data?. Computer Methods and Programs in Biomedicine, 110(3):361, doi: 10.1016/j.cmpb.2013.02.001 
A part of this thesis has been removed from this publication due to copyright. 